\title{
BIOSYSTEMATICS OF THE MALAGASY FROGS II. THE GENUS BOOPHIS (RHACOPHORIDAE)
}

\author{
by \\ R. M. A. BLOMMERS-SCHLÖSSER \\ Institute of Taxonomic Zoology (Zoölogisch Museum), University of Amsterdam, The Netherlands
}

\begin{abstract}
This paper concerns the genus Boophis Tschudi, 1938 (= Malagasy Rbacophorus Kuhl \& Van Hasselt, 1822). Apart from a reconsidering of adult morphology, certain new taxonomic characters, such as the colouration in life, the morphology of the tadpole and some mating calls, are presented. Karyotypes and nuclear DNA amount were reported upon elsewhere.

This study produces a sharper definition of the endemic genus, permitting its clear separation from the genus Mantidactylus Boulenger, 1895.

Various sibling species are reported; as a result different synonymies are revised and new species presented. Four new species are described, viz. Boophis mandraka, $B$. viridis, $B$. reticulatus and $B$. billenii. A lectotype is designated for Rhacophorus majori Boulenger, 1896.

The following bonae species, new synonyms and new combinations are proposed: Boophis erythrodactylus (Guibé, 1953), comb. nov. (from Hyperolius); Boophis difficilis (Boettger, 1892), bona species; Boophis miniatus (Mocquard, 1902), bona species; Boophis goudoti Tschudi, 1938 (syn. Rhacophorus fasciolatus Ahl, 1929 and Rhacophorus kanbergi Ahl, 1929); Boophis untersteini (Ahl, 1928), bona species; Boophis pauliani (Guibé, 1953), comb. nov. (from Hypero. lius) Boophis microtympanum (Boettger, 1881), comb. nov. (from Rhacophorus boettgeri Boulenger, 1882: substitute name for Hylambates microtympanum Boettger, 1881).
\end{abstract}

\section{INTRODUCTION}

Tschudi (1838) created the genus Boophis for a single Malagasy species, Boophis goudoti. The genus Boophis has been considered a synonym of Rhacophorus Kuhl \& Van Hasselt, 1822, by most authors (among others: Boulenger, 1882, Ahl, 1931, and Guibé, 1978).

Laurent (1943) noted differences in the osteological characters between the Asiatic and the Malagasy Rhacophorus species; so he proposed to reserve the name Boophis for the latter. Liem (1970), studying mainly osteological and muscular characters, agreed with Laurent's opinion.

Our failure to observe foamy nests of eggs (eggs were always found in water), so characteristic of Asiatic Rhacophorus, supports the opinion of the latter authors. Consequently, I prefer also to use the name Boophis for the Malagasy species.

In an earlier paper on the biosystematics of the Malagasy Mantellinae (Blommers-Schlösser, 1979) it has been argued already that Boophis is not so closely related to Mantidactylus Boulenger, 1895, as was presumed by previous workers. The main argument was the great difference in reproductive behaviour. Earlier taxonomic studies concerning the genus Boophis Tschudi, 1838, were based entirely on preserved material (Ahl, 1931, and Guibé, 1978).

The author and her husband collected 21 species of this genus (about $80 \%$ of those known) in Madagascar between November 1970 and May 1973. The natural history, the larval morphology, the mating call and the colouration in life were investigated in many species. A combination of these new "field" taxonomic characters and the morphology of the species are sometimes essential for identification, because clear morphological characters separating sibling species are often missing.

A careful study of the Malagasy Boophis Tschudi, 1838, has demonstrated the impracticability of attempting a dichotomous key to all species. The earlier keys of Ahl, 1931, and Guibé, 1978 , are not very useful for identification of all species, since the characters used might include some features of several closely allied species as well.

Therefore I have attempted to assemble the species into several natural groups, based on affinity in structural characters, of ten together with colour similarities. I have then presented a diagnosis for the species within each group. 
The following groups are recognized: B. rappiodes group, luteus group, rhodoscelis group, goudoti group, tephraeomystax group, opisthodon group and pauliani group. A remaining group consists of species which have their occurrence in high mountains in common.

The following species were neither studied nor included in any of the groups: $B$. leucomaculatus (Guibé, 1975), B. microtis (Guibé, 1974), B. brygooi (Guibé, 1974), and B. laurenti Guibé, 1947.

\section{ACKNOWLEDGEMENTS}

The investigations were supported by the Foundation for Fundamental Biological Research (B.I.O.N.), which is subsidized by the Netherlands Organization for the Advancement of Pure Research (Z.W.O.).

Material was made available by Mrs. Dr. R. Roux-Estève and Prof. Dr. J. Guibé, Muséum National d'Histoire Naturelle, Paris (MNHP), Prof. Dr. G. Peters, Zoologisches Museum, Berlin (ZMB), Mr. A. F. Stimson and Mrs. A. G. C. Grandison, British Museum (Natural History), London (BMNH), Prof. Dr. K. Klemmer, Naturmuseum und Forschungsinstitut Senckenberg, Frankfurt (SMF), and Dr. F. Tiedemann, Naturhistorisches Museum, Wien (WM). The author is very much indebted for these loans.

I am very grateful to Dr. M. S. Hoogmoed (Leiden) for examining the holotype of Rhacophorus femoralis Boulenger, 1882 , in London.

I wish to thank in particular Prof. Dr. J. Guibé, who allowed me to read his manuscript before it was published.

I am very grateful to Mr. Andriamampianina and his staff (Dépt. d'Eaux et Forêt, Repoblika Malagasy) for their permission to stay and work in some of the most beautiful forests of Madagascar.

I express my gratitude to Dr. D. Hillenius (Amsterdam), for encouragement during this study, to Prof. Dr. J. H. Stock (Amsterdam) and Prof. Dr. J. T. Wiebes (Leiden) for critically reading my manuscript, to Mr. W. J. van der Weyden (Free University, Amsterdam) for making the sonagrams of the tape recordings, to Mr. L. A. van der Laan (Amsterdam) for making the photographic prints and to Mr. A. Ameling (Amsterdam) for typing a part of the manuscript.

\section{MATERIAL AND METHODS}

The material is deposited in the Zoölogisch Museum Amsterdam (ZMA). The ZMA registration numbers are given under each species with the number of specimens in parentheses.

The definitions of measurements and characters of both tadpoles and adults and the terminology concerning the sonagrams and the bioclimatic areas in Madagascar are the same as used previously (Blommers-Schlösser, 1979). For certain localities the distance to Tananarive (in $\mathrm{km}$ ) along the various highroads is provided.
Summarizing: Measurements and characters of both tadpoles and adults and the terminology concerning the sonagrams are in accordance with Duellman's (1970). In describing the larvae, I have defined the stages according to Gosner (1960). Webbing formula: the numbers $1,2 i$, $2 e$ refer to the first toe (or finger), the inner side of the second, the outer side of the second and the numbers in parentheses refer to the number of phalanges free of web. Tooth formula: the tooth rows are numbered from top to bottom both in the upper and lower lip. The separation between both lips is indicated by a double slant line. $\mathbf{A}$ median gap between the lateral tooth rows is marked by a plus sign. The tooth formula is given from stage 28 onwards (complete). The bioclimatic areas correspond to those of Koechlin (1972). Lotic means living in brook or river. Lentic, living in swamp, pool or pond.

Since this paper comes out shortly after the publication of Guibé (1978) "Les Batraciens de Madagascar", in which a description is given of all frog species occurring in Madagascar, I have not given a very detailed description of all Boophis species. The study in the field revealed that there are more species than Guibé (1978) estimated on the base of alcohol material only; it also appeared that the juvenile of the one resembles much the adult of the other, resulting in a changing of synonymy. Therefore I have given a very detailed description of juveniles of several species, of sibling species, species removed from previous synonymy and of course of the new species.

The description of other species is concise, and placed mainly within the group description, making identification possible.

The four species not included in the present paper (see introduction) are not common and known only from their type localities (see Guibé, 1978).

\section{Genus Boophis Tschudi, 1838}

Boophis Tschudi, 1838: 36, 76; Laurent, 1943: 13; Guibé, 1947: 438; Guibé, 1978: 59 (in synonymy of Rhacophorus); Bachmann \& Blommers-Schlösser, 1975: 17 (nuclear DNA amount); Blommers-Schlösser, 1978: 30-37 (chromosomes).

Rhacophorus Kuhl \& Van Hasselt, 1822: 104 (part.).

Type species: Boophis goudoti Tschudi, 1838: 77, by monotypy.

Def in ition. - Vertebral column procoel. Second tarsal not free, but connected with third and fourth tarsal. Omosternum with bony style, not or only slightly forked at base. Sternum with long bony style, not forked. Length of style of sternum greater than that of omosternum. Maxillary teeth present. Vomerine teeth mostly present. Tongue distinctly bifid and free behind. Pupil horizontal. Intercalary cartilage present between disc and adjacent phalanx. Digital pads completely surrounded by ventro-marginal groove. Fingers with a small trace of web to three-fourths webbed. 
TABLE I

Key to the groups.

\begin{tabular}{lcccccccccc}
\hline & 1 & 2 & 3 & 4 & 5 & 6 & 7 & 8 & 9 & 10 \\
\hline B. rappiodes group & $\mathrm{a}$ & $\mathrm{a}$ & $\mathrm{a}$ & $1 / 3-1 / 2$ & + & $\mathrm{a}$ & - & - & - & $\mathrm{a}$ \\
B. luteus group & $\mathrm{b}$ & $\mathrm{a}$ & $\mathrm{a}$ & $1 / 2$ & + & $\mathrm{b}$ & \pm & + & - & $\mathrm{a}$ \\
B. rhodoscelis group & $\mathrm{a}$ & $\mathrm{a}+\mathrm{b}$ & $\mathrm{a}$ & $1 / 3-1 / 2$ & + & $\mathrm{a}$ & + & \pm & - & $\mathrm{a}$ \\
B. goudoti group & $\mathrm{b}$ & $\mathrm{a}+\mathrm{b}$ & $\mathrm{a}$ & $2 / 5-3 / 4$ & + & $\mathrm{a}$ & + & \pm & \pm & $\mathrm{a}$ \\
B. tephraeomystax group & $\mathrm{a}+\mathrm{b}$ & $\mathrm{b}$ & $\mathrm{b}$ & $1 / 3-2 / 3$ & + & $\mathrm{a}$ & + & - & - & $\mathrm{b}$ \\
B. opisthodon group & $\mathrm{b}$ & $\mathrm{b}$ & $\mathrm{b}$ & $\geqslant 3 / 4$ & + & $\mathrm{a}$ & + & - & - & $\mathrm{b}$ ? \\
B. pauliani group & $\mathrm{a}$ & $\mathrm{b}$ & $\mathrm{a}$ & $<1 / 3$ & - & $\mathrm{a}$ & + & + & - & $\mathrm{b}$ ? \\
Montane species & $\mathrm{a}+\mathrm{b}$ & $\mathrm{b}$ & $\mathrm{b}$ & $<1 / 3$ & + & $\mathrm{a}$ & \pm & - & - & $\mathrm{a}$ \\
\hline
\end{tabular}

1. Snout-vent length of adults: $a=\leqslant 35 \mathrm{~mm} ; b=\geqslant 35 \mathrm{~mm}$.

2. Tibiotarsal articulation: $a=$ reaching the tip of the snout or beyond; $b=$ not reaching as far as the tip of the snout.

3. Webbing of the fingers: $a=$ one-third or more webbed, the web reaching at least the base of the penultimate phalanx of the fourth and the middle of the antepenultimate phalanx of the third finger; $b=$ trace of web, less than one-third webbed.

4. Size of tympanum, expressed in the ratio of the horizontal diameter of the tympanum to that of the eye.

5. Vomerine teeth: +- present; $-=$ absent.

6. External subgular vocal sac: $a=$ single, median; $b=$ paired, lateral.

7. Transverse bars on the limbs: $+=$ present; $-=$ absent.

8. Dermal fringe along the lateral edge of lower arm and tarsus: $+=$ present; $-=$ absent.

9. Dermal flap on heel: $+=$ present; $-=$ absent.

10. Breeding site: $a=$ streaming water; $b=$ standing water.

Toes half to fully webbed. Outer metatarsal tubercle absent. Lateral metatarsalia separated. Males smaller than females. Nuptial pads present in males.

Amplexus axillary, sometimes lumbal. Eggs small, laid in water. Tadpoles in streams (lotic) and in stagnant water (lentic). Chromosomes: $2 n$ = 26; N.F. (number of chromosome arms) = 52. Nuclear DNA amount: 7.0-9.9 pg (diploid).

A key to the species groups is presented in table I. The colouration is also characteristic in most groups, but not included in the key, since it is difficult to express in symbols.

\section{Boophis rappiodes group}

Diagnosis. - The members of this group are small-sized, stream-breeding species. The dorsum is bright green (yellowish in preservative) and the bones are green. There are no distinctive markings on the posterior surface of the thighs and no transverse bars on the limbs. Dermal fringes and flaps are lacking on the limbs. The skin on the dorsum is smooth or finely granular.
Vomerine teeth are present. The horizontal diameter of the tympanum is one-third to the half of the horizontal diameter of the eye. The vocal sac is single, median, subgular. The snout is short and rounded. The commissure of the mouth is slightly curved upwards (rappiodes, erythrodactylus, mandraka) or straight (viridis). The tibiotarsal articulation extends beyond the tip of the snout. The discs are well developed. The fingers are half webbed; between the third and fourth finger the webbing extends to the bases of the penultimate phalanges. The toes are three-fourths to almost entirely webbed, the webbing reaching the discs of the first and fifth toe.

Contents: B. rappiodes (Ahl, 1928), B. mandraka sp. nov., B. erytbrodactylus (Guibé, 1953) and $B$. viridis sp. nov.

Dif ferential diagnosis.- The colour in life is the best character to distinguish the species (pl. IV figs. 1-3, 5), but much of it disappears in alcohol. Therefore $I$ have tried to find other diagnostic characters for each of the species. $B$. viridis is larger than the other species, the nostrils are strongly protruding and the length of 
TABLE II

Diagnostic characters in the Boophis rappiodes group.

\begin{tabular}{|c|c|c|c|c|}
\hline & B. viridis & B. rappiodes & $\begin{array}{l}\text { B. erythro- } \\
\text { dactylus }\end{array}$ & B. mandraka \\
\hline Snout-vent length of adult $\hat{\delta}(\mathrm{mm})$ & $29 \cdot 31$ & 24 & $19.5 \cdot 25.0$ & $21-26$ \\
\hline Ratio hand length/body length (mean) & 0.33 & 0.26 & 0.33 & 0.33 \\
\hline Ratio hor. diameter tympanum/eye (mean) & 0.35 & 0.33 & 0.47 & 0.32 \\
\hline \multicolumn{4}{|l|}{ Length of snout compared with distance } & shorter \\
\hline $\begin{array}{l}\text { Position of nostrils in respect of tip of } \\
\text { snout and anterior corner of eye }\end{array}$ & $\begin{array}{l}\text { nearer tip } \\
\text { of snout }\end{array}$ & $\begin{array}{l}\text { nearer tip } \\
\text { of snout }\end{array}$ & $\begin{array}{l}\text { nearer tip } \\
\text { of snout }\end{array}$ & nearer eye \\
\hline Character of nostrils & $\begin{array}{l}\text { strongly } \\
\text { protruding }\end{array}$ & $\begin{array}{l}\text { slightly } \\
\text { protruding }\end{array}$ & $\begin{array}{l}\text { slightly } \\
\text { protruding }\end{array}$ & $\begin{array}{l}\text { slightly } \\
\text { protruding }\end{array}$ \\
\hline Colouration & \multicolumn{4}{|c|}{ cf. text description species and pl. IV figs. 1-3, 5} \\
\hline
\end{tabular}

the snout is longest of all. $B$. rappiodes has much smaller hands than the other species. $B$. erythrodactylus has the largest tympanum. B. mandraka differs from the other three in the position of the nostrils, which are nearer to the eye than to the tip of the snout. These characters are shown in table II.

\section{Boophis rappiodes (Ahl, 1928)}

Text-figs. 1-2; pl. IV fig. 1.

Rhacophorus rappiodes Ahl, 1928: 315; Guibé, 1978: 78 (as dubious species, because of bad condition of the type). Material. - ZMA 7164 (1 \& and 1 o) ), 14.XI.72; 7167 (eggs deposited by 7164), collected near Perinet (highroad R.N. 2 at $\mathrm{km} \mathrm{142)}$ alt. $900 \mathrm{~m}$; ZMA 7165 (tadpoles), 24.IX.72 at the same locality, but alt. $1100 \mathrm{~m}$. - ZMA 7168 (tadpoles and young reared from them), IV.VIII.72 collected in the Mandraka valley (highroad R.N. 2 at $\mathrm{km} \mathrm{69);} \mathrm{ZMA}$ 7161 (tadpoles), 24.IX.72 at the same locality, but at $\mathrm{km} 70$, alt. $1100 \mathrm{~m}$. - ZMA 7166 (tadpoles), 29.VIII.72 collected along the road from Moramanga to Anosibe at km 27.

Natural history. - The couple was found in axillary amplexus, in the shrubbery along a stream in woodland, during a rainy night. One day later, the female deposited 260 glutinous eggs ( $2 \mathrm{~mm}$ in diameter) of a light green colour in the vivarium. The eggs dried up quickly on land, which might indicate that normal oviposition occurs in water. The tadpoles were collected in the still parts of streams, where abundant vegetation on the side shaded the water.

T a x o n o my - Although the holotype of $R$. rappiodes is in a bad condition (Guibé, 1978),
I believe that the present couple belongs to this species. It agrees with the original description of $R$. rappiodes.

Description (see table IV for measurements). - The ratio of the hand length to snoutvent length is $0.25-0.28$. The ratio of the tibia length to snout-vent length is $0.58-0.59$. The ratio of the foot length to snout-vent length is 0.42 0.44 . The ratio of the horizontal diameter of the tympanum to that of the eye is $0.33-0.34$. Snoutvent length of male $24 \mathrm{~mm}$, of female $32 \mathrm{~mm}$.

The body is in the postaxillary region equal to the head width. The head is wider than long. The head width is about one-third of the body length. The snout is bluntly rounded in dorsal and lateral profile. The snout is equal to the horizontal diameter of the eye, and shorter than the distance between the anterior corners of the eye. The nostrils are much nearer to the tip of the snout, than to the anterior corner of the eye. The canthus is distinct and concave. The loreal region is slightly concave. The interorbital region is slightly convex. The internarial distance is slightly smaller than the interorbital distance. The interorbital distance is about $11 / 2$ times the width of an upper eyelid. The nostrils are protruding, the opening is directed laterally. The commissure of the mouth is curved upwards. The pupil is horizontally elliptical.

There is a straight weak dermal fold over the tympanum, reaching a point behind the insertion of the arm. The fold covers the dorsal margin of the tympanum. The tympanum is rather indistinct, 
its horizontal diameter is one-third of the horizontal diameter of the eye. The distance from the eye to the tympanum is about three-fourths of the horizontal diameter of the tympanum.

The largest diameter of the disc of the third finger is equal to the horizontal diameter of the tympanum, the discs of the fourth and second finger are about equal and of the first smaller. The relative lengths of the fingers from shortest to longest are 1-2-4-3. The subarticular tubercles are small, distinct and round. There is an inner flat oval metacarpal tubercle. A small unpigmented, glandular nuptial pad is present dorsolaterally on the first finger of the male. The formula of the webbing of the hand: 1 (1), $2 \mathrm{i}(1)$, $2 \mathrm{e}(1), 3 \mathrm{i}(2), 3 \mathrm{e}(1), 4(1)$. The web is glandular.

The arms and legs are slender. When the limbs are laid along the side, the knee and elbow overlap slightly. The adpressed heels meet. The tibiotarsal articulation extends just beyond the tip of the snout. The inner metatarsal tubercle is small, elliptical. A small web connects the tip of the inner metatarsal tubercle with the first toe to the middle of the antepenultimate phalanx. There is no outer metatarsal tubercle. The discs on the toes are equal to those on the fingers. The subarticular tubercles are small and round. The fifth toe is slightly longer than the third. The formula of the webbing of the foot: $1(0), 2 \mathrm{i}(0), 2 \mathrm{e}(0), 3 \mathrm{i}(0)$, $3 \mathrm{e}(0), 4 \mathrm{i}(1), 4 \mathrm{e}(1), 5(0)$. The ventral surface of the web is glandular. The lateral metatarsalia are separated.

The anal opening is directed posteriorly at the upper level of the thighs. The anal sheath is short.

The tongue is heart-shaped and distinctly bifid posteriorly. The vomerine teeth are situated medially, behind the choanae in two small straight groups. The vocal slits are small, situated in the floor of the mouth, near the angles of the jaws. The vocal sac is single medially, subgular and moderately distensible.

The skin on the dorsum is smooth. The skin on the throat is finely granular. The skin on the belly, and proximal posteroventral surfaces of the thighs and below the anal opening is granular; elsewhere on the venter the skin is smooth.

The colour in preservative is light yellowish.
The dorsum is covered with minute dark spots. A white line runs from the nostril over the eyelid and the tympanum and ends behind the insertion of the arm. The upper eyelids are creamish. The iris is silvery grey with brown pigment, surrounded by a black ring. The upper rim of the palpebral membrane is slightly pigmented. The lower rim is pigmented anteriorly and posteriorly in the same colour as the skin.

The colour in life is yellow-green with red pigment (pl. IV fig. 1). The white lines (in alcohol) are yellow. In both male and female much red pigment is present on the eyelids and around the nostrils. The red pigment is present in irregular spots and markings on the whole dorsal surface, more extensively in the female than in the male. The belly is uniformly coloured. The bones are green.

T a d poles. - Thirteen tadpoles in stage 25 have body lengths of $5.9 \mathrm{~mm}$ and total lengths of 15-27 mm. Twenty tadpoles in stages 26-30 have body lengths of $8.5-13.0 \mathrm{~mm}$ and total lengths of $24-37 \mathrm{~mm}$. Eleven tadpoles in stages 31.41 have body lengths of $9-13 \mathrm{~mm}$ and total lengths of $28-36 \mathrm{~mm}$. The average ratio of the tail length to the body length in the 44 tadpoles listed above is 1.9 (range 1.75-2.10). Six metamorphosing young measure $11.5-14.0 \mathrm{~mm}$ from snout to vent (mean $12 \mathrm{~mm}$ ).

The mouth and lateral view of a tadpole in stage 31 (ZMA 7165) are shown in text-figs. 1-2. The body is depressed. The nostrils are dorsal, the opening is anterolaterally, situated slightly nearer to the anterior corners of the eyes than to the tip of the snout. The eyes are small and directed laterally. The spiracular opening is sinistral, situated at about 5/8 from the tip of the snout and the end of the body. The cloacal tube is wide and dextral to the caudal fin. The caudal musculature is robust, especially in the first half of the tail. The dorsal caudal fin is reduced anteriorly. At midlength of the tail, the height of the caudal musculature represents about $2 / 5$ of the total tail height. The mouth is small and directed ventrally. The papillary border has a wide median gap anteriorly. There are 1-2 rows of papillae. The oral disc is indented laterally and medio- 

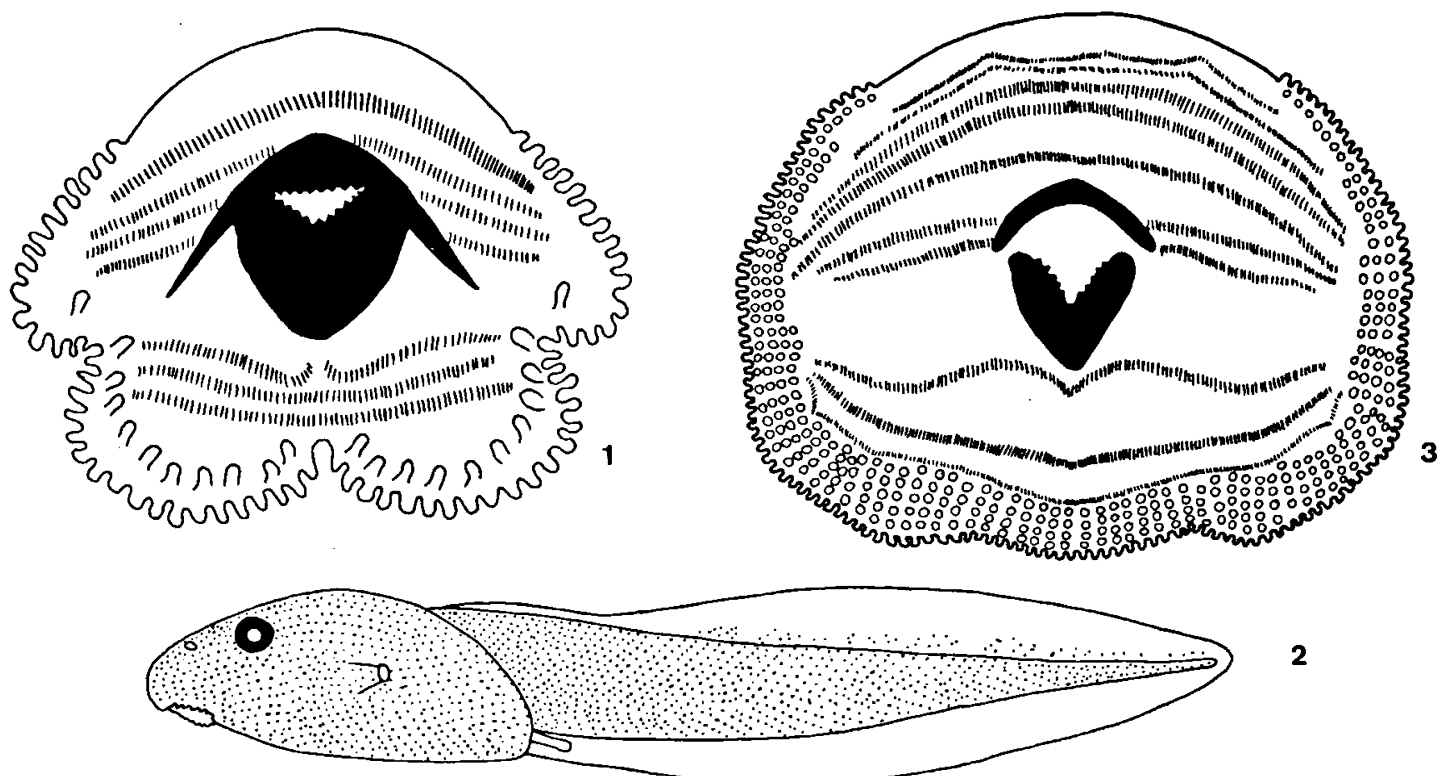

2
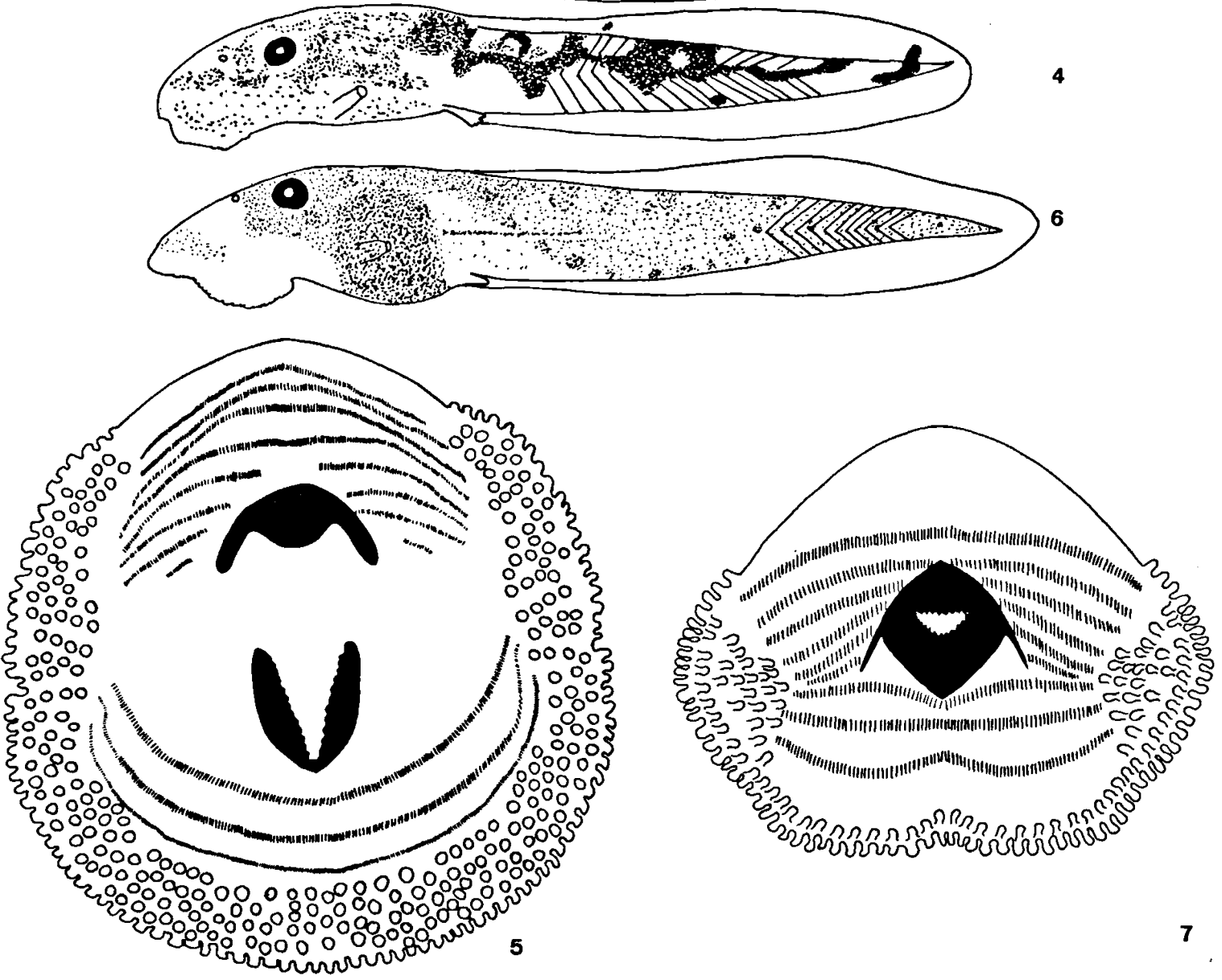

Figs. 1-7. 1-2, Boophis rappiodes: 1, mouth of tadpole, ZMA 7165.X.25; 2, tadpole, ZMA 7165.X.3; 3-4, B. mandraka: 3, mouth of tadpole, ZMA 7121.X.12.5; 4, tadpole, ZMA 7121.X.3; 5-6, B. erythrodactylus: 5, mouth of tadpole, ZMA 7208.X.12.5; 6, tadpole, ZMA 7208.X.3; 7, B. luteus: mouth of tadpole, form A, ZMA 7005.X.12.5. 
posteriorly. The tooth formula is $1 / 3+3 / / 1+1 / 2$ or $1 / 2+2 / / 1+1 / 2$. The horny beak is well developed.

The colour in life of the tadpole is blackish, covered with small bright green spots.

Metamorphosis occurred in November (beginning of hot season).

Y o u n . - The colour of the living young is is nearly identical to that of the adults. The ground colour is green and the bones are green. The yellow line at each side of the head is already present. Red pigment is present on the eyelids and between the eyes. The back is covered with blackish speckles. The nostrils are nearer to the tip of the snout than to the anterior corners of the eye. The young are assigned readily to $B$. rappiodes.

Boophis mandraka sp. nov.

Text-figs. 3, 4, 8, 41; pl. IV fig. 2.

Boophis aff. erythrodactylus; Blommers-Schlösser, 1978: 35 (chromosomes).

Material. - ZMA 7119A, male holotype and ZMA 7119B, six male paratypes 4.III.73; ZMA 7118 six male paratypes, 27.III.73; all collected in the Mandraka valley (highroad R.N. 2 at $\mathrm{km} \mathrm{67),} \mathrm{alt.} 1200 \mathrm{~m}$.

ZMA 7120 (tadpoles and young reared from them); ZMA 7121 (one tadpole); all collected from June till October 1972 in the rivulet Vokanatetezandava, in the nursery garden of the city of Tananarive in the Mandraka valley (highroad R.N. 2 at $\mathrm{km} \mathrm{69),} \mathrm{alt.} 1200 \mathrm{~m}$.

The present species is closiest allied to the sibling species $B$. erythrodactylus (Guibé, 1953). It was discovered in the field that the mating call and the larva are clearly different in both. B. mandraka can be distinguished from erytbrodactylus by its difference in colouration (see text description and pl. IV figs. 2-3), by the smaller size of the tympanum, and the position of the nostrils, which is nearer to the eye than to the tip of the snout.

$\mathrm{Natural} \mathrm{h}$ is tory. - The males are calling from shrubbery alongside rapids, on rainy nights. The tadpoles are clearly lotic and found in rapids. The adults and tadpoles occur mingled with those of $B$. erythodactylus (see B. erythrodactylus).

Description (see table IV for measurements). - The ratio of hand length to snout-vent length is $0.30-0.36$ (mean 0.33 ). The ratio of tibia length to snout-vent length is 0.54-0.59 (mean 0.57). The ratio of foot length to snout-vent length is $0.43-0.55$ (mean 0.47 ). The ratio of the horizontal diameter of the tympanum to that of the eye is $0.29-0.34$ (mean 0.32). Snout-vent length in males $21-26 \mathrm{~mm}$.

Holotype: head length is $6.8 \mathrm{~mm}$; head width is $8.1 \mathrm{~mm}$; internarial distance is $2.8 \mathrm{~mm}$; interorbital distance is $3 \mathrm{~mm}$; snout-vent length is $23.5 \mathrm{~mm}$.

The head is wider than the body, and somewhat wider than long. The head width is one-third of the body length. The snout is rounded in dorsal and lateral profile. The snout is slightly longer than the horizontal diameter of the eye, and distinctly shorter than the distance between the anterior corners of the eye. The nostrils are nearer to the anterior corners of the eye than to the tip of the snout. The distance from the nostril to the anterior corner of the eye is distinctly shorter than the horizontal diameter of the eye. The canthus is distinct and rounded. The loreal region is slightly concave. The interorbital region is flat. The internarial distance is slightly shorter than the interorbital distance. The interorbital distance is about $11 / 2$ times the width of an upper eyelid. The nostrils are slightly protruding, the opening is laterodorsally. The commissure of the mouth is curved upwards. The pupil is horizontally elliptical.

There is a dermal fold from the posterior edge of the eye, over the tympanum, curving downwards to a point just behind the shoulder. The fold covers the dorsal margin of the tympanum. The tympanum is distinct and round. The horizontal diameter of the tympanum is about onethird of the horizontal diameter of the eye. The distance from the eye to the tympanum is equal to the horizontal diameter of the tympanum.

The diameter of the disc of the third finger is larger than the diameter of the tympanum, the discs of the fourth and second finger are slightly smaller, and the disc of the first finger is much smaller. The relative lengths of the fingers from shortest to longest are 1-2-4-3. The subarticular tubercles are small, round and flat. There is an inner, oval, flat metacarpal tubercle. There is a small unpigmented, glandular nuptial pad, dorso- 
laterally on the first finger. Supernumerary tubercles are present on the base of the fingers. The fingers are about half webbed. The formula of the webbing of the hand: 1 (1), $2 \mathrm{i}$ (1), $2 \mathrm{e}$ (1), $3 i(2), 3 e(1), 4\left(1-1 \frac{1}{2}\right)$. The ventral surface of the web is glandular.

The arms and legs are slender. When the limbs are laid along the side, the knee and elbow overlap. The adpressed heels meet. The tibiotarsal articulation extends beyond the tip of the snout. The inner metatarsal tubercle is distinct, small, elliptical and protruding. There is no outer metatarsal tubercle. A small web connects the tip of the inner metatarsal tubercle with the first toe till the base of the penultimate phalanx. The terminal discs are somewhat smaller than those on the fingers. The fifth toe is slightly longer than the third. The subarticular tubercles are small, flat and round. The formula of the webbing of the foot: $1(0), 2 \mathrm{i}(0)$, 2e (0), 3i (1), 3e (1/2-0), 4i (1), 4e (1), $5(0)$. The lateral metatarsalia are separated. The ventral surface of the web is glandular. The ventral surface of the foot is granular.

The anal opening is directed posteriorly at upper level of the thighs. The dermal flap above the anal opening continues in a fold on each side of the anal opening, together forming a $\Lambda$-shaped figure.

The tongue is heart-shaped and distinctly bifid posteriorly. The vomerine teeth are situated medially, far behind the choanae, in two small oblique groups. The vocal slits are small, situated in the floor of the mouth, near the angles of the jaws. The vocal sac is median, subgular and moderately distensible.

The skin on the dorsum is shagreened, on the throat and chin finely granular and on the belly granular. The ventral surface of the limbs is smooth, except the ventral surface of the hands, feet and posterior part of the thighs, which is granular. The skin below the anus is coarsely granular.

The colour in life of the dorsum is bright green, with scattered brown spots (pl. IV fig. 2). The upper eyelids are yellow with brown. A moderately wide yellow line running from the tip of the snout over the nostrils to the anterior corner of the eye is bordered with brown spots. The venter is pale green. The bones are green. The iris is silvery white with a brown reticulation.

The colour in preservative is yellowish. The brown spots are still visible and the yellow line in life has become whitish. The upper rim of the palpebral membrane is pigmented. The lower rim is broadly pigmented in the same colour as the skin of the dorsum. The iris is silvery grey with brown reticulation, surrounded by a black ring.

Comparison with paratypes. - The paratypes agree with the description of the holotype. The distal tubercles of the fingers are often bifid, especially those on the third and fourth finger. In some specimens there are a few large yellow spots on the dorsum (in life).

Vo ice. - The males were heard on an evening in March. The sonagram (fig. 8) made of a male (ZMA 7119) on 4 March at 12 p.m. shows that the duration of one call is about $0.75 \mathrm{sec}$. One call consists of three loud melodious clicks followed by a very soft click. The dominant frequency is about $3500 \mathrm{~Hz}$.

E t y molog y . - B. mandraka derives its name from the river flowing in the Mandraka valley.

T a d poles. - Fourteen tadpoles in stage 25 have body lengths of $8.5-11.0 \mathrm{~mm}$ and total lengths of $26.2-34.5 \mathrm{~mm}$. Four tadpoles in stages 27-28 have body lengths of $10.5-12.0 \mathrm{~mm}$ and total lengths of $31.5-35.0 \mathrm{~mm}$. Four tadpoles in stages 33-37 have body lengths of 11.0-12.5 mm and total lengths of $33-35 \mathrm{~mm}$. Four tadpoles in stages $40-42$ have body lengths of $12.5-14.0 \mathrm{~mm}$ and total lengths of $37-40 \mathrm{~mm}$. The average ratio of tail length to body length in the twenty-six tadpoles listed above is 2 (range 1.8-2.2). One metamorphosing young has a body length of $13 \mathrm{~mm}$.

The mouth and lateral view of a tadpole in stage 34 (ZMA 7121) are shown in text-figs. 3-4. The body is depressed. The nostrils are dorsal, the opening is anterolaterally, situated at about $2 / 3$ from the tip of the snout and the anterior corner of the eye. The eyes are situated laterally. The spiracular opening is sinistral, situated at about 


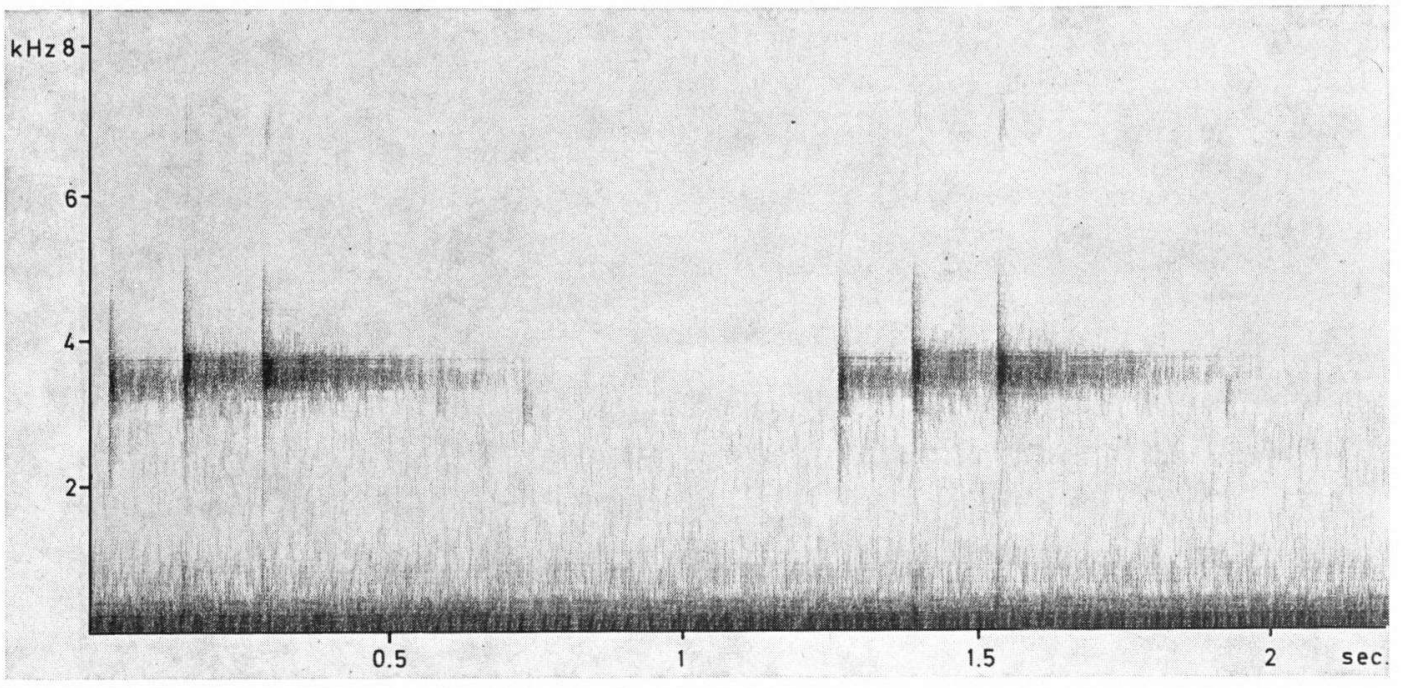

Fig. 8. Sonagram, filter wide, Boophis mandraka.

$2 / 3$ from the tip of the snout and the end of the body. The cloacal tube is long and dextral to the caudal fin. The caudal musculature is robust. The caudal fin is shallow anteriorly and deepest at about $2 / 3$ of its length. At midlength of the tail, the height of the caudal musculature represents $1 / 2$ of the total tail height. The mouth is broad and directed ventrally. The papillary border has a wide median gap. There are $2-4$ rows of papillae laterally and 5-6 posteriorly. The tooth formula is $5 / 2+2 / / 3$. The upper row of the upper lip and the lower row of the under lip consist of very small teeth. The upper horny beak is narrow and moon-shaped. The lower horny beak is V-shaped with heavy serrations.

The colour of the tadpole in life is brown on the back; the belly is black in stage 25 and silvery grey in later stages. The caudal musculature has large well-defined dark brown patterns with a creamish background. The caudal fin is transparent with a few dark brown markings.

The tadpoles were collected in rapids from June till October, together with the tadpoles of $B$. erytbrodactylus. The rearing was only successful with far developed tadpoles.

Young. - The young frog is green. Brown pigment is present on the eyelids and around the nostrils. There are white spots on the black. The bones are green. The hindlimbs are relatively shorter than in the adult frog.
Boophis erythrodactylus (Guibé, 1953)

Text-figs. 5, 6, 9; pl. I figs. 1-2, pl. IV fig. 3.

Hyperolius erytbrodactylus Guibé, 1953: 102; Guibé, 1978: 90.

Boophis erythrodactylus; Blommers-Schlösser, 1978: 35 (chromosomes).

Materia 1. - MNHP 53-171, four syntypes of Hyperolius erytbrodactylus. Type locality: forest of Mahajeby, near Morafenobe, West Madagascar. Coll. Paulian, 1952.

ZMA 6924 ( $1 \&$ and $1 \hat{\delta}), 18 . I I .73 ; 6925$ ( $6 \hat{\delta} \hat{\delta})$, 27.III.73; 6926 (2 ô ô), 27.III.73; 6927 (1 $\hat{\delta})$ ), 26.XII.72; 6928 (4 of o ), 4.III.73; 6930 ( 1 o ) , 6.I.73; 7207 (tadpoles and young reared from them), VI-X.72; 7208 (one tadpole), VII.72; all collected in the Mandraka valley (highroad R.N. 2 at $\mathrm{km} \mathrm{67-69),} \mathrm{alt.} 1200 \mathrm{~m}$. - ZMA 7205 (tadpoles), VIII.72; 7206 (one tadpole), 21.III.73; collected at Manjakotompo, forest station, Ankaratra mts. (near Ambatolampy), alt. 1800-2000 m. - ZMA 6929 (2 ô ô ), 13.XI.72 collected near Perinet (highroad R.N. 2 at km 142), alt $1100 \mathrm{~m}$.

$\mathrm{N}$ at u r a h is tory. - The species was never noticed during the day. The males were calling from leaves of shrubs and trees alongside rapids, in the evening. The female (gravid) was also captured in such a place. In the Mandraka valley at $\mathrm{km} 67$ the species occurs together with $B$. mandraka. They are collected in the same thicket, while sitting at short distance from each other. The mating calls of both are much alike, but could be distinguished. When touched, both secrete a strong smelling fluid, which serves probably also for species recognition. The two species resemble each other in morphology, but differ in colouration. The tadpoles of both are clearly lotic, and 
occur in the same torrents with stony bottom where Hydrostachys spp. grows: in the rivulet Vokanatetezandava, in the nursery garden of the city of Tananarive, at $\mathrm{km} \mathrm{69}$, Mandraka valley. The tadpoles collected at Manjakotompo were found in rapids with gravelly bottom.

Tax on omy. - Our specimens agree with the type material of Hyperolius erythrodactylus. The description of Guibé, 1953, is very brief, but the typical red punctation is described and still visible in the type. Vomerine teeth are present in the syntypes and our material. Both sternum and omosternum have a bony style; the style of the sternum is longer than the style of the omosternum. Thus the species belongs to the genus Boophis.

Description (see table IV for measurements). - The ratio of hand length to snoutvent length is $0.30-0.38$ (mean 0.33 ). The ratio of tibia length to snout-vent length is 0.54-0.67 (mean 0.59). The ratio of foot length to snoutvent length is $0.45-0.56$ (mean 0.49 ). The ratio of the horizontal diameter of the tympanum to that of the eye is 0.41-0.59 (mean 0.47). Snout-vent length of males $19.5-25.0 \mathrm{~mm}$, of female $32 \mathrm{~mm}$. Of the ratios mentioned, only the last is different from that in $B$. mandraka, in which species the tympanum is smaller and the eye larger.

Since $B$. erytbrodactylus and $B$. mandraka are much alike, I have restricted the description of the adult features of $B$. erythrodactylus mainly to those in which it differs from $B$. mandraka. All remaining features are identical to those mentioned above for $B$. mandraka.

The snout is bluntly rounded in lateral profile in the male and rounded in the female. The nostrils are slightly nearer to the tip of the snout than to the anterior corners of the eye. The distance from the nostril to the anterior corner of the eye is subequal to the horizontal diameter of the eye. The canthus is distinct and slightly angular.

The horizontal diameter of the tympanum is $2 / 5$ to $2 / 3$ of the horizontal diameter of the eye. The distance from the eye to the tympanum is $1 / 2$ to $3 / 4$ of the diameter of the tympanum. The largest diameter of the disc of the third finger equals the diameter of the tympanum.

The skin on the throat and chin is smooth in the female, finely granular in the male (as in $B$. mandraka).

The colour in life of the dorsum is bright green, covered with numerous red spots, which are surrounded by a thin yellow circle (pl. IV fig. 3 ). There is a yellow line from the nostril to the anterior corner of the eye. Another straight yellow dorsolateral line extends from the posterior corner of the eye over the tympanum, where it deviates from the tympanic fold, which is curved, and fades behind the shoulder. Two other yellow parallel lines run from the level where the former ends, but nearer to the midline, over the entire back. The upper eyelids are yellow, with brown spots. In some specimens there are also brown spots on the shanks and around the nostrils. The discs of the two lateral fingers and fourth toe are red; in some specimens all discs are red. The belly is pale blue-green. The bones are green. The iris is silvery grey with a blue periphery.

In preservative, the general colouration is yellowish. The dorsal surface is covered with silver-white spots. There is a silver-white line from the nostril to the eye. The upper eyelids are white with brown. The other lines are invisible. The red colour has disappeared completely in the ZMA collection, probably because the collection was exposed to the light for some time.

V o i c e. - The males were heard from November till April in the evening. The sonagram (fig. 9) made of a male (ZMA 6928) on 4 March 1973 at 11 p.m. shows that the duration of one call varies from $0.5-0.7 \mathrm{sec}$. One call consists of 4 to 5 rather melodious clicks. The dominant frequency is about $2500 \mathrm{~Hz}$.

Eg gs. - In the dissected female the eggs are cream-white and $2 \mathrm{~mm}$ in diameter; their number is about 200.

T a d poles. - ZMA 7207, 7208. Twentyfour tadpoles in stage 25 have body lengths of $5.0-10.2 \mathrm{~mm}$ and total lengths of $15.0-30.5 \mathrm{~mm}$. Five tadpoles in stages 27 and 28 have body 


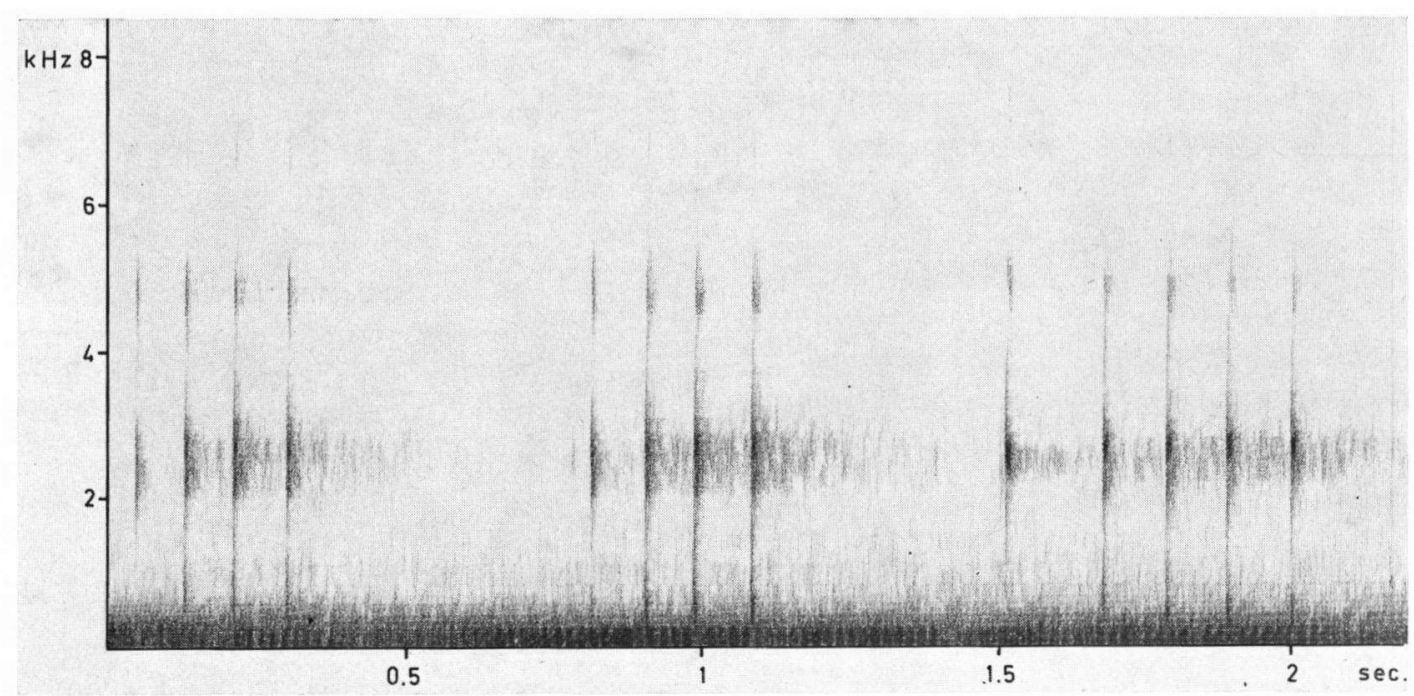

Fig. 9. Sonagram, filter wide, Boophis erytbrodactylus.

lengths of $10.5-11.8 \mathrm{~mm}$ and total lengths of 32.0-35.5 mm. Five tadpoles in stages $31-36$ have body lengths of $10.5-11.0 \mathrm{~mm}$ and total lengths of $29.5-34.0 \mathrm{~mm}$. One tadpole in stage 41 has a body length of $31.5 \mathrm{~mm}$ and a total length of $41.0 \mathrm{~mm}$. All these tadpoles were caught in the Mandraka valley, at $1200 \mathrm{~m}$ alt. Those collected in the Ankaratra mts. are larger; two tadpoles in stages 31 and 34 have body lengths of 12 and $14 \mathrm{~mm}$ and total lengths of $36-39 \mathrm{~mm}$ (ZMA 7205). The average ratio of tail length to body length in the thirty-seven tadpoles listed above is 2 (range 1.72.1). Five metamorphosing young have body lengths of $13-15 \mathrm{~mm}$ (mean $14 \mathrm{~mm}$ ).

The mouth and lateral view of a tadpole in stage 28 (ZMA 7208) are shown in text-figs. 5-6. The body is depressed. The nostrils are dorsal, the opening is anterolaterally, situated at about $3 / 4$ from the tip of the snout and the anterior corner of the eye. The eyes are situated laterally. The spiracular opening is sinistral, situated at about $3 / 4$ from the tip of the snout and the end of the body. The cloacal tube is long and dextral to the caudal fin. The caudal musculature is robust. The caudal fin is shallow anteriorly and deepest at about three-fourths of its length. At midlength of the tail, the height of the caudal musculature represents $1 / 2$ of the total height. The mouth is broad and directed ventrally. The papillary border has a wide median gap. There are 3-4 rows of large papillae laterally, and 5-6 rows of large papillae posteriorly. The oral disc is round. The tooth formula is $4 / 4+4 / / 3$. The upper row of the upper lip and the lower row of the under lip consist of very small teeth. The horny beak is well developed. The lower beak is U-shaped with robust serrations.

The colour of the tadpole in life is brown on the back, the belly is black in stage 25 and becomes silver-grey in later stages. The caudal musculature has dark brown patterns and the caudal fin is transparent.

The tadpoles were collected in rapids from June till October, together with those of $B$. mandraka. Metamorphosis occurred in October (at the beginning of the hot season). Only fully developed tadpoles could be brought through metamorphosis in the vivarium.

Young. - It was rather difficult to assign the young frogs reared from the different tadpoles of the two sibling species $B$. erythrodactylus and $B$. mandraka. I have assigned the young from the tadpole described above to $B$. erytbrodactylus, because the young frog in life shows the typical yellow line from the nostril to the anterior corner of the eye and another straight yellow line from the posterior corner of the eye to behind the shoulder. This green froglet has yellow spots all over the dorsal surface, and yellow hands and feet. 
The bones are green. The canthus is angular. The hindlimbs are relatively shorter than in the adult, which is a common phenomenon in young frogs.

\section{Boophis viridis sp. nov.}

Pl. IV fig. 5.

Materia 1. - ZMA 7100A, male holotype, ZMA 7100B, two male paratypes, collected 14.XI.72 near Perinet (highroad R.N. 2 at $\mathrm{km} \mathrm{142),} \mathrm{alt.} 900 \mathrm{~m}$.

The present species resembles the other species of the rappiodes group. $B$. viridis can be distinguished from rappiodes, mandraka and erytbrodactylus by its larger body size (snout-vent length $29-31 \mathrm{~mm}$ of adult males), by the strongly protruding nostrils, by the relatively longer snout, and by its difference in colouration (see text description).

$\mathrm{H}$ a b it a t . - The males were found on a rainy evening, calling on leaves of shrubs and trees, along running water, in forest.

Description (see table IV for measurements). - The ratio of hand length to snout-vent length is $0.32-0.34$ (mean 0.33 ). The ratio of tibia length to snout-vent length is $0.58-0.62$ (mean $0.60)$. The ratio of foot length to snout-vent length is $0.45-0.48$ (mean 0.46 ). The ratio of the horizontal diameter of the tympanum to that of the eye is $0.32-0.36$ (mean 0.35). Snout-vent length of males $29-31 \mathrm{~mm}$.

Holotype: head length is $9 \mathrm{~mm}$; head width is $11 \mathrm{~mm}$; internarial and interorbital distance is $3 \mathrm{~mm}$; snout-vent length is $31 \mathrm{~mm}$.

The body in the postaxillary region is little narrower than the greatest width of the head. The head is wider than long. The head width is onethird of the body length. The snout is truncate in dorsal and lateral profile. The snout is longer than the horizontal diameter of the eye, and equal to the distance between the anterior corners of the eyes. The nostrils are much nearer to the tip of the snout than to the anterior corners of the eyes. The canthus is distinct and rounded. The loreal region is slightly concave. The interorbital region is slightly convex. The ratio between the internarial and interorbital distance is 1 . The interorbital distance is about one and a half times the width of an upper eyelid. The nostrils are strongly protruding, the opening is laterally. The commissure of the mouth is straight. The pupil is horizontally elliptical.

There is a weak dermal fold from the posterior edge of the eye, over the tympanum, curving downwards to a point just behind the insertion of the arm. The fold covers the dorsal margin of the tympanum. The tympanum is rather indistinct, its horizontal diameter is one-third of the horizontal diameter of the eye. The distance from the eye to the tympanum is about $3 / 4$ of the horizontal diameter of the tympanum.

The largest diameter of the disc of the third finger equals the horizontal diameter of the tympanum, the discs of the fourth and second finger are about equal and of the first much smaller. The relative lengths of the fingers from shortest to longest are 1-2-4-3. The subarticular tubercles are small, distinct and round. The distal tubercles on the fourth and third finger are bifid. There is an inner flat, oval metacarpal tubercle. A small unpigmented, glandular nuptial pad is present dorsolaterally on the first finger. There are some supernumerary tubercles on the base of the fingers. The formula of the webbing of the hand: 1 (1), $2 \mathrm{i}(1), 2 \mathrm{e}(1), 3 \mathrm{i}(2), 3 \mathrm{e}(1), 4(1)$. The web is glandular.

The arms and legs are slender. When the limbs are laid along the side, the knee and elbow overlap noticeably. The adpressed heels meet. The tibiotarsal articulation extends beyond the tip of the snout. The inner metatarsal tubercle is small, distinct, elliptical. A small web connects the tip of the inner metatarsal tubercle with the first toe to the middle of the antepenultimate phalanx. There is no outer metatarsal tubercle. The discs of the toes are equal to those of the fingers. The subarticular tubercles are small, distinct and round. The fifth toe is longer than the third. The formula of the webbing of the foot: $1(0), 2 \mathrm{i}(1 / 2), 2 \mathrm{e}(0)$, $3 \mathrm{i}(1 / 2), 3 \mathrm{e}(0), 4 \mathrm{i}(1), 4 \mathrm{e}(1), 5(0)$. The ventral surface of the web is glandular. The lateral metatarsalia are separated. A weak tarsal fold is present.

The anal opening is directed posteriorly at the upper level of the thighs. The anal sheath is short.

The tongue is heart-shaped and distinctly bifid 
posteriorly. The vomerine teeth are situated medially, far behind the choanae, in two small straight groups. The vocal slits are small, situated in the floor of the mouth, near the angles of the jaws. The vocal sac is single, median subgular and noticeably distensible.

The skin on the dorsum and throat is finely granular. The skin on the belly and posteroventral surfaces of the thighs is granular. The skin beneath the anal opening is coarsely granular. Elsewhere on the venter, the skin is smooth.

The general colouration in life is light green, the upper eyelid is yellow and the dorsum is covered with red speckles (pl. IV fig. 5). The iris is orange-brown with a blue periphery, surrounded by a black ring. The bones are green.

The colour in preservative is entirely light yellowish, the upper eyelid is whitish, especially the border. The iris is beige-brown, surrounded by a black ring. The upper rim of the palpebral membrane is slightly pigmented. The lower rim is broadly pigmented in the same colour as the skin of the upper eyelid.

Etymology. - The specific name refers to the green colour of the species.

\section{Boophis luteus group}

D i a $\mathrm{g}$ o os is. - The members of this group are moderate- to large-sized, stream-breeding species. The dorsum is dark green, the bones are green. There are no distinctive markings on the posterior surface of the thighs. There are white lateral fringes along the lateral edge of the lower arm and tarsus. The skin on the dorsum is smooth. Vomerine teeth are present. The vocal sac is paired, lateral, subgular. The horizontal diameter of the tympanum is half that of the eye. The snout is rounded, the eyes are large. The tibiotarsal articulation extends to the tip of the snout. The discs are well developed. The fingers are half or more webbed. The toes are entirely or almost entirely webbed.

Contents: B. luteus (Boulenger, 1882) and $B$. albilabris (Boulenger, 1888).
Differential diagnosis

1. Large species $(75.95 \mathrm{~mm})$, toes entirely webbed, the webbing reaching the discs between the third and fourth finger . . . . . . B. albilabris (Boulenger)

2. Medium-sized species $(40-55 \mathrm{~mm})$, one phalanx of fourth toe free of web, the webbing reaching the bases of the penultimate phalanges between the third and fourth finger... . . . B. luteus (Boulenger)

Re marks. - Although I have not seen $B$. albilabris in life, I consider the species closely related to $B$. luteus. Boulenger (1888) in the original description, mentioned the paired, lateral, subgular, vocal sac, the white lateral fringes alongside the lower arm and tarsus, and supposed a green colour in life.

\section{Boophis luteus (Boulenger, 1882)}

Text-figs. 7, 10-12; pl. I fig. 3, pl. IV fig. 4.

Rhacophorus luteus Boulenger, 1882: 468; Guibé, 1978: 73, figs. 172-177 (equals isabellinus).

Rhacophorus isabellinus Boettger, 1913: 277, pl. XXIII fig. 6. Boophis luteus; Bachmann \& Blommers-Schlösser, 1975: 17 (DNA); Blommers-Schlösser, 1978: 30 (chromosomes).

Materia 1. - SMF 6821, holotype of Rbacophorus isabellinus. Type locality: Moramanga. Coll. Voeltzkow.

ZMA 6840 (3 ô ô ), 27.III.73; 6838 (1 $\hat{\delta}, 1$ \&), 4.III. 73; 7094 (eggs of 6838); collected in the Mandraka valley (highroad R.N. 2 at km 67); 7005 (tadpoles and young reared from them), 1.IV.-1.X.72 same locality at km 69; 7092 (tadpoles), 24.IX.72 same locality at $\mathrm{km} \mathrm{70,} \mathrm{alt.} 1100$ m. - ZMA 6839 (5 ô ô ), 13.XI.72; 7090 (tadpoles and young reared from them), 24.IX.72; collected near Perinet (highroad R.N. 2 at $\mathrm{km} \mathrm{142),} \mathrm{alt.} 1100 \mathrm{~m}$. - ZMA 7091 (tadpoles and young reared from them), 12.IX.71 collected near Tampoketsa d'Ankazobe forest station (highroad R.N.

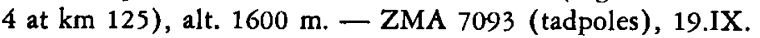
71 collected at Manjakotompo, forest station, Ankaratra mts., alt. $1800 \mathrm{~m}$. - ZMA 7146 (tadpoles), 29.VIII.72 collected along the road from Moramanga to Anosibe at km 27, alt. $800 \mathrm{~m}$.

$\mathrm{Nat}$ u $\mathrm{ra}$ l history. - The males are calling from the leaves of shrubs and trees along rapids in the forest, during rainy nights. The female was found with a male in axillary amplexus. The tadpoles occur in swiftly flowing waters.

Measurements (see table IV). - The ratio of hand length to snout-vent length is 0.28 0.32 (mean 0.29). The ratio of tibia length to snout-vent length is 0.51-0.57 (mean 0.54). The 
ratio of foot length to snout-vent length is 0.44 0.51 (mean 0.48). The ratio of the horizontal diameter of the tympanum to that of the eye is 0.44-0.49 (mean 0.48). Snout-vent length of males $37-40 \mathrm{~mm}$, of female $54 \mathrm{~mm}$.

Sexual dimorphism. - The male has a white nuptial pad latero-dorsally on the first finger. The vocal slits are small, situated in the floor of the mouth, near the angles of the jaws. The vocal sac is paired subgular. The male is smaller than the female.

Colour in 1 if e. - The general colouration is dark, slightly bluish, green (pl. IV fig. 4). The bones are green. The iris is orange, or whitish in the middle surrounded with dark red, or red in the middle and whitish around.

Voice. - The call of B. luteus is conspicuous and very characteristic. It is a melodious sound, repeated quickly and constantly for as long as 30 seconds. It reminds of a New York police car. At first, we did not suspect a frog to produce it. The males could be heard every evening during the rainy season. The sonagram (fig. 10) made of a male (ZMA 6838) on 4 March 1973, at 11.30 p.m. shows only a part of the very long note. The dominant frequency, here also fundamental frequency, is about $3000 \mathrm{~Hz}$.

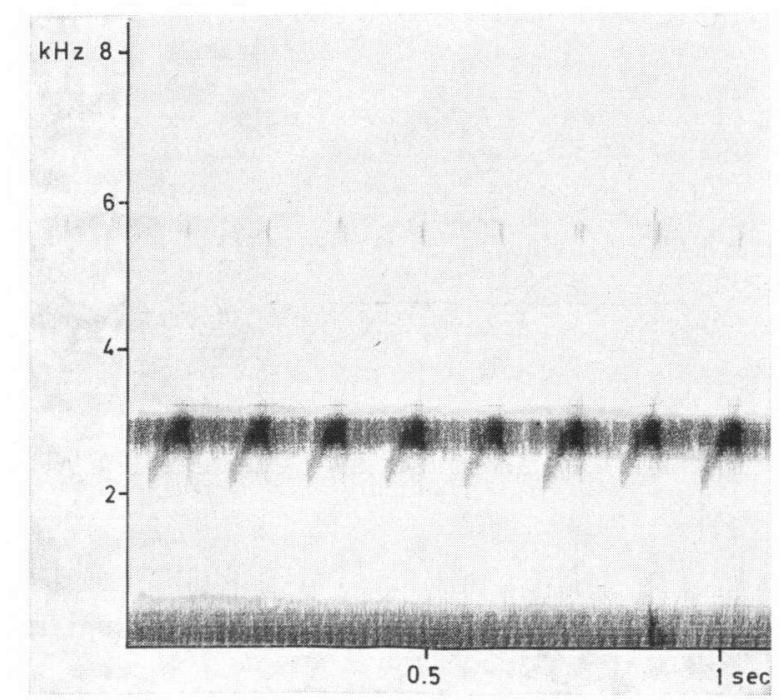

Fig. 10. Sonagram, filter wide, Boophis luteus.
E g g s. - The female deposited about 200 black, very sticky, eggs in a collecting bag. The eggs measure $2 \mathrm{~mm}$ in diameter. Development of the eggs did not occur.

T a d p o l e s. - Tadpoles, which developed into young of $B$. luteus are dimorphous in the structure of the mouth. I could not discover differences in the young developing from the different tadpoles, but it is possible that one belongs to $B$. albilabris.

Form A (ZMA 7005, 7092, 7146) and form B (ZMA 7090, 7091, 7093). A: Fifty-seven tadpoles in stage 25 have body lengths of 4.5-11.0 $\mathrm{mm}$ and total lengths of $14-28 \mathrm{~mm}$. The average ratio of tail length to body length is 1.7 (range 1.5-1.9). Twenty-nine tadpoles in stages $26-30$ have body lengths of $9.0-14.5 \mathrm{~mm}$ and total lengths of $24-30 \mathrm{~mm}$. Ten tadpoles in stages $31-40$ have body lengths of $14-20 \mathrm{~mm}$ and total lengths of $38-59 \mathrm{~mm}$. The average ratio of tail length to body length in the stages $26-40$ is 1.7 (range 1.5-1.9). Thirteen metamorphosing young have body lengths of $18-22 \mathrm{~mm}$ (mean $20.5 \mathrm{~mm}$ ). B: Fourteen tadpoles in stage 25 have body lengths of $7-13 \mathrm{~mm}$ and total lengths of $19-38 \mathrm{~mm}$. Three tadpoles in stages 26-30 have body lengths of 14$15 \mathrm{~mm}$ and total lengths of $39-41 \mathrm{~mm}$. Five tadpoles in stages 35-38 have body lengths of 18-22 $\mathrm{mm}$ and total lengths of $50-65 \mathrm{~mm}$. The average ratio of tail length to body length in the twentytwo tadpoles listed above is 1.7 (range 1.5-1.9). Three metamorphosing young measure 21.0-24.5 $\mathrm{mm}$ from snout to vent.

The mouth (form A) of a tadpole in stage 36 (ZMA 7005) and the mouth (form B) of a tadpole in stage 27 (ZMA 7090) are shown in textfigs. 7 and 11.

A: The mouth is small and directed ventrally. The papillary border has a wide median gap anteriorly. There are two rows of papillae and laterally there are numerous supernumerary papillae. The oral disc is very slightly indented medioposteriorly. The tooth formula is $1 / 5+5 / / 3$ or $1 / 4+4 / / 3$, the first row of the lower lip is sometimes slightly interrupted in the middle. The horny beak is well developed.

B: The mouth is small and directed ventrally. The papillary border has a wide median gap 

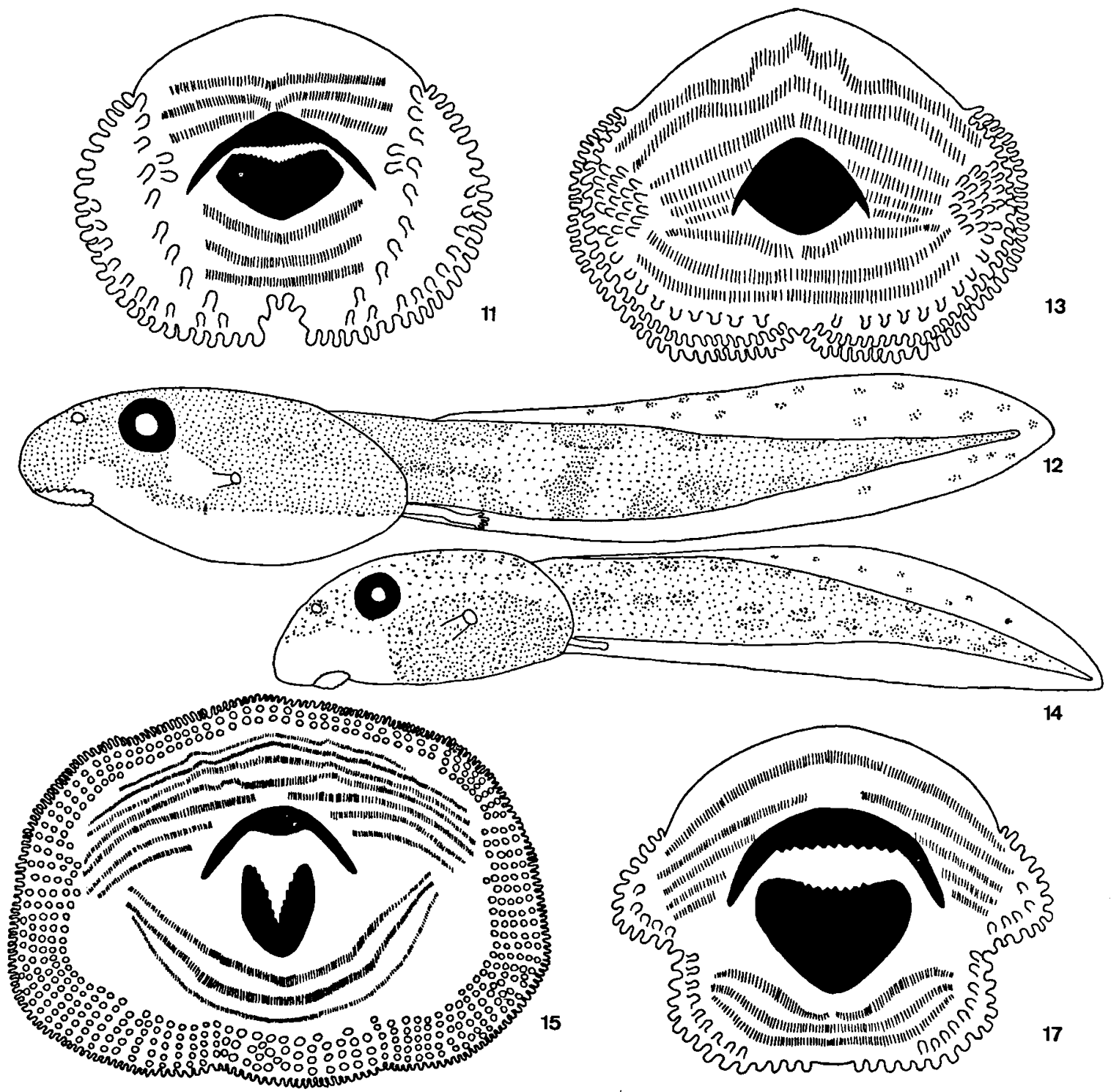

14
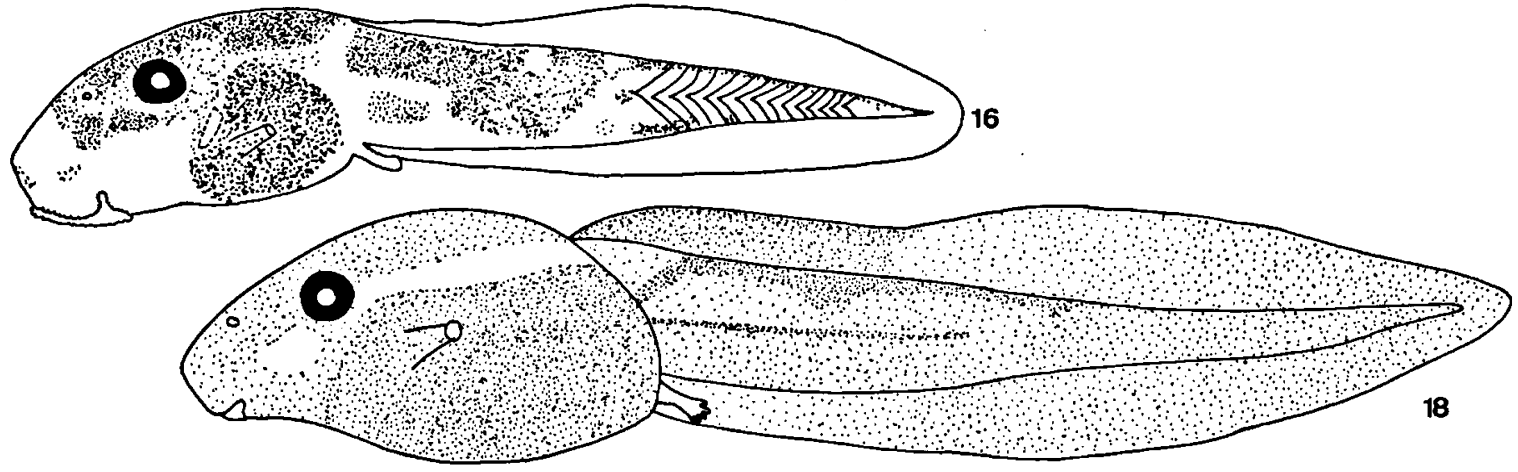

Figs. 11-18. 11-12, Boophis luteus: 11, mouth of tadpole, form B, ZMA 7090.X.12.5; 12, tadpole, ZMA 7005.X.3; 13-14, B. sp.: 13, mouth of tadpole, ZMA 7154.X.12.5; 14, tadpole, ZMA 7154.X.3; 15-16, B. majori: 15, mouth of tadpole, ZMA 7096.X.12.5; 16, tadpole, ZMA 7096.X.3; 17-18, B. goudoti: 17, mouth of tadpole, ZMA 7209.X.12.5; 18, tadpole, ZMA 7209.X.1.5. 
anteriorly. There are 1-2 rows of fringing papillae and a supernumerary row, more inside laterally with a few supernumerary papillae. The oral disc is indented medioposteriorly. The tooth formula is $1 / 2+2 / / 3$ or $1 / 3+3 / / 3$, the first row of the lower lip is sometimes slightly interrupted in the middle. The horny beak is well developed.

Since the morphology of both forms $(A, B)$ is similar in the other features, the description is given once. The lateral view of a tadpole in stage 36 (ZMA 7005) is shown in fig. 12. The body is depressed. The nostrils are dorsal, the opening is large and directed to the front, situated slightly nearer to the anterior corners of the eyes than to the tip of the snout. The eyes are large and directed laterally. The spiracular opening is sinistral, situated at about 5/8 from the tip of the snout and the end of the body. The cloacal tube is wide and dextral to the caudal fin. The caudal musculature is robust, especially in the first half of the tail. The dorsal caudal fin is reduced anteriorly. At midlength of the tail, the height of the caudal musculature represents about $2 / 5-1 / 2$ of the total tail height.

The colour of the tadpole is brownish or blackish in life; it becomes greenish in the late metamorphic stages. The belly is transparent in the early stages and silvery in the later stages of development. The caudal musculature is densely pigmented with brown or black spots and the caudal fin has a few dispersed brown spots.

Metamorphosis occurs in October and the beginning of November. The tadpoles were collected from streams with stony or muddy bottom. Those collected from the streams with a stony bottom are blackish; the others are brownish.

Young. - In life the colour of the back is green with a red spot between the eyes; sometimes the red pigment covers more of the back. There are two lateral yellow lines from the tip of the snout over the eye to the insertion of the hindlimbs. The belly is greenish. The bones are green. The iris is orange. The white lateral folds from the elbow to the disc of the fourth finger and from the heel to the disc of the fifth toe are already visible in some specimens. The webbing of hand and feet is identical to that of adults of $B$. luteus.
Boophis albilabris (Boulenger, 1888)

Rhacophorus albilabris Boulenger, 1888: 105, pl. VI, fig. 1; Guibé, 1978: 71, figs. 164-165.

This species was not collected by the author.

The tadpole of the following unknown species resembles much the tadpole of $B$. luteus, therefore its description follows here.

\section{Boophis sp.}

Text-figs. 13-14; pl. I fig. 4.

Material. - ZMA 7154 (tadpoles and young reared from them), 1.IV-I.X.72; 7147 (tadpoles), 24.IX.72; collected in the Mandraka valley (in the Mandraka and Vokanatetezandava river), (highroad R.N. 2 at $\mathrm{km} \mathrm{69-70),} \mathrm{alt.}$ $1200 \mathrm{~m}$.

$\mathrm{Hab}$ it a t. - The tadpoles were collected in rather large streams with stony bottom. An adult specimen was never noticed.

T a d pol es . - Thirty-two tadpoles in stage 25 have body lengths of $5.5-9.5 \mathrm{~mm}$ and total lengths of $16.0-26.5 \mathrm{~mm}$. The average ratio of tail length to body length in this stage is 1.85 (range 1.65 2.00 ). Twelve tadpoles in stages $26-30$ have body lengths of 9-11 mm and total lengths of 24-29 $\mathrm{mm}$. Seventeen tadpoles in stages 31-40 have body lengths of $11.0-13.5 \mathrm{~mm}$ and total lengths of $29.0-36.5 \mathrm{~mm}$. The average ratio of tail length to body length in the stages $26-40$ is 1.7 (range 1.601.85 ). Three metamorphosing young measure 13$15 \mathrm{~mm}$ from snout to vent.

The mouth and lateral view of a tadpole in stage 31 (ZMA 7154) are shown in figs. 13-14. The body is depressed. The nostrils are dorsal, the opening is large and directed to the front, situated slightly nearer to the anterior corners of the eyes than to the tip of the snout. The eyes are large and directed laterally. The spiracular opening is sinistral, situated at about $5 / 8$ from the tip of the snout and the end of the body. The cloacal tube is wide and dextral to the caudal fin. The caudal musculature is robust, especially in the first half of the tail. The dorsal caudal fin is reduced anteriorly. At midlength of the tail, the height of the 
caudal musculature represents about 2/5-1/2 of the total tail height. The mouth is rather broad and directed ventrally. The papillary border has a wide median gap anteriorly. There are three rows of papillae and laterally there are three rows of supernumerary papillae. The oral disc is slightly indented medioposteriorly. The tooth formula is $2 / 4+4 / / 3$ or $2 / 4+4 / / 1+1 / 2$. The two upper rows of the upper lip are situated distinctly above the horny beak. The teeth are large. The horny beak is well developed.

The colour of the tadpole is brownish in life. The caudal musculature is densely pigmented with brown spots and the caudal fin has a few dispersed brown spots.

Metamorphosis occurs in October (beginning of the hot season). The tadpoles resemble those of $B$. luteus (Boulenger, 1882), collected from the same streams. The diagnostic feature is the mouth and the smaller size of the metamorphosing tadpoles. It is not possible to identify the young with certainty, since we collected no adults at the same place.

You ng. - In life the colour of the back is beige with brown spots. The venter is equally creamish. There are two lateral light beige lines from behind the eyes to the groin. The nostrils are slightly nearer to the tip of the snout than to the anterior corners of the eye. The tibiotarsal articulation extends to the centre of the eye. The adpressed heels meet. The formula of the webbing of the foot: $1(0), 2 \mathrm{i}(1), 2 \mathrm{e}(0), 3 \mathrm{i}(1), 3 \mathrm{e}(0)$, $4 i(1), 5(0)$. The formula of the webbing of the hand: $3 \mathrm{e}(2), 4$ (1). A trace of web between the others. The discs are moderately developed. The skin of the back and chin and throat is finely granular. The skin of the belly and the ventral surface of the thigh is coarsely granular. The remaining ventral surface is smooth.

\section{Boophis rhodoscelis group}

Diagnosis. - The members of this group are small-sized, stream-breeding species. The dorsum is beige or red. There are transverse bars on the limbs, but no distinctive markings on the posterior surface of the thighs. There are white lateral fringes along the lateral edge of the lower arm and tarsus (difficilis, majori, miniatus). The ventral surface of the hindlimbs, the web between the toes, the posterior and anterior surface of the thighs are usually violet-red. The skin on the dorsum is smooth or slightly granular. Vomerine teeth are present. The horizontal diameter of the tympanum is one-third to half that of the eye. The vocal sac is single, median, subgular. The snout is short and rounded. The commissure of the mouth is slightly curved upwards except in rbodoscelis, in which the commissure of the mouth is straight. The tibiotarsal articulation does not extend beyond the tip of the snout. The discs are well developed. The fingers are one-third webbed, the web connects the middle of the antepenultimate phalanx of the third finger with the base of the penultimate phalanx of the fourth. The toes are two-thirds to three-fourths webbed. One to two phalanges of the fourth toe are free of web.

Contents: B. rbodoscelis (Boulenger, 1882), B. difficilis (Boettger, 1892), B. majori (Boulenger, 1896), and B. miniatus (Mocquard, 1902).

R e m a rks. - B. difficilis, B. majori and $B$. miniatus are hard to distinguish morphologically. They were collected, when calling, during rainy nights. It was heard that the mating call is clearly different in each of them. The nuclear DNA amount (diploid) was $7.8 \mathrm{pg}$ in $B$. majori and 9.1 $\mathrm{pg}$ in $B$. difficilis (Bachmann \& BlommersSchlösser, 1975). Once ascertained that there are three species, I have made an attempt to find diagnostic features for each of them.

\section{Differential diagnosis}

1. Tibiotarsal articulation reaching the eye, lateral fringes alongside the lower arm and tarsus absent, commissure of mouth straight, canthal and temporal region dark brown. . B. rbodoscelis (Boulenger)

2. Tibiotarsal articulation reaching beyond the eye, lateral fringes alongside the lower arm and tarsus present, commissure of mouth curved upwards, canthal and temporal region same colour as dorsum . . . B. difficilis (Boettger), B. majori (Boulenger), B. miniatus (Mocquard)

Between the latter three are very small differences, which are shown in table III. 
TABLE III

Diagnostic characters between Boophis difficilis, B. majori and B. miniatus.

\begin{tabular}{|c|c|c|c|}
\hline & B. difficilis & B. majori & B. miniatus \\
\hline Snout-vent length of adult $\hat{\delta}(\mathrm{mm})$ & $27-31$ & $22.0-26.5$ & $31-34$ \\
\hline $\begin{array}{l}\text { Ratio hor. diameter tympanum/eye (mean) } \\
\text { Fringes alongside lower arm and tarsus }\end{array}$ & $\begin{array}{c}0.36 \\
\text { well developed }\end{array}$ & $\begin{array}{l}0.35 \\
\text { well developed }\end{array}$ & $\begin{array}{c}0.50 \\
\text { weak developed }\end{array}$ \\
\hline $\begin{array}{l}\text { Position of nostrils in respect of tip of } \\
\text { snout and anterior corner of eye }\end{array}$ & $\begin{array}{l}\text { much nearer tip } \\
\text { of snout }\end{array}$ & $\begin{array}{l}\text { midway tip of } \\
\text { snout and eye }\end{array}$ & $\begin{array}{l}\text { slightly nearer } \\
\text { tip of snout }\end{array}$ \\
\hline $\begin{array}{l}\text { Character of nostrils } \\
\text { Skin on the back, chin and throat } \\
\text { Colouration }\end{array}$ & $\begin{array}{l}\text { strongly } \\
\text { protruding } \\
\text { smooth } \\
\text { cf. text descriptio }\end{array}$ & $\begin{array}{l}\text { slightly } \\
\text { protruding } \\
\text { finely granular } \\
\text { ecies }\end{array}$ & $\begin{array}{l}\text { slightly } \\
\text { protruding } \\
\text { smooth }\end{array}$ \\
\hline
\end{tabular}

Boophis rhodoscelis (Boulenger, 1882)

Rhacophorus rhodoscelis Boulenger, 1882: 466; Guibé, 1978: 74, figs. 181.182 (equals andrangoloaka and brevirostris). Rhacophorus andrangoloaka Ahl, 1928: 311; Guibé, 1978: 74 (in synonymy of rbodoscelis).

Rhacophorus brevirostris Ahl, 1928: 313; Guibé, 1978: 74 (in synonymy of rhodoscelis).

Materia 1. - BMNH 1947.2.7.66-67, two syntypes of Rhacophorus rbodoscelis. Type locality: East Betsileo. Coll. Cowan.

ZMB 30510, two syntypes of Rhacophorus andrangoloaka. Type locality: Central Madagascar. Coll. Hildebrandt.

ZMB 30518, holotype of Rhacophorus brevirostris. Type locality: N.W. Madagascar. Coll. Hildebrandt.

ZMA 7194 (one young reared from tadpole), 12.IX.71 collected near Tampoketsa d'Ankazobe, forest station (high-

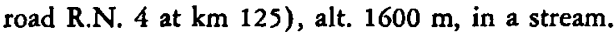

You n g. - The hatched young measures $19 \mathrm{~mm}$ from snout to vent (adult of this species about $35 \mathrm{~mm}$ ). It has already the crimson colouration on the ventral surface of the hindlimbs.

Boophis difficilis (Boettger, 1892) bona species Pl. IV fig. 6.

Rhacophorus difficilis Boettger, 1892: 14; Boettger, 1913: 276, pl. XXIX fig. 1; Guibé, 1947: 439 (in synonymy of depressiceps); Guibé, 1975a: 1763 (elimination of synonymy of depressiceps); Guibé, 1978: 65 (in synonymy of tephraeomystax; in part).

Boophis sp. 2; Bachmann \& Blommers-Schlösser, 1975: 17 (DNA).

Material. - SMF 6762, holotype of Rhacophorus difficilis. Type locality: Foizana, E. Madagascar. Bought from Schneider, Basel, 1880.

ZMA 7098 ( 1 ô ), 14.XI.72; 7099 (6 ô ô), 24.XII.72;

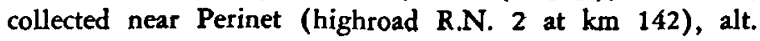
$900 \mathrm{~m}$.
$\mathrm{N}$ at u r a $\mathrm{l}$ his tory. - The species was never heard or noticed during daytime. The males were found on rainy evenings, calling in the vegetation along a brook, in forest. They were seen moving down from the trees.

Des cription of ZMA material (see table IV for measurements). - The ratio of hand length to snout-vent length is $0.29-0.32$ (mean 0.305). The ratio of the tibia length to snout-vent length is 0.52-0.59 (mean 0.56). The ratio of the foot length to snout-vent length is $0.43-0.50$ (mean 0.46 ). The ratio of the horizontal diameter of the tympanum to that of the eye is $0.34-0.38$ (mean 0.36 ). Snout-vent length of males $27-31 \mathrm{~mm}$.

The head is wider than the body, and somewhat wider than long. The head length is one-third of the body length. The snout is rounded in dorsal profile, and sloping to truncate in lateral profile. The snout is slightly longer than the horizontal diameter of the eye, and somewhat shorter than the distance between the anterior corners of the eye. The nostrils are much nearer to the tip of the snout than to the anterior corners of the eye. The distance from the nostril to the anterior corner of the eye is shorter than the horizontal diameter of the eye. The canthus is rather distinct and rounded. The loreal region is slightly concave. The interorbital region is flat. The ratio of the internarial distance to the interorbital distance is $4 / 5$. The interorbital distance is somewhat wider than the width of an upper eyelid. The nostrils are strongly protruding, the opening is laterally. The commissure of the mouth is slightly curved upwards. The pupil is horizontally elliptical. 
TABLE IV

Dimensions in $\mathrm{mm}$ of Boophis rappiodes, B. mandraka, B. erythrodactylus, B. viridis, B. luteus, B. difficilis, B. majori and $B$. miniatus. $\mathbf{A}=$ snout to vent; $B=$ length of lower arm; $C=$ hand length; $D=$ length of hind limb; $\mathbf{E}=$ tibia length; $F=$ length of foot and tarsus; $G=$ foot length; $H=$ horizontal diameter of tympanum; $I$ = horizontal diameter of eye.

\begin{tabular}{|c|c|c|c|c|c|c|c|c|c|}
\hline & A & B & C & $\mathrm{D}$ & $\mathbf{E}$ & $\mathbf{F}$ & $\mathbf{G}$ & $\mathbf{H}$ & I \\
\hline \multicolumn{10}{|l|}{ B. rappiodes } \\
\hline 1 oิ ZMA & 24 & 11 & 6 & 42 & 14 & 16 & 10 & 1 & 3 \\
\hline 1 ㅇ ZMA & 32 & 16 & 9 & 55 & 19 & 22 & 14 & 1.2 & 3.5 \\
\hline \multicolumn{10}{|l|}{ B. mandraka } \\
\hline$\hat{o}$ holotype ZMA & 23.5 & 12.5 & 7.5 & 41 & 13 & 16.5 & 10.5 & 1 & 3 \\
\hline 12 ô $\hat{o}$ paratypes ZMA & $21-26$ & $12.0-13.5$ & $7-8$ & 39.42 & $12.5-14.0$ & $16-18$ & $10.5-11.5$ & $0.8-1.0$ & $2.8-3.0$ \\
\hline \multicolumn{10}{|l|}{ B. erythrodactylus } \\
\hline 25 ô $\hat{o} \mathrm{ZMA}$ & $19.5-25.0$ & $11-13$ & $7-8$ & 40.44 & $12.5-14.5$ & $15.5 \cdot 18.5$ & $10.5-12.0$ & $1.0-1.3$ & $2.2-2.9$ \\
\hline 1 을 & 32 & 17 & 9.5 & 55.5 & 17 & 22.5 & 15 & 1.8 & 3.2 \\
\hline \multicolumn{10}{|l|}{ B. viridis } \\
\hline ô holotype ZMA & 31 & 15.5 & 10 & 57 & 18 & 23 & 14 & 1.2 & 4 \\
\hline 2 \& $\delta$ paratypes ZMA & 29 & 15 & 10 & $52-53$ & $17 \cdot 18$ & 22 & $13-14$ & $1.2-1.3$ & 3.6 \\
\hline \multicolumn{10}{|l|}{ B. luteus } \\
\hline 9 ô ô ZMA & $37-40$ & $18-20$ & $10.5-12.0$ & $61-68$ & $19-22$ & $27-30$ & $17-20$ & $2.0-2.2$ & 4.1-4.5 \\
\hline 1 \% $\mathrm{MA}$ & 54 & 25 & 15 & 90 & 29 & 39 & 25 & 2.2 & 5 \\
\hline \multicolumn{10}{|l|}{ B. difficilis } \\
\hline holotype SMF & 28 & 13.5 & 8.5 & 44 & 14.5 & 18 & 12 & 1.2 & 3.2 \\
\hline 7 คิ ใิ ZMA & $27-31$ & $13.5-15.0$ & $8.5-9.5$ & $46-52$ & $14.5-16.5$ & $19.0-21.5$ & $12-14$ & 1.2 & $3.2-3.5$ \\
\hline \multicolumn{10}{|l|}{ B. majori } \\
\hline lectotype BMNH $\hat{o}$ & 24 & 12 & 7 & 41 & 13 & 18 & 11 & 1.1 & 3 \\
\hline 32 oิ oิ ZMA & $22.0-26.5$ & $12-13$ & $7-8$ & $40-45$ & 13.15 & $16.5-19.0$ & $10-12$ & $1.1-1.2$ & $2.8-3.2$ \\
\hline 1 \& ZMA & 32 & 16 & 10 & 57 & 18 & 25 & 15 & 1.2 & 4 \\
\hline \multicolumn{10}{|l|}{ B. miniatus } \\
\hline holotype MNHP & 27 & 13.5 & 8 & 45 & 15 & 20 & 11.5 & 1.8 & 3.5 \\
\hline 3 के के ZMA & $31-34$ & $15-16$ & $9-11$ & 49.56 & $16.5-18.0$ & $22-24$ & $13.5-15.0$ & $1.9-2.2$ & $3.8-4.1$ \\
\hline
\end{tabular}

There is a weak dermal fold from the posterior edge of the eye, over the tympanum, curving downwards to a point just behind the insertion of the arm. The fold covers the dorsal margin of the tympanum. The tympanum is distinct and round, its diameter is about one-third to two-fifths of the horizontal diameter of the eye. The distance from the eye to the tympanum is about half the diameter of the tympanum.

The largest diameter of the disc of the third finger equals the diameter of the tympanum; the disc of the fourth finger is subequal, of the second finger slightly smaller and of the first much smaller. The relative lengths of the fingers from shortest to longest are 1-2-4-3. The subarticular tubercles are distinct and round. The distal tubercles of the fourth and third finger are sometimes bifid. There is an inner oval, flat metacarpal tubercle and no palmar tubercle. There is a small unpigmented, glandular nuptial pad dorsolaterally on the first finger. Supernumerary tubercles are present on the base of the fingers. There is a trace of web between the fingers. Between the fourth and third finger the web extends from the middle of the antepenultimate phalanx of the third to the base of the penultimate phalanx of the fourth. The web is glandular.

The arms and legs are slender. When the limbs are laid along the side the knee and elbow overlap strongly. The adpressed heels overlap slightly. The tibiotarsal articulation extends to a point between the nostril and the tip of the snout, or to the tip of the snout. The inner metatarsal tubercle is distinct, small, elliptical and protruding. There is no outer metatarsal tubercle. A small web connects the middle of the inner metatarsal tubercle with the first toe to the base of the penultimate phalanx. The terminal discs are somewhat smaller than those on the hand. The fifth toe is somewhat longer than the third. The subarticular tubercles are distinct and round. The formula of the webbing of the foot: $1(0), 2 \mathrm{i}(1), 2 \mathrm{e}(0)$, $3 \mathrm{i}(1), 3 \mathrm{e}(0), 4 \mathrm{i}(2), 4 \mathrm{e}\left(1 \frac{1}{2}\right), 5(1 / 2)$. The lateral metatarsalia are separated. The ventral 
surface of the web is glandular. The ventral surface of the foot is slightly granular. A white fringe goes from the elbow along the side of the lower arm and fourth finger to the disc. Another white tuberculous fringe goes from the heel along the side of the tarsus and fifth toe to the disc.

The anal opening is directed posteriorly at the upper level of the thighs. The dermal flap above the anal opening is short.

The tongue is heart-shaped and distinctly bifid posteriorly. The vomerine teeth are situated medially just behind the large choanae in two small oblique groups. The vocal slits are small, situated in the floor of the mouth near the angles of the jaws. The vocal sac is median, subgular and moderately distensible.

The skin on the dorsum, chin and throat is smooth. The skin on the belly, below the anal opening and on the ventral surface of the heel is very coarsely granular and white. The skin on the posteroventral surface of the thigh is moderately granular. Elsewhere on the limbs the skin is smooth.

The colour in preservative is yellowish. There is a brown transverse line from the edge of one eye to the other, and two oblique brown lines from behind the eyes form a V-shaped figure, ending behind the forelimbs. From this point the back is more or less brown spotted, the border of this spotted region is $\wedge$-shaped anteriorly. There are brown crossbands on the limbs. Brown pigment is present around the nostrils, around the anal opening and on the ventral surface of the tarsus, and sometimes along the canthus. The upper rim of the palpebral membrane is entirely pigmented, and the lower rim only anteriorly and posteriorly. The iris is silvery grey with some dark pigment, surrounded by a black ring.

In life, the back is orange-red with numerous dark red spots, the markings (brown in preservative) are blackish (pl. IV fig. 6). The fringes along the lower arm and tarsus are white. The belly is white. The iris is silvery, surrounded by a black ring.

Remarks. - The holotype of Rhacophorus difficilis agrees largely with the description above. Boettger, 1892, described the terminal discs on the toes being about half the size of the discs on the fingers. Examination of the holotype showed that the discs on the toes are shrunken. This specimen, collected in 1880 , probably already had shrunken discs when Boettger saw it. The hindlimbs are relatively slightly shorter in the holotype than in our specimens.

Boophis majori (Boulenger, 1896)

Text-figs. 15-16; pl. I fig. 5.

Rhacophorus majori Boulenger, 1896: 402; Guibé, 1978: 77 (equals miniatus; in part).

Boophis sp. 3; Bachmann \& Blommers-Schlösser, 1975: 17 (DNA).

Boophis aff. majari; Blommers-Schlösser, 1978: 35 (chromosomes).

Materia 1. - BMNH 1947.2.7.67, male lectotype of Rhacophorus majori by present designation. Type locality: Ambohimitombo forest (near Perinet). Coll. F. Major. BMNH 1947.2.7.66, paralectotype, same data as lectotype; other two original syntypes not examined.

ZMA 7095 (2 ô ô ), 6.1.73; 7096 (one tadpole), VI.72; 7097 (tadpoles and young reared from them), VI-X.72; 7102 (1 $\hat{\delta}), 15 . X I .72 ; 7103$ ( $7 \hat{\delta} \hat{\delta}$ and $1 \%$ ), 26.XII.72; 7104

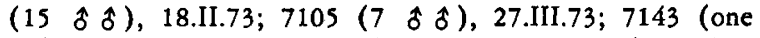
tadpole), 24.IX.72; all collected near Mandraka valley (highroad R.N. 2 at $\mathrm{km} \mathrm{69),} \mathrm{rivulet} \mathrm{Vokanatetezandava,} \mathrm{in}$ the nursery garden of the city of Tananarive, alt. $1200 \mathrm{~m}$.

$\mathrm{Nat}$ u r a l his tory. - The species was never heard or noticed during the day. The males were found in the evening, calling in the vegetation along the rivulet. The female was found with a male in axillary amplexus. The female was gravid. The tadpoles were found in the rivulet. The mating call resembles high chirping of birds.

Des cription of ZMA material (see table IV for measurements). - The ratio of hand length to snout-vent length is $0.29-0.33$ (mean 0.31). The ratio of tibia length to snout-vent length is $0.52-0.59$ (mean 0.55). The ratio of foot length to snout-vent length is $0.40-0.50$ (mean 0.44). The ratio of the horizontal diameter of the tympanum to that of the eye is $0.31-0.40$ (mean 0.35). Snout-vent length of males $22.0-26.5 \mathrm{~mm}$, of female $32.0 \mathrm{~mm}$.

The head is wider than the body, and somewhat wider than long. The head width is one-third of the body length. The snout is rounded in dorsal 
profile and bluntly rounded in lateral profile in the male, rounded in the female. The snout is slightly longer than the horizontal diameter of the eye, and somewhat shorter than the distance between the anterior corners of the eye. The nostrils are at equal distances from the tip of the snout and the anterior corners of the eye. The distance from the nostril to the anterior corner of the eye is shorter than the horizontal diameter of the eye. The canthus is distinct and rounded. The loreal region is slightly concave. The interorbital region is flat. The ratio of the internarial to the interorbital distance is $7 / 10$. The interorbital distance is one and a half times the width of an upper eyelid. The nostrils are slightly protruding, the opening is dorsolaterally. The commissure of the mouth is slightly curved upwards. The pupil is horizontally elliptical.

There is a weak dermal fold from the posterior edge of the eye over the tympanum, curving downwards to a point just above the insertion of the arm. The fold covers the dorsal margin of the tympanum. The tympanum is rather indistinct and round; its diameter is about one-third to two-fifths of the horizontal diameter of the eye. The distance from the eye to the tympanum is a half to threefourths of the horizontal diameter of the tympanum.

The largest diameter of the disc of the third finger equals the diameter of the tympanum; the disc of the fourth finger is subequal, of the second finger slightly smaller, and of the first much smaller. The relative lengths of the fingers from shortest to longest are 1-2-4-3. The subarticular tubercles are distinct and round. The distal tubercles on the fourth and third finger are often bifid. There is an inner oval flat metacarpal tubercle and no palmar tubercle. There is a small unpigmented glandular nuptial pad, dorsolaterally on the first finger. Supernumerary tubercles are present on the base of the fingers. There is a trace of web between the fingers. Between the third and fourth finger the web extends from the middle of the antepenultimate phalanx of the third to the base of the penultimate phalanx of the fourth. The web is glandular.

The arms and legs are slender. When the limbs are laid along the side, the knee and elbow overlap slightly. The adpressed heels overlap slightly. The tibiotarsal articulation extends to a point between the nostril and the tip of the snout in males and between the eye and the nostril in the female. The inner metatarsal tubercle is distinct, small elliptical and protruding. There is no outer metatarsal tubercle. A small web connects the middle of the inner metatarsal tubercle with the first toe to the base of the penultimate phalanx. The discs on the toes are almost as large as those on the fingers. The fifth toe is somewhat longer than the third. The subarticular tubercles are distinct and round. The formula of the webbing of the foot: $1(1 / 2), 2 \mathrm{i}(1 / 2), 2 \mathrm{e}(0), 3 \mathrm{i}(1), 3 \mathrm{e}(0), 4 \mathrm{i}\left(1 \frac{1}{2}\right.$ 2), $4 \mathrm{e}(11 / 2), 5\left(1 / 2^{-0}\right)$. The lateral metatarsalia are separated. The ventral surface of the web is glandular. The ventral surface of the foot is granular. A white tuberculous fringe goes from the elbow along the side of the lower arm and fourth finger to the disc and another from the heel along the side of the tarsus and fifth toe to the disc.

The anal opening is directed posteriorly at the upper level of the thighs. The dermal flap above the anal opening is short.

The tongue is heart-shaped and distinctly bifid. The vomerine teeth are situated medially just behind the large choanae, in two small oblique groups. The vocal slits are small, situated in the floor of the mouth near the angles of the jaw. The vocal sac is median, subgular and moderately distensible.

The skin on the back, chin and throat is finely granular. The skin on the ventral surface of the shank and upper arm is smooth. The skin on the posteroventral surface of the thigh, lower arm and tarsus is moderately granular. The skin below the anal opening, on the elbow and heel and on the belly is white and coarsely granular.

The colour in preservative is beige with dark beige and dark brown. The back is beige with some brown spots. There is a dark beige transverse line from the edge of one eye to the other. Behind the eyes is a more or less X-shaped figure with a broad transverse line behind it in the same dark beige colour. A dirty white vertebral line is in general present on the back. There are dark beige crossbands on the limbs. Dark brown pigment is usually present around the anal opening and on the ventral 
surface of the tarsus and feet. The venter is uniform creamish. The lower rim of the palpebral membrane is pigmented. The iris is silvery beige with brown pigment, surrounded by a narrow dark ring.

In life, the colour is about the same, except the ventral surface of the hindlimb and the web between the toes, being violet-red, the venter light blue-green and the bones light green. The iris is brown with orange, surrounded by a narrow brown ring.

R e m a rks. - The lectotype of Boophis majori is conform to the description above. It has retained the green skeleton and the body is light brown with dark brown markings. It is questionable whether the paralectotype belongs to the same species. It differs from the lectotype in colour, being reddish with dark brown markings. The chin and throat are not granular, but smooth. Tuberculous folds along lower arm and tarsus are not discernible. It is neither entirely similar to $B$. difficilis nor to $B$. miniatus.

E g g s . - In dissected female, $2 \mathrm{~mm}$ in diameter, creamish; number about 120 .

T a d p o l e s. - Twenty-seven tadpoles in stage 25 have body lengths of $4.1-8.0 \mathrm{~mm}$ and total lengths of $13.5-24.5 \mathrm{~mm}$. Ten tadpoles in stages 26-31 have body lengths of $8.0-10.0 \mathrm{~mm}$ and total lengths of $23.2-30.0 \mathrm{~mm}$. Two tadpoles in stages 39 and 40 have body lengths of $10.5-11.0 \mathrm{~mm}$ and total lengths of $32.0-32.5 \mathrm{~mm}$. The average ratio of tail length to body length in the thirty-nine tadpoles listed above is 2 (range 1.8-2.2). Five metamorphosing young have body lengths of 10.5 $12.0 \mathrm{~mm}$ (mean $11.5 \mathrm{~mm}$ ).

The mouth and lateral view of a tadpole in stage 31 (ZMA 7096) are shown in figs. 15-16. The body is ovoid. The nostrils are dorsal, the opening is dorsolaterally, situated at about two-thirds from the tip of the snout and the anterior corner of the eye. The eyes are situated laterally. The spiracular opening is sinistral, situated at about threefourths from the tip of the snout and the end of the body. The cloacal tube is long and dextral to the caudal fin. The caudal musculature is strong. The caudal fin is shallow anteriorly and is deepest at about three-fifths of its length. At midlength of the tail, the height of the caudal musculature represents two-fifths to the half of the total tail height. The mouth is broad and directed ventrally. The whole contour of the lip has papillae: about 3-4 rows anteriorly, 5-6 rows laterally and posteriorly, except in the median part of the lower lip, which has about 4 rows of papillae of larger size. The oral disc, which is contracted when preserved in alcohol, shows lateral notches and a strong median notch in the lower lip. The tooth formula is $4 / 3+3 / / 3$. The upper row of the upper lip and the lower row of the under lip consists of very small teeth. The horny beak is well developed, the upper beak is more or less moon-shaped and the lower beak is $U$-shaped with robust serrations.

The colour of the tadpole in life is beige with dark brown markings; the belly is golden-coloured.

The tadpoles were collected in a fast-running current from June till October. The metamorphosis occurred only in October (beginning of the hot season). The rearing was only successful when starting with the late metamorphosis stages.

Young. - The metamorphosed froglet is coloured as the adult, except that the hands and feet are yellow, and that the red-violet colour is not yet present on the ventral surface of the hindlimbs. The fringes along the lower arm and tarsus are already present. The legs are relatively shorter than in the adults.

\section{Boophis miniatus (Mocquard, 1902) bona species Pl. I fig. 6.}

Rhacophorus miniatus Mocquard, 1902: 19, pl. II fig. 1; Guibé, 1978: 77 (equals majori; in part).

M a t e ri a l . - MNHP 1901-386, holotype of Rhacophorus miniatus. Type locality: forest between Isaka and valley of Ambobo, near Fort-Dauphin, S. Madagascar.

ZMA 7162 (2 ô ồ), 4.IV.72; 7163 (1 ô), 14.XI.72;

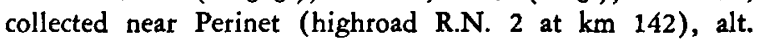
$900 \mathrm{~m}$.

$\mathrm{Nat}$ u r a h i s tory. - The species was never heard nor noticed during the day. The males were found in the evening, calling in vegetation along a brook in the forest. They were observed moving down from the trees. 
Description of ZMA material (see table IV for measurements). - The ratio of hand length to snout-vent length is $0.29-0.32$ (mean 0.30). The ratio of tibia length to snout-vent length is 0.53 . The ratio of foot length to snout-vent length is $0.43-0.44$. The ratio of the horizontal diameter of the tympanum to that of the eye is 0.48-0.54 (mean 0.50). Snout-vent length of males is $31-34$ $\mathrm{mm}$.

The head is wider than the body, and the head width is equal to the head length. The head length is one-third of the body length. The snout is rounded to slightly acuminate in dorsal profile, and sloping to truncate in lateral profile. The snout is as long as the horizontal diameter of the eye, and somewhat shorter than the distance between the anterior corners of the eye. The nostrils are somewhat nearer to the tip of the snout than to the anterior corner of the eye. The distance from the nostril to the anterior corner of the eye is shorter than the horizontal diameter of the eye. The canthus is distinct and slightly angular. The loreal region is slightly concave. The interorbital region is flat. The internarial distance is equal to the interorbital distance. The interorbital distance is somewhat wider than the width of an upper eyelid. The nostrils are slightly protruding, and opening laterally. The commissure of the mouth is slightly curved upwards. The pupil is horizontally elliptical.

There is a dermal fold from the posterior edge of the eye, over the tympanum, curving downwards to a point just behind the insertion of the arm. The fold covers the dorsal margin of the tympanum. The tympanum is distinct and round; its diameter is about half the horizontal diameter of the eye. The distance from the eye to the tympanum is about one-fifth of the diameter of the tympanum.

The largest diameter of the disc of the third finger is about $4 / 5$ of the diameter of the tympanum; the discs of the fourth and second finger are subequal, and of the first much smaller. The relative lengths of the fingers from shortest to longest are 1-2-4-3. The subarticular tubercles are distinct and round. The distal tubercle of the fourth finger is sometimes bifid. There is an inner oval flat metacarpal tubercle and no palmar tubercle. There is a small unpigmented, glandular nuptial pad, in a dorsolateral position on the first finger. Supernumerary tubercles are present on the base of the fingers. There is a trace of web between the fingers. Between the fourth and third finger the web extends from the middle of the antepenultimate phalanx of the third finger to the base of the penultimate phalanx of the fourth one. The web is glandular.

The arms and legs are slender. When the limbs are laid along the side the knee and elbow overlap slightly. The adpressed heels overlap slightly. The tibiotarsal articulation extends to a point between the eye and the nostril. The inner metatarsal tubercle is distinct, small, elliptical and protruding. There is no outer metatarsal tubercle. A small web connects the middle of the inner metatarsal tubercle with the first toe to the base of the penultimate phalanx. The discs on the toes are somewhat smaller than those on the fingers. The fifth toe is slightly longer than the third. The subarticular tubercles are distinct and round. The formula of the webbing of the foot: $1(1 / 2), 2 \mathrm{i}(1 / 2), 2 \mathrm{e}(0)$, $3 \mathrm{i}(1), 3 \mathrm{e}(1 / 2), 4 \mathrm{i}(1), 4 \mathrm{e}(1), 5(0)$. The ventral surface of the web is glandular. The lateral metatarsalia are separated. The ventral surface of the foot is slightly granular. A weak white fold goes from the elbow along the side of the lower arm and fourth finger to the disc, and another from the heel along the side of the tarsus and fifth toe to the disc.

The anal opening is directed posteriorly at the upper level of the thighs. The dermal flap above the anal opening is short.

The tongue is heart-shaped and distinctly bifid posteriorly. The vomerine teeth are situated medially just behind the large choanae, in two small oblique groups. The vocal slits are small, situated in the floor of the mouth, near the angles of the jaws. The vocal sac is median subgular, moderately distensible.

The skin on the back, chin and throat is smooth. The skin on the belly and below the anal opening is coarsely granular and white. The skin on the posteroventral surfaces of the thigh, heel and elbow is moderately granular and the skin on the ventral surface of the limbs is smooth.

The colour in preservative is yellowish. There 
are dark brown spots on the back and dark brown crossbands on the limbs. Dark brown pigment is also present on the ventral surface of the tarsus and around the anal opening. It was conspicuous that beige specimens preserved in formalin became red on the back with blackish spots (in life the species was also able to change its colour. Sometimes the back was red at night and beige during the day). The upper rim of the palpebral membrane is pigmented entirely and the lower rim only anteriorly and posteriorly. The iris is silvery grey with some dark pigment, surrounded by a black ring.

In life, the back is usually beige to brownish with darker brown spots and markings, sometimes red with blackish spots at night. The ventral surfaces of the hindlimbs, feet and hands, and the posterior and anterior surfaces of the thighs are violet-red. The iris is creamish and brownish in the middle, surrounded by a blackish ring.

Remarks. - The holotype of Rhacophorus miniatus agrees with the description above. Only the relative length of its hindlimbs is slightly larger.

\section{Boophis goudotigroup}

Diagnos is. - The members of this group are medium- to large-sized species, with a preference for more quiet parts of streams. The young differ greatly from the adults. The dorsum is usually $\tan$ or grey and often green in the young. There are distinct transverse bars on the limbs. The posterior surface of the thighs is usually dark with light spots. The temporal region and the streak along the canthus is usually dark brown. One or more triangular white subocular blotches are present in the young and still in some of the adults. There are white fringes along the lateral edge of the lower arm and tarsus and a small dermal flap on the heel and elbow in the halfgrowns and in some of the adults. Vomerine teeth are present. The horizontal diameter of the tympanum is two-fifths to three-fourths of that of the eye. The skin on the dorsum is smooth, granular or covered with irregular reticulate ridges. The vocal sac is single median subgular. The tibiotarsal articulation extends to the nostril or beyond. The fingers are one-third to half webbed, the web reaching the base of the penultimate phalanx of the fourth finger in all species. The toes are twothirds to three-fourths webbed. One to two phalanges of the fourth toe are free of web.

Contents: B. goudoti Tschudi, 1838, B. madagascariensis (Peters, 1874), B. untersteini (Ahl, 1928), B. byloides (Ahl, 1929), B. callichromus (Ahl, 1928) and $B$. reticulatus sp. nov.

\section{Dif ferential diagnosis}

Large species $(80-100 \mathrm{~mm})$ in the adult stage.

1. White fringes along the lateral edges of lower arm and tarsus and distinct triangular dermal flaps on elbow and heel present . . . . B. madagascariensis (Peters)

2. Fringes and dermal flaps absent . . B. goudoti Tschudi

However, the half-growns of $B$. goudoti show low fringes along the lateral edge of lower arm and tarsus and small dermal flaps on the elbow and heel. The half-growns of $B$. madagascariensis show less developed fringes and flaps than the adults. Therefore, the four remaining species are difficult to distinguish from the half-growns of goudoti and madagascariensis. In the following key to the medium-sized species those half-growns are included.

1. Nostril equidistant from tip of snout and eye.

a. Dorsum covered with tubercles and ridges, forming an irregular network, interorbital distance equals the width of the upper eyelid, upper arm robust, small triangular dermal flaps on heel and elbow. .

$B$. reticulatus sp. nov.

b. Dorsum smooth with a few dispersed tubercles, interorbital distance $11 / 2 \times$ the width of the upper eyelid, tympanic fold curved, upper arm slender, tubercles on heel and elbow . . . . . B. untersteini (Ahl)

c. Dorsum smooth, interorbital distance $11 / 2 \times$ the width of the upper eyelid, tympanic fold straight, upper arm robust, small triangular dermal flaps on elbow and heel . . B. madagascariensis (Peters), half-grown

2. Nostril nearer to eye than to tip of snout.

a. Dorsum granular . . . . B. byloides (Ahl)

b. Dorsum smooth, blue-grey with round red-brown spots (in alcohol). . . . . B. callicbromus (Ahl)

c. Dorsum smooth, grey or brown with irregular dark brown markings (in alcohol)

B. goudoti Tschudi, half-grown

R e m a r ks. - In the field and in the aquarium I noticed slight differences among robust tadpoles with a moderately developed tail musculature and a medium-sized mouth, occurring in quieter parts 
of streams and occasionally in adjacent pools. These differences, mainly in size and relative tail length, permitted to distinguish three forms, which were often collected simultaneously. Young frogs were reared from several batches of each form from different localities, mixed batches being segregated soon after collection. The young emerging from each type of tadpole were also clearly distinct, and constantly so, in the various batches. Thus it appears beyond doubt that these tadpoles represent three different species. However, the young reared were difficult to relate with the adults. They showed a typical juvenile colour pattern, gradually disappearing as they grew older. Since the juveniles of these species are of a rather large size, I have compared the whole series from young to adult with the type material of many species. In that manner I have noted that some described species are, in fact, juveniles of other nominal species. I found the tadpoles belonging to $B$. goudoti, $B$. madagascariensis and $B$. understeini.

\section{Boophis goudoti Tschudi, 1838}

Text-figs. 17-19; pl. I fig. 7, pl. II fig. 1.

Boophis goudoti Tschudi, 1838: 77; Guibé, 1947: 439 (equals flavoguttatus); Bachmann \& Blommers-Schlösser, 1975: 17 (DNA); Blommers-Schlösser, 1978: 36 (chromosomes).

Rhacophorus goudoti; Boulenger, 1882: 76; Arnoult \& Razarihelisoa, 1966: 114 (tadpole ecology); Razarihelisoa, 1969: 953 (tadpole); Guibé, 1978: 71-72, figs. 166-171 (equals obscurus and flavoguttatus).

Rhacophorus obscurus Boettger, 1913: 275, pl. XXIII fig. 3; Guibé, 1978: 72 (in synonymy of goudoti).

Rhacophorus fasciolatus Ahl, 1929: 478 (new synonymy); Guibé, 1978: 76 (in synonymy of callichromus).

Rhacophorus flavoguttatus Ahl, 1929: 479; Guibé, 1947: 439 (in synonymy of goudoti); Guibé, 1978: $71-72$ (in synonymy of goudoti).

Rhacophorus kanbergi Ahl, 1929: 482 (new synonymy); Guibé, 1978: 76 (in synonymy of callicbromus).

Materia 1. - MNHP 4578, female holotype of Boophis goudoti. Type locality: Madagascar.

SMF 6763, male lectotype of Rbacophorus obscurus, designed by Mertens, 1967. Type locality: Fianarantsoa, S.E. Madagascar. Coll. Voetzkow.

ZMB 30527 A, B, C, three syntypes of Rhacophorus fasciolatus. Type locality: N.W. Madagascar. Coll. Hildebrandt.

ZMB 30517, juvenile holotype of Rhacophorus kanbergi. Type locality: N.W. Madagascar. Coll. Hildebrandt.
ZMB 30508 A, B, two syntypes of Rbacophorus callicbromus. Type locality: N.W. Madagascar. Coll. Hildebrandt.

ZMA 6802 (1), 4.IV.72; 6804 (1), 6.II.72; 6805 (2), 19.I.73; 6792 (1 young), 6.XII.70; 7209 (tadpoles and young reared from them), 22.X.72; all collected near Perinet

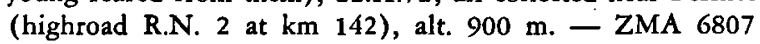
(1), 13.X.72; 6809 (2), 15.XI.72; 6852 (1), 6.I.73; 7211 (one young reared from tadpole), VIII.72; 7212 (one juvenile), 15.XI.72; collected in the Mandraka valley (high-

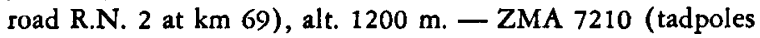
and young reared from them), 29.VIII.72 collected along the road from Moramanga to Anosibe at km 27, alt. $900 \mathrm{~m}$. - ZMA 6801 (5), 6.IX.71 collected in Tananarive, alt. 1300 m. - ZMA 7004 (1), 19.IX.71; 6799 (1), 21.III.73; collected at Manjakotompo forest station, Ankaratra mts. (near Ambatolampy), alt. 1800-2200 m. - ZMA 6808 (4), 14.VIII.71; 6806 (7), 14.VIII.71; collected in Tsinioarivo (46 km S.E. of Ambatolampy) alt. $1600 \mathrm{~m}$.

Natural history. - The species was found during day and night in or near stagnant or slowly running water in both forests and ricefields. Being touched, they inflated themselves. Pairs in axillary amplexus were found in August. Both males and females are calling during day and night. The tadpoles were found in slowly running waters and adjacent pools. Arnoult \& Razarihelisoa (1966) have observed that $B$. goudoti feeds on large prey, like grasshoppers, moth and beetle larvae. They found $B$. goudoti also in trees, although this species is a poor climber. Reproduction started at the end of November. They observed lumbal amplexus, which I have never noticed. The eggs were deposited in lumps of 30 , attached to rocks and roots in water.

Synonymy. - Rhacophorus kanbergi and $R h$. fasciolatus were synonymized with $R h$. callichromus by Guibé, 1978, but are identified with $B$. goudoti in the present paper. Studying the entire ZMA series of specimens of Boophis goudoti, I have noticed transitional forms from the juvenile to the adult. So it was not difficult to relate the young to the present species. Transitional characters exist till the specimens have reached a size of about $50 \mathrm{~mm}$. The syntypes $A$ and $C$ of Rhacophorus fasciolatus are conform to the adults of $B$. goudoti and syntype B still shows some colour characters of the juveniles. The holotype of Rhacophorus kanbergi agrees with the young of $B$. goudoti, of which a description follows below. Comparison with the type material of Rhaco- 
TABLE V

Dimensions in mm of Boophis goudoti, B. callichromus, B. byloides, B. untersteini and B. reticulatus. A = snout to vent; $B=$ length of lower arm; $C=$ hand length; $D=$ length of hind limb; $E=$ tibia length; $F=$ length of foot and tarsus; $G=$ foot length; $H=$ horizontal diameter of tympanum; $I$ = horizontal diameter of eye.

\begin{tabular}{|c|c|c|c|c|c|c|c|c|c|}
\hline & $\mathbf{A}$ & B & C & $\mathrm{D}$ & $\mathrm{E}$ & $\mathbf{F}$ & $\mathbf{G}$ & $\mathrm{H}$ & I \\
\hline \multicolumn{10}{|l|}{ B. goudoti } \\
\hline \% holotype MNHP & 80 & 39 & 25 & 132 & 42 & 57 & 38 & 5 & 8 \\
\hline o lectotype obscurus SMF & 50 & 25 & 15 & 86 & 27 & 38 & 23.5 & 3.5 & 6.5 \\
\hline syntypes fasciolatus ZMB A & 56 & 31 & 20 & 106 & 36 & 46 & 30 & 3.8 & 8 \\
\hline B & 52 & 26 & 17 & 86 & 29 & 35 & 24 & 3 & 6.5 \\
\hline C & 49 & 28 & 16 & 91 & 32 & 40 & 26 & 4 & 7 \\
\hline 15 adults ZMA & $56-87$ & $30-43$ & $18-29$ & $105-175$ & $37-55$ & $46-68$ & $31-50$ & $4-6$ & $7 \cdot 11$ \\
\hline holotype kanbergi ZMB & 32 & 15.5 & 10 & 52 & 17 & 21 & 15 & 1.5 & 3.5 \\
\hline 7 juveniles ZMA & $30-32$ & $15-16$ & $9.5-10.5$ & $50-54$ & $16-18$ & $21-22$ & $13-15$ & $1.5-1.8$ & $3.5-4.0$ \\
\hline 2 halfgrown ZMA & $40-41$ & $20-21$ & $12.5-14.0$ & $71-75$ & 23 & 31 & $18.5-21.0$ & $2.0-2.5$ & 5 \\
\hline \multicolumn{10}{|l|}{ B. callicbromus } \\
\hline $\begin{array}{l}\text { syntype ZMB A } \\
\text { B. byloides }\end{array}$ & 38 & 20 & 14 & 69 & 22 & 31 & 19.5 & 2 & 5 \\
\hline holotype ZMB & 42 & 20 & 13 & 68 & 23 & 29 & 19 & 2.5 & 5 \\
\hline \multicolumn{10}{|l|}{ B. untersteini } \\
\hline is holotype ZMB & 26 & 13.5 & 8.5 & 45 & 15 & 19 & 12.5 & 2 & 4 \\
\hline 3 halfgrown $\delta \hat{z} \mathrm{ZMA}$ & $27.5-36.0$ & $14.0-19.5$ & $9-12$ & $45-62$ & $15-21$ & $19-25$ & $12.5-17.0$ & 2.3 & $4.0-5.5$ \\
\hline \multicolumn{10}{|l|}{ B. reticulatus } \\
\hline$\hat{\delta}$ holotype ZMA & 35 & 18.5 & 11 & 61 & 20 & 26 & 16 & 2 & 4 \\
\hline 8 of $\delta$ paratypes ZMA & $30-36$ & $15-19$ & $9-12$ & $54-61$ & $18-20$ & $23-26$ & $14-16$ & $1.8-2.2$ & $3.8-4.2$ \\
\hline
\end{tabular}

phorus callichromus shows no morphological differences from $R$. kanbergi, but the colour (bluegrey with red-brown spots) is quite different, as was already described by Ahl (1928). In fact the colour resembles that of preserved Boophis microtympanum (Boettger, 1881), which is green with red spots in life, but differs in morphology. Morphological features to distinguish between species are scanty in the genus Boophis, but since the colour is a very useful character, I regard Boophis callicbromus (Ahl, 1928) a distinct species.

Description of the juvenile of Boophis goudoti (see table $\mathrm{V}$ for measurements). Based on ZMB 30517, the holotype of $R$. kanbergi, seven metamorphosing young, ZMA 7209, 7210 and 7211 , and two half-grown specimens ZMA 7212 and 6792. The ratio of hand length to snout-vent length is $0.31-0.34$ (mean 0.33 ). The ratio of tibia length to snout-vent length is 0.53 0.58 (mean 0.55). The ratio of foot length to snout-vent length is $0.43-0.51$ (mean 0.47). The ratio of the horizontal diameter of the tympanum to that of the eye is $0.40-0.50$ (mean 0.45 ). Snoutvent length is $30-41 \mathrm{~mm}$.
The body in the post-axillary region is equal to the head width. The head is somewhat wider than long. The head length is one-third of the body length. The snout is round in dorsal and lateral profile. The snout is longer than the horizontal diameter of the eye, and equals the distance between the anterior corners of the eye. The nostrils are nearer to the anterior corner of the eye than to the tip of the snout. The distance from the nostril to the anterior corner of the eye is slightly shorter than the horizontal diameter of the eye. The canthus is distinct, concave. The loreal region is oblique and slightly concave. The interorbital region is slightly convex. The ratio between the internarial and interorbital distance is about 1. The interorbital distance is one and a half times the width of an upper eyelid. The nostrils are protruding with lateral openings. The commissure of the mouth is straight. The pupil is horizontally elliptical.

There is a distinct dermal fold from the posterior edge of the eye, over the tympanum, curving downwards to a point just above the insertion of the arm. The fold covers the dorsal. margin of the distinct and round tympanum, its 
diameter is two-fifths to half that of the horizontal diameter of the eye (the tympanum is not yet visible in all young). The distance from the eye to the tympanum is about half the diameter of the tympanum.

The largest diameter of the disc of the third finger is equal to the diameter of the tympanum; the disc of the fourth finger is about equal in size, that of the second finger slightly smaller and of the first finger much smaller. The relative lengths of the fingers from shortest to longest are 1-2-4-3. The subarticular tubercles are small, distinct and round. There is an inner flat metacarpal tubercle and no palmar tubercle. Many distinct supernumerary tubercles are present on the base of the fingers. The formula of webbing of the hand: between 1 and $2 \mathrm{i}$ a trace of web, $2 \mathrm{e}(1), 3 \mathrm{i}(2), 3 \mathrm{e}(11 / 2)$, 4 (1). The web is glandular.

The upper arm is robust. When the limbs are laid along the side, the knee and elbow overlap. The adpressed heels overlap slightly. The tibiotarsal articulation extends to a point between the nostril and the tip of the snout. The inner metatarsal tubercle is small, elliptical and protruding. There is no outer metatarsal tubercle. A small web connects the tip of the inner metatarsal tubercle with the first toe to the base of the penultimate phalanx. The discs on the toes are nearly as large as those on the fingers. The fifth toe is slightly longer than the third. The subarticular tubercles are small, round and protruding. The formula of the webbing of the foot: $1(0), 2 \mathrm{i}(1), 2 \mathrm{e}(0)$, $3 \mathrm{i}(1), 3 \mathrm{e}(1), 4 \mathrm{i}(11 / 2), 4 \mathrm{e}(11 / 2), 5(1 / 2)$. The lateral metatarsalia are separated. The ventral surface of the web is glandular. A white fringe goes from the elbow along the side of the lower arm and the fourth finger to the disc and another goes from the heel along the side of the tarsus and the fifth toe to the disc. A small white tubercle is present on the heel and the elbow.

The anal opening is directed posteriorly at the upper level of the thighs. The dermal flap above the anal opening continues in a fold on each side of the anal opening, which results into a $\wedge$-shaped figure.

The tongue is heart-shaped and distinctly bifid. The vomerine teeth are situated medially behind the choanae in two small, oblique groups.
The skin on the back, chin, throat and on the ventral surfaces of the limbs (except the thighs) is smooth. The skin on the belly and posteroventral surface of the thighs is coarsely granular. The skin below the anal opening is tubercular.

The dorsal colour of preserved specimens is brown or grey with irregular dark brown markings. The venter is uniformly yellowish (in live specimens the ventral surface of the hindlimbs is orange). There are distinct, dark brown transverse bars on the limbs. Dark brown streaks are present ventrally along the white lateral fringes of lower arm and tarsus. The posterior surface of the thighs is brown with light spots. There are also light spots on the flanks. The streaks along the canthus and the tympanic region are dark brown. A triangular white spot is present both anteriorly and posteriorly of the tympanum. A white band often runs from underneath the anterior part of the eye obliquely to the front, separated by a dark brown band from the triangular white spot behind. The upper and lower rim of the palpebral membrane are pigmented. The iris is silvery grey with a dark brown reticulation.

The colour in life is similar, but more intense.

A d u lts of $B$. goudoti (see table V for measurements). - Ratios of 20 specimens (holotype goudoti, lectotype obscurus, syntypes of fasciolatus, and 15 specimens ZMA). The ratio of hand length to snout-vent length is $0.30-0.38$ (mean 0.33 ). The ratio of tibia length to snout-vent length is 0.53-0.66 (mean 0.60). The ratio of foot length to snout-vent length is $0.46-0.57$ (mean 0.52). The ratio of the horizontal diameter of the tympanum to that of the eye is $0.46-0.66$ (mean 0.60). Snout-vent length is $49-87 \mathrm{~mm}$.

The adults differ from the juveniles in the following features: the white fringes along the side of the lower arm and fourth finger and along the tarsus and fifth toe and the white tubercles on the elbow and heel disappear during growth. In some adults there are still tubercles on the heel and elbow. The large white spots underneath the eye and near the tympanum disappear also. The horizontal diameter of the tympanum is threefifths of the horizontal diameter of the eye in the adults; in consequence the largest diameter of the 
disc of the third finger is two-thirds of the diameter of the tympanum. The hindlimb is longer than in the young, the tibiotarsal articulation extends to the tip of the snout or beyond.

Sex u l dimorph is m. - The males have well-developed white nuptial pads laterodorsally on the first and dorsally on the second finger in the breeding season. The back, chin and throat are covered with small sharp tubercles in that period. The males are much smaller than the females.

Colour in life. - The ground colour is highly variable, from nearly entirely blackish to yellowish with blackish spots. The venter is uniformly yellow or orange with or without blackish spots.

Voice. - The species was heard in August and September during the day and evening. The sonagram (fig. 19) made of a couple in axillary amplexus (ZMA 6808) in August 1971 at 9 p.m. shows the call of the male and the female. The duration of one male call is about $0.3 \mathrm{sec}$. It is a pulsed low-pitched note with about 10 pulses in one note. These notes are repeated about one minute and their frequency is about one note per sec. The indistinct dominant frequency is from $500-1000 \mathrm{~Hz}$. The call of the female is a low buzzing sound. It is repeated with intervals of

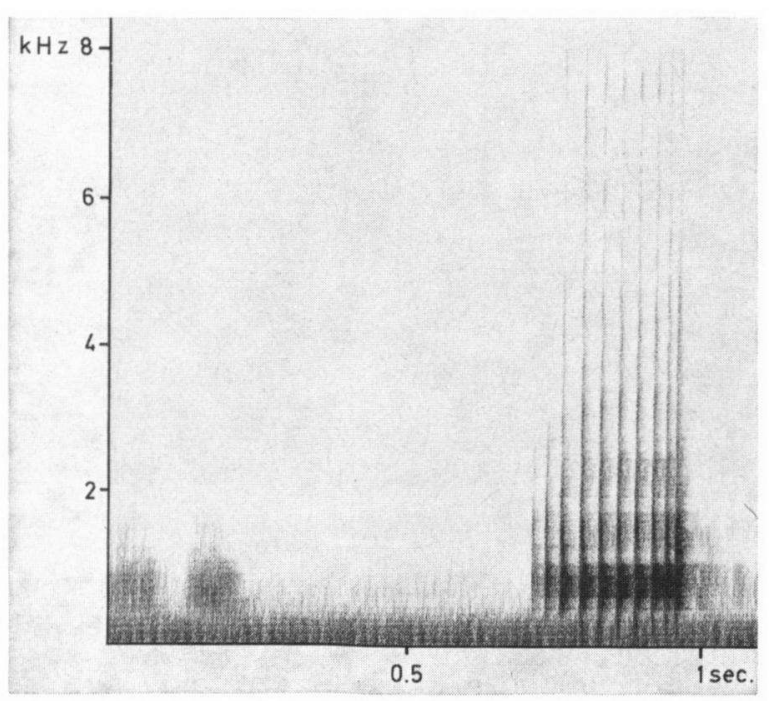

Fig. 19. Sonagram, filter wide, Boophis goudoti. about $7 \mathrm{sec}$. The duration of one call is about $0.5 \mathrm{sec}$. The frequency goes up to about $1500 \mathrm{~Hz}$.

Eggs. - In dissected females about 1000, 2 $\mathrm{mm}$ in diameter, dark brown with cream.

T a d pol es. - Four tadpoles in stage 25 have body lengths of $12-23 \mathrm{~mm}$ and total lengths of $31-61 \mathrm{~mm}$. Two tadpoles in stage 26 have body lengths of $26-27 \mathrm{~mm}$ and a total length of $68 \mathrm{~mm}$. Two tadpoles in stages 31 and 37 have a body length of $27 \mathrm{~mm}$ and a total length of $73 \mathrm{~mm}$. One tadpole in stage 41 has a body length of 27 $\mathrm{mm}$ and a total length of $73 \mathrm{~mm}$. The average ratio of tail length to body length in the eight tadpoles listed above is 1.65 (range 1.5-1.7). Seven metamorphosing young measure $30-32 \mathrm{~mm}$ (mean 30 $\mathrm{mm}$ ) from snout to vent.

The mouth and lateral view of a tadpole in stage 37 (ZMA 7209) are shown in figs. 17-18. The body is ovoid. The nostrils are dorsal, the openings are situated dorsolaterally at equal distances from the tip of the snout and the anterior corner of the eye. The eyes are situated dorsolaterally. The spiracular opening is sinistral, situated at about $1 / 2^{-2} / 3$ from the tip of the snout and the end of the body. The cloacal tube is long and dextral to the caudal fin. The caudal musculature is moderately developed. The caudal dorsal fin is shallow anteriorly. At midlength of the tail, the heigth of the caudal musculature accounts for $1 / 4$ to $3 / 10$ of the total tail height. The mouth is small and directed ventrally. The margin of the oral disc is indented laterally. The papillary border has a wide median gap anteriorly and a narrow median gap posteriorly. There are two rows of papillae laterally, and one posteriorly. The horny beak is heavy. The tooth formula is $1 / 3+3 / / 1+$ $1 / 2$ or $1 / 4+4 / / 1+1 / 2$.

Metamorphosis was observed in October and the beginning of November.

The colour of the tadpole is brownish. The tadpoles were found in gently running and in stagnant water.

Arnoult \& Razarihelisoa (1966) described the tadpole of $B$. goudoti as well. The whole development took three months in captivity. Their description agrees largely with the more detailed description given above. 
Boophis callichromus (Ahl, 1928)

Rhacophorus callichromus Ahl, 1928: 314; Guibé, 1978: 76, figs. 188-191 (equals untersteini, fasciolatus, kanbergi in part).

Materi a 1. - ZMB 30508 A, B, two syntypes of Rhacophorus callichromus. Type locality: N.W. Madagascar. Coll. Hildebrandt.

R e m a rks . - I was unable to find any morphological difference between the half-grown of $B$. goudoti and $B$. callichromus $(40 \mathrm{~mm})$. However, the colouration of the back is quite different: bluish grey with reddish brown spots in $B$. callicbromus (measurements table V).

\section{Boophis hyloides (Ahl, 1929)}

Rhacophorus byloides Ahl, 1929: 481; Guibé, 1978: 75, fig. 183.

M a teria 1. - ZMB 30495, holotype of Rhacophorus byloides. Type locality: central Madagascar. Coll. Hildebrandt.

R e m a rk. - The only difference between $B$. byloides $(40 \mathrm{~mm})$ and the half-grown of $B$. goudoti is the granular skin of the dorsum in $B$. byloides (measurements table V).

Boophis madagascariensis (Peters, 1874)

Text-figs. 20-23, 42; pl. II figs. 2-3.

Rhacophorus madagascariensis Peters, 1874: 618, pl. I fig. 3; Guibé, 1978: 73, figs. 178-180 (equals brachychir and berthae).

Rhacophorus brachychir Boettger, 1882: 480; Guibé, 1947: 439 (in synonymy of madagascariensis); Guibé, 1978: 73 (in synonymy of madagascariensis).

Rhacophorus berthae Ahl, 1929: 480; Ahl, 1931: 157, fig. 104; Guibé, 1978: 73 (in synonymy of madagascariensis).

Boophis madagascariensis; Guibé, 1947: 439 (equals brachychir) Bachmann \& Blommers-Schlösser, 1975: 17 (DNA); Blommers-Schlösser, 1978: 35 (chromosomes).

Materia1. - ZMA 6820 (3), 15.XI.72; 6834 (3), 6.I.73; 6845 (1), 2.IV.72; 6847 (2), 18.II.73; 6849 (1), 26.VIII.72; 7065 (tadpoles), 14.III.72; 7068 (one tadpole), VIII.72; 7070 (tadpoles and young reared from them), 22. X.71; all collected in the Mandraka valley, in the nursery garden of the city of Tananarive (highroad R.N. 2 at $\mathrm{km} \mathrm{69)}$, alt. $1200 \mathrm{~m}$. - ZMA 6835 (1), 17.II.72; 6837 (7), 6.II.72; $6846(1), 13 . I I .72 ; 7062$ (eggs, tadpoles and young reared from them), II.72; 7063 (eggs and embryos), 6.II.72; 7067 (tadpoles and young reared from them), 20.X.71; 7071 (tadpoles), 6.XII.70; all collected near Perinet (highroad

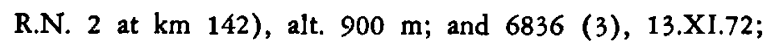
7002 (tadpoles), 24.1X.72; 7003 (young reared from 7002), at the same locality, but alt. $1100 \mathrm{~m}$. - ZMA 6848 (1), 20.IX.71 collected near Anjozorobe, alt. $1300 \mathrm{~m}$. - ZMA 7064 (tadpoles and young reared from them), 13.X.71 collected near Foulpointe, sea-level. - ZMA 7066 (tadpoles and young reared from them), 29.III.72 collected near Tampoketsa d'Ankazobe, alt. $1600 \mathrm{~m}$. - ZMA 7069 (tadpoles and young reared from them), 1.VII.71 collected near Ranomafana, alt. $800 \mathrm{~m}$.

Natural history. - The males were noticed by their groaning call, in the evening. They call in low vegetation, less than $1 \mathrm{~m}$ above shallow, small muddy streams. During the day the species was occasionally found in the leaf-axils of large plants. The eggs and tadpoles were found in the same streams; occasionally the tadpoles were found also in adjacent shallow pools. It is a real forest species, difficult to keep alive in the vivarium where it incessantly attempted to move upwards. In the breeding season, the males tried to embrace any frog, including those of other species who happened to be in the same bag. The amplexus was always lumbal.

Colour in lif e. - The ground colour of the back in the adults varies from beige to reddish brown. The posterior part of the thigh is black with light blue spots. On the limbs dark brown crossbands are present, and a transverse dark brown line behind the eyes is mostly present. The venter is creamish.

Voice. - The males were heard from September till April and in July, in the evening, occasionally during the day. The sonagram (fig. 20) made of a male (collected in Ranomafana 4.VII.71, sent to the Paris museum) at 9 p.m. on the same day, shows that the duration of one note is about $1 \mathrm{sec}$. The note consists of a series of rather melodious clicks. The indistinct dominant frequency is about $1000 \mathrm{~Hz}$.

E g g s . - Numerous black single eggs of about $3 \mathrm{~mm}$ in diameter were collected in shallow (depth $20-30 \mathrm{~cm}$ ) slowly running water, in the shade, at the same place where the males were calling the evening before. The eggs hatched after one week. The hatchling (fig. 21) measures $9 \mathrm{~mm}$; 


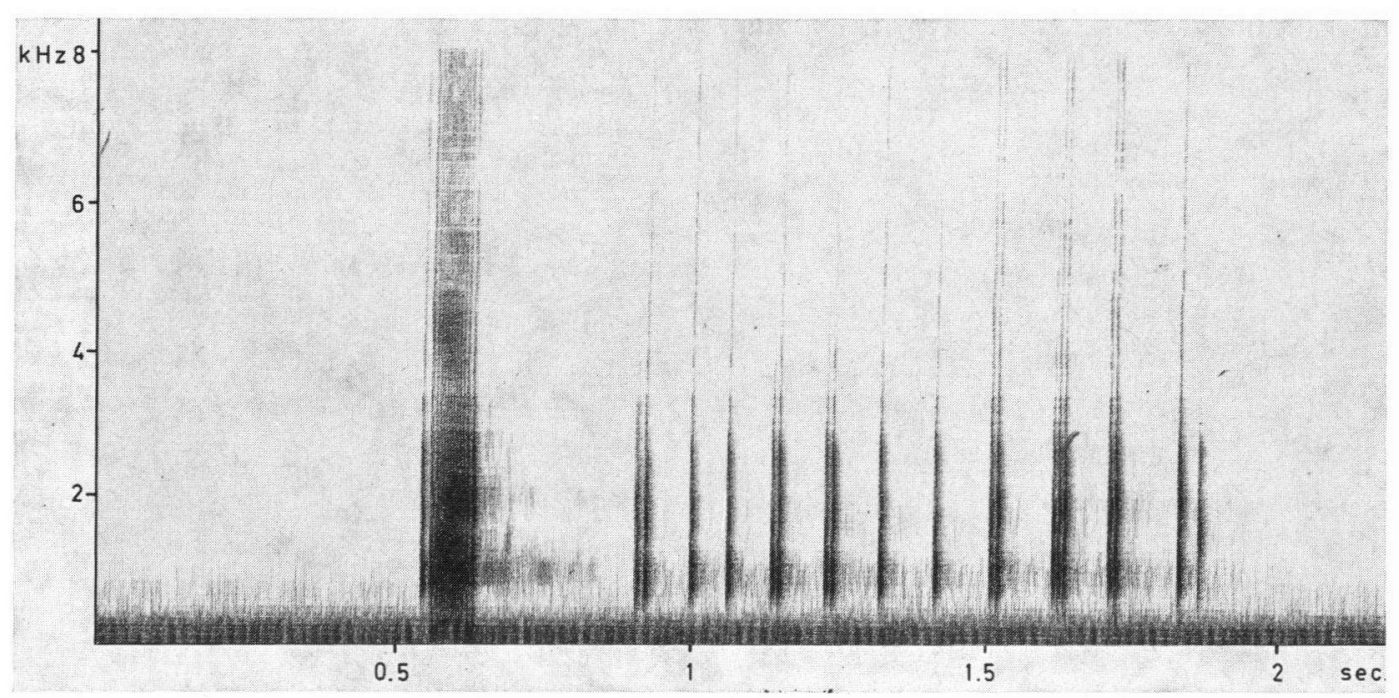

Fig. 20. Sonagram, filter wide, Boopbis madagascariensis.

it has no external gills. The nostrils, the rudiment of two suckers, the beginning of mouth, eyes and anus are present. After fourteen days, the tadpole reached a length of $16 \mathrm{~mm}$. The tail is twice the body length. The tooth formula is then $1 / 1+1 / /$ $1 / 2+2$.

T a d poles. - Since the tadpoles and metamorphosing young show a rather large variation in size in the different batches, they are treated separately.

ZMA 7062 (reared from eggs). Twenty-five tadpoles in stage 25 have body lengths of $5-9 \mathrm{~mm}$ and total lengths of $15-25 \mathrm{~mm}$. Five tadpoles in stages 26-28 have body lengths of 9-12 $\mathrm{mm}$ and total lengths of $27-36 \mathrm{~mm}$. Four tadpoles in stages 34-40 have body lengths of $13-15 \mathrm{~mm}$ and total lengths of $39-46 \mathrm{~mm}$. Three metamorphosing young have body lengths of $15-16 \mathrm{~mm}$.

ZMA 7065. Three tadpoles in stage 25 have body lengths of $7-10 \mathrm{~mm}$ and total lengths of 22-31 mm. Two tadpoles in stages $28-29$ have body lengths of 10-11 and total lengths of 33-35 $\mathrm{mm}$. Two tadpoles in stages 30 and 38 have a body length of $12 \mathrm{~mm}$ and a total length of 37-40 mm.

ZMA 7069. Two tadpoles in stage 26 have body lengths of $8.5-9.0 \mathrm{~mm}$ and total lengths of 26-27 $\mathrm{mm}$. Two metamorphosing young have body lengths of $17-18 \mathrm{~mm}$.
ZMA 7070. Two tadpoles in stage 25 have body lengths of $6.0-6.5 \mathrm{~mm}$ and total lengths of 17.0$18.5 \mathrm{~mm}$. Four tadpoles in stages $26-29$ have body lengths of $9.5-11.5 \mathrm{~mm}$ and total lengths of 28.5 $33.5 \mathrm{~mm}$. Two tadpoles in stages 33 and 37 have body lengths of $11.5-14.0 \mathrm{~mm}$ and total lengths of $34.5-41.0 \mathrm{~mm}$. Two metamorphosing young have body lengths of 15 and $16 \mathrm{~mm}$.

ZMA 7002. Eight tadpoles in stage 25 have body lengths of $5.5-15.0 \mathrm{~mm}$ and total lengths of 16.5-45.0 mm. Three tadpoles in stages 26-28 have body lengths of $14-15 \mathrm{~mm}$ and total lengths of $42-45 \mathrm{~mm}$. Thirteen tadpoles in stages $34-40$ have body lengths of $15-19 \mathrm{~mm}$ and total lengths of $45.57 \mathrm{~mm}$. Sixteen metamorphosing young (ZMA 7003 reared from 7002) have body lengths of $17-24 \mathrm{~mm}$ (mean $20 \mathrm{~mm}$ ).

ZMA 7068. One tadpole in stage 25 has a body length of $13 \mathrm{~mm}$ and a total length of $39 \mathrm{~mm}$.

ZMA 7064. One tadpole in stage 25 has a body length of $11 \mathrm{~mm}$ and a total length of $32 \mathrm{~mm}$. Three tadpoles in stages $32-37$ have body lengths of $14-15 \mathrm{~mm}$ and total lengths of $42.45 \mathrm{~mm}$. Six metamorphosing young have body lengths of 13 $17 \mathrm{~mm}$.

ZMA 7067. One tadpole in stage 25 has a body length of $9 \mathrm{~mm}$ and a total length of $27 \mathrm{~mm}$. One tadpole in stage 37 has a body length of $18 \mathrm{~mm}$ and a total length of $54 \mathrm{~mm}$. Three metamorphosing young have a body length of $18 \mathrm{~mm}$. 


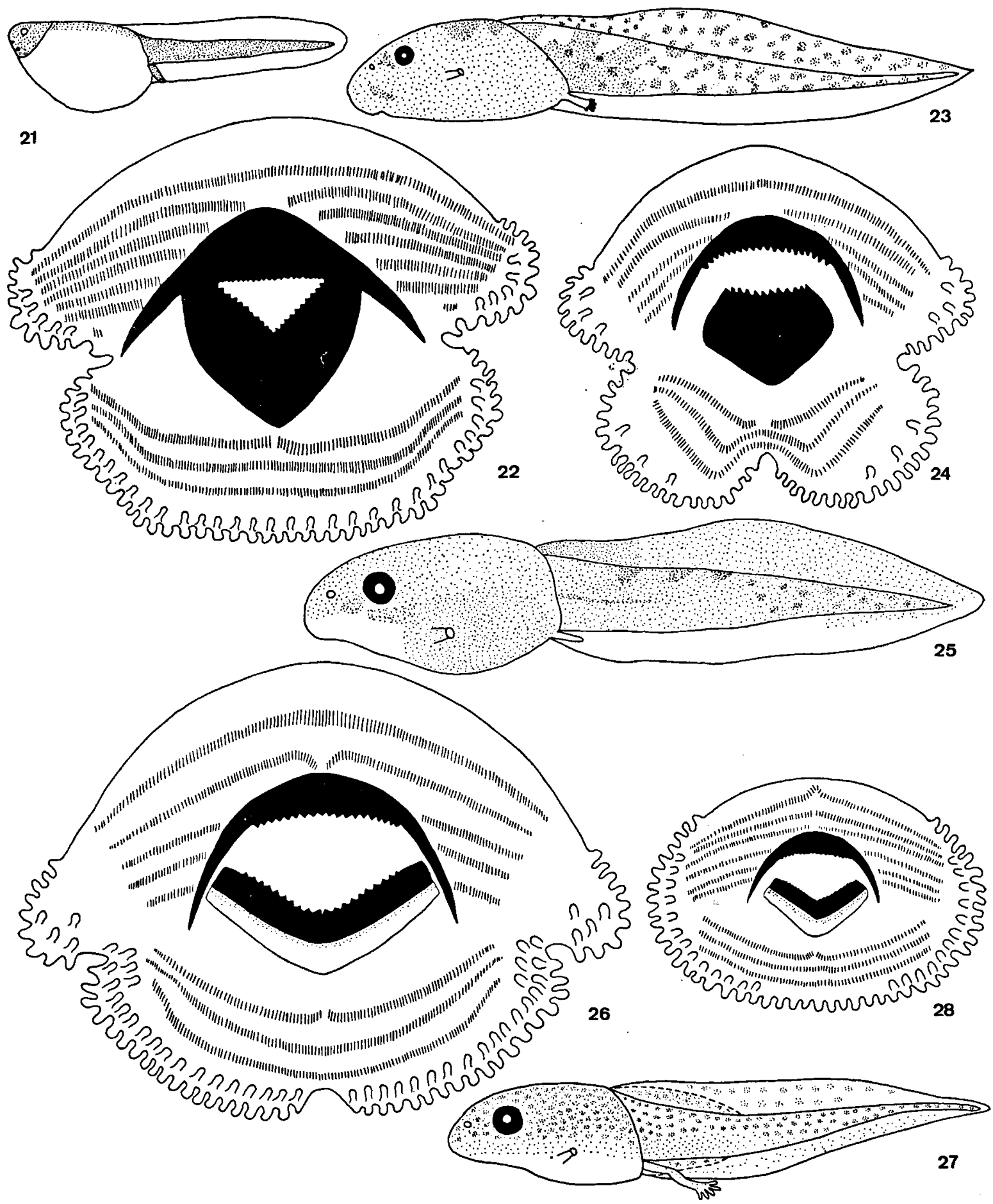

Figs. 21-28. 21-23, Boophis madagascariensis: 21, hatchling, ZMA 7063.X.6; 22, mouth of tadpole, ZMA 7002.X.25; 23, tadpole, ZMA 7066.X.1.5; 24-25, B. untersteini: 24, mouth of tadpole, ZMA 7090.X.12.5; 25, tadpole, ZMA 7090.X.1.5; 26-27, B. tephraeomystax: 26, mouth of tadpole, ZMA 7011.X.25; 27, tadpole, ZMA 7011.X.1.5; 28, B. billenii: mouth of tadpole, ZMA 7122.X.25. 
ZMA 7066. Five tadpoles in stages 26-28 have body lengths of $13-15 \mathrm{~mm}$ and tatal lengths of 38-46 mm. Seven tadpoles in stages 33-37 have body lengths of $14-20 \mathrm{~mm}$ and total lengths of $42-60 \mathrm{~mm}$. Two metamorphosis young have body lengths of $19-21 \mathrm{~mm}$. The average ratio of tail length to body length in the tadpoles listed above is 2 (range 1.8-2.3).

The mouth (ZMA 7002) in stage 28 and the lateral view (ZMA 7066) in stage 36 are shown in figs. 22-23. The body is depressed. The nostrils are situated dorsally with lateral openings slightly nearer to the eye than to the tip of the snout. The spiracular opening is sinistral, situated at equal distances from the snout and the end of the body. The cloacal tube is dextral to the caudal fin. The caudal musculature is slender. The caudal dorsal fin is shallow anteriorly. At midlength of the tail, the height of the caudal musculature accounts for $2 / 7$ of the total tail height. The mouth is small and directed ventrally. The margin of the oral disc is indented laterally. The papillary border has a wide median gap anteriorly. Two rows of papillae are present. The horny beak is heavy. The tooth formula is in general $1 / 4+4 / / 1 / 2+2$; it varies from $1 / 3+3 / / 1 / 2+2-1 / 6+6 / / 1 / 2+2$, from stage 26 onwards. Metamorphosis was observed in May and in October and the beginning of November. The whole development took about three months in the vivarium in the hot season. The development is retarded in the cool dry season (June-September), in which period we did not observe any metamorphosis. The tadpoles of the last eggs (April) hatched in the beginning of the hot season.

The colour of the tadpole is brownish.

Young. - The hatched young frogs are quite distinct from the adults. They agree with the description of Rhacophorus berthae Ahl, 1929. Some hatchlings were maintained in the vivarium for another 2-3 months, after which period they had reached a body length of $41 \mathrm{~mm}$, and were resembling the adults of $B$. madagascariensis.

The ground colour of the back of just metamorphosed young is light green. There are dark brown spots on the back, dark brown crossbands on the limbs and a transverse dark brown line behind the eyes. The tympanic fold and the canthus are bordered with a broad dark brown band; the region underneath this band is milky white with a dark brown longitudinal band under the eye. The hands and feet and the ventral surface of the hindlimbs are yellow or light orange. The belly is very pale green. There are weak tubercles on heel and elbow, developing into the characteristic triangular dermal flaps of Boophis madagascariensis during growth. At an early stage the young's ground colour changes from green into the adult's beige or brown. Just after metamorphosis the lateral folds along lower arm and tarsus are not yet present, but during growth they soon become apparent.

Boophis untersteini (Ahl, 1928) bona species Text-figs. 24-25; pl. II figs. 4-6.

Rhacophorus untersteini Ahl, 1928: 317; Guibé, 1978: 76 (in synonymy of callichromus).

M a teria 1. - ZMB 30497, half-grown holotype of $R$ bacophorus untersteini. Type locality: central Madagascar. Coll. Hildebrandt.

ZMB 30508 A, B, syntypes of Rbacophorus callichromus. Type locality: N.W. Madagascar. Coll. Hildebrandt.

ZMA 7190 (tadpoles and young reared from them), August 1972 collected near Mandraka valley (highroad R.N. 2 at $\mathrm{km} \mathrm{69),} \mathrm{rivulet} \mathrm{Vokanatetezandava,} \mathrm{in} \mathrm{the} \mathrm{nursery}$ garden of the city of Tananarive, alt. $1200 \mathrm{~m}$. - ZMA 7191 (tadpoles and young reared from them), 24.IX.72 collected near Perinet (highroad R.N. 2 at km 142), alt. $1100 \mathrm{~m} .-$ ZMA 7189 (tadpoles and one young reared), 29.VIII.72 collected along the road from Moramanga to Anosibe at km 25, alt. $800 \mathrm{~m}$. - ZMA 7193 (tadpoles and one young reared), 12.IX.71 collected near the forest station of Tampoketsa d'Ankazobe (highroad R.N. 4), alt. $1600 \mathrm{~m}$.

$\mathrm{Habitat}$. - The tadpoles were collected in slowly running water near forest, at all localities. No adult specimens were caught.

T a x o n o my. - The young reared from the tadpoles have a typical juvenile colour pattern, which changed drastically during subsequent growth. Some young were reared during 2-3 months. I have compared these half-grown specimens with the type material. They appeared to be similar with the holotype of Rhacophorus untersteini (not with $R$. callichromus, see $B$. goudoti). The largest half-grown specimen in our collection was already calling and made attempts to mate. 
Description (see table $V$ for measurements). - Based on the holotype of $R$. untersteini, the two largest specimens of ZMA 7190, and the largest of ZMA 7191. All are half-grown males, having vocal slits. The ratio of hand length to snout-vent length is 0.33 . The ratio of tibia length to snout-vent length is 0.55-0.58 (mean 0.58). The ratio of foot length to snout-vent length is $0.45-0.48$ (mean 0.47 ). The ratio of the horizontal diameter of the tympanum to that of the eye is 0.49-0.55 (mean 0.51).

The head is much wider than the body, and somewhat wider than long. The head length is one-third of the body length. The snout is broadly rounded in dorsal profile and sloping in lateral profile. The snout is slightly longer than the horizontal diameter of the eye, and somewhat shorter than the distance between the anterior corners of the eye. The nostrils are at equal distances from the anterior corner of the eye and the tip of the snout. The distance from the nostril to the anterior corner of the eye is shorter than the horizontal diameter of the eye. The canthus is distinct, angular, somewhat concave. The loreal region is concave and inclined laterally. The interorbital region is flat. The ratio between the internarial and interorbital distance is about 1 . The interorbital distance is one and a half times the width of an upper eyelid. The nostrils are strongly protruding, their openings are lateral. The commissure of the mouth is straight. The pupil is horizontally elliptical.

There is a distinct dermal fold from the posterior edge of the eye, over the tympanum, curving downwards to a point above the insertion of the arm. The fold covers the dorsal margin of the tympanum. The tympanum is distinct and round; its diameter is half the horizontal diameter of the eye. The distance from the eye to the tympanum is about one-fourth of the diameter of the tympanum.

The largest diameter of the disc of the third finger is about two-thirds of the diameter of the tympanum; the disc of the fourth finger is about equal to the diameter of the tympanum, that of the second finger is slightly smaller and that of the first finger much smaller; the discs are truncate. The relative lengths of the fingers from shortest to longest are 1-2-4-3. The subarticular tubercles are small, distinct and round. The distal tubercle of the fourth finger is sometimes bifid. There is an inner oval flat metacarpal tubercle and no palmar tubercle. Many distinct supernumerary tubercles are present on the base of the fingers. The formula of the webbing of the hand: between 1 and $2 \mathrm{i}$ a trace of web, $2 \mathrm{e}(1), 3 \mathrm{i}(2), 3 \mathrm{e}(1), 4$ (1). The web is glandular.

The upper arm is slender. When the limbs are laid along the side, the knee and elbow overlap. The adpressed heels overlap slightly. The tibiotarsal articulation extends to a point between the nostril and the tip of the snout. The inner metatarsal tubercle is distinct, small, elliptical and protruding. There is no outer metatarsal tubercle. A small web connects the tip of the inner metatarsal tubercle with the first toe to the base of the penultimate phalanx. The discs on the toes are nearly as large as those on the fingers. The third and fifth toe are about equal. The subarticular tubercles are small, round and protruding. Many distinct supernumerary tubercles are present on the base of the foot. The formula of the webbing of the foot: $1(1 / 2), 2 \mathrm{i}(1), 2 \mathrm{e}(0), 3 \mathrm{i}(1), 3 \mathrm{e}(0), 4 \mathrm{i}\left(1 \frac{1}{2}\right)$, $4 \mathrm{e}\left(1 \frac{1}{2}\right)$, $5(1 / 2)$. The lateral metatarsalia are separated. The ventral surface of the web is glandular. A white fold runs from the elbow along the side of the lower arm and the fourth finger to the disc, and another white fold runs from the heel along the side of the tarsus and the fifth toe to the disc. A small white tubercle is present on the heel and elbow.

The anal opening is directed posteriorly at the upper level of the thighs. The dermal flap above the anal opening continues in a fold on each side of the anal opening, thus forming together a $\wedge$-shaped figure.

The tongue is heart-shaped and distinctly bifid. The vomerine teeth are situated medially behind the choanae, in two small straight groups. The vocal slits are small, situated in the floor of the mouth near the angles of the jaw. The vocal sac is median, subgular and moderately distensible.

The skin on the back is smooth with dispersed small tubercles. The skin on the chin, throat and on the ventral surface of the limbs (except the thighs) is smooth. The skin on the belly and 
posteroventral part of the thighs is coarsely granular. The skin below the anal opening is covered with small white tubercles. There are white tubercles on the heel and elbow.

The colour in preservative is beige or brown. The venter is uniformly cream. There are distinct dark brown transverse bars on the limbs. Dark brown streaks are present ventrally along the white lateral folds on lower arm and tarsus. The posterior surface of the thigh is brown with or without cream-coloured spots. The region below the canthus and the tympanic region are dark brown. A broad white band runs from underneath the posterior part of the eye obliquely backwards and sometimes another white band runs from underneath the anterior part of the eye obliquely to the front. These white bands are separated from each other by a dark brown patch. The upper rim of the palpebral membrane is pigmented. The iris is silvery grey with a dark brown reticulation and surrounded by a dark brown ring.

The colour in life is similar, but more intense.

Tadpoles. - (ZMA 7189-7191, 7193). Seventeen tadpoles in stage 25 have body lengths of $12-17 \mathrm{~mm}$ and total lengths of $35-47 \mathrm{~mm}$. The average ratio of tail length to body length in stage 25 is 1.8 (range 1.7-1.9). Sixteen tadpoles in stages $26-29$ have body lengths of $18-23 \mathrm{~mm}$ and total lengths of $47-61 \mathrm{~mm}$. The average ratio of tail length to body length is 1.7 (range 1.6-1.9). Nine tadpoles in stages 32-39 have body lengths of $18-26 \mathrm{~mm}$ and total lengths of $48-80 \mathrm{~mm}$. The average ratio of tail length to body length is 1.8 (range 1.65-1.85). Seven metamorphosing young measure $21.25 \mathrm{~mm}$ (mean $24 \mathrm{~mm}$ ) from snout to vent (ZMA 7189, 7190, 7193). Two metamorphosing young (ZMA 7191) measure 18 and 19 $\mathrm{mm}$ from snout to vent.

The mouth and lateral view of a tadpole in stage 30 (ZMA 7090) are shown in figs. 24-25. The body is ovoid. The nostrils are dorsal, the openings are situated dorsolaterally at equal distances from the tip of the snout and the anterior corner of the eye. The eyes are situated laterally. The spiracular opening is sinistral, situated at about $1 / 2$ from the tip of the snout and the end of the body. The cloacal tube is long and situated on the right of the caudal fin. The caudal musculature is moderately developed. The dorsal caudal fin is shallow anteriorly. At midlength of the tail, the height of the caudal musculature accounts for $1 / 3$ of the total tail height. The mouth is small and directed ventrally. The margin of the oral disc is indented laterally, and somewhat medioposteriorly. The papillary border has a wide median gap anteriorly and a very narrow gap posteriorly. There is one row of papillae with a few dispersed supernumerary papillae. The horny beak is heavy. The tooth formula is $1 / 4+4 / / 1+$ $1 / 2$ or rarely $1 / 5+5 / / 1+1 / 2$. Metamorphosis was observed in October and the beginning of November.

The colour of the tadpole is brownish.

Young. - The hatched young are quite distinct from the half-grown, especially in colouration. They resemble the young of $B$. madagascariensis in having small tubercles on the heel and elbow, whereas the lateral folds along the lower arm and tarsus are not yet present. The amount of webbing of the hands and feet is also the same as in $B$. madagascariensis.

The colour on the back of just metamorphosed young is olive-green with a broad chocolate-brown marking in the middle, extending over the upper eyelids. The shape of this marking is variable (see pl. II figs. 4-5). The sides are chocolate-brown interrupted by two light green spots anteriorly and posteriorly underneath the eye. The dorsal surfaces of the limbs are olive-green with dark brown crossbands. The hands and feet are orange. The belly is light green. The ventral surface of the hindlimbs is orange.

\section{Boophis reticulatus sp. nov. Pl. III fig. 1.}

Boophis sp. 1; Bachmann \& Blommers-Schlösser, 1975: 17 (DNA).

Material. - ZMA 7101A, male holotype and ZMA 7101B, eight male paratypes, 13.XI.72 collected near Perinet (highroad R.N. 2 at km 142), alt. $1100 \mathrm{~m}$.

The present species resembles the other species of the goudoti group. $B$. reticulatus is readily distinguished from untersteini, madagascariensis, by- 
loides, callichromus and goudoti by the structure of the skin of the dorsum, which is covered with tubercles and ridges, forming an irregular network.

$\mathrm{H}$ a b it a t - - The males were found on a rainy evening, calling on leaves of shrubs and trees, along running water in open woodland.

Description (see table V for measurements). - The ratio of hand length to snout-vent length is $0.29-0.32$ (mean 0.305). The ratio of tibia length to snout-vent length is $0.53-0.60$ (mean 0.57 ). The ratio of foot length to snoutvent length is $0.42-0.50$ (mean 0.45 ). The ratio of the horizontal diameter of the tympanum to that of the eye is $0.48-0.52$ (mean 0.50). Snoutvent length in males is $30-36 \mathrm{~mm}$.

Holotype: head length is $11 \mathrm{~mm}$; head width is $12.5 \mathrm{~mm}$; internarial and interorbital distance is $4 \mathrm{~mm}$; snout-vent length $35 \mathrm{~mm}$.

The body in the postaxillary region is little narrower than the greatest width of the head. The head is somewhat wider than long. The head length is one-third of the body length. The snout is rounded in dorsal profile, round to sloping in lateral profile. The snout is longer than the horizontal diameter of the eye, and equal to the distance between the anterior corners of the eyes. The nostrils are at equal distances from the tip of the snout and the anterior corner of the eye. The canthus is distinct, concave. The loreal region is distinctly concave and oblique. The interorbital region is slightly convex. The ratio between the internarial and interorbital distance is 1 . The interorbital distance is about the width of an upper eyelid. The nostrils are protruding, with lateral openings. The commissure of the mouth is straight. The pupil is horizontally elliptical.

There is a distinct straight dermal fold from the posterior edge of the eye, over the tympanum, reaching to a point just behind the insertion of the arm. The fold covers the dorsal margin of the tympanum. The tympanum is rather distinct, its horizontal diameter is about half the horizontal diameter of the eye. The distance from the eye to the tympanum is about half the horizontal diameter of the tympanum.

The largest diameter of the disc of the third finger is equal to the horizontal diameter of the tympanum; the disc of the fourth finger is about equal, of the second finger slightly smaller, and of the first much smaller. The relative lengths of the fingers from shortest to longest are 1-2-4-3. The subarticular tubercles are small, distinct and oval. The distal tubercles of the fourth and third fingers are bifid. There is an inner flat, oval metacarpal tubercle. A white nuptial pad is situated dorsolaterally on the first finger. There are two oval flat, palmar tubercles. Many distinct supernumerary tubercles are present on the base of the fingers. The formula of the webbing of the hand: between 1 and $2 \mathrm{i}$ a trace of web, $2 \mathrm{e}$ (1), $3 \mathrm{i}$ (2), 3e (1), 4 (1). The web is glandular.

The upper arm is robust. When the limbs are laid along the side, the knee and elbow overlap. The adpressed heels overlap. The tibiotarsal articulation extends to a point between the nostril and the tip of the snout. The inner metatarsal tubercle is small, distinct and oval. A small web connects the tip of the inner metatarsal tubercle with the first toe to the middle of the antepenultimate phalanx. There is no outer metatarsal tubercle. The discs on the toes are slightly smaller than those on the fingers. The subarticular tubercles are distinct, small and round. There are some supernumerary tubercles on the base of the toes. The third and fifth toe are about equal in size. The formula of the webbing of the foot: $1(0), 2 \mathrm{i}(1)$, $2 \mathrm{e}(0), 3 \mathrm{i}(1), 3 \mathrm{e}(1), 4 \mathrm{i}(1), 4 \mathrm{e}(1), 5$ (0). The ventral surface of the web is glandular. The lateral metatarsalia are separated.

The anal opening is directed posteriorly at the upper level of the thighs. The dermal flap above the anal opening is tubercular, and continues in a fold on each side of the anal opening, together forming a U-shaped figure.

The tongue is heart-shaped and distinctly bifid. The vomerine teeth are situated medially behind the choanae in two large oblique groups. The vocal slits are small, situated in the floor of the mouth, near the angles of the jaws. The vocal sac is single, median, subgular, and noticeably distensible.

The skin on the back is covered with elevated ridges and tubercles, forming an irregular network. The tubercles are most numerous on the upper eyelid and the end of the back. There are 
also tubercles on the knee, a row of three or four situated longitudinally on the middle of the shank, a row along the side of the tarsus, a row along the side of the lower arm, and dispersed tubercles on the dorsal middle of the lower arm. Large white triangular tubercles are present on the heel and elbow. There are fringes along the side of the fifth toe and fourth finger. The skin on the belly is coarsely granular. The skin on the chin and posteroventral part of the thigh is granular. There are distinct, large white tubercles beneath the anal opening, and on the anal sheath. The remaining ventral surface of the limbs is smooth.

The colour in preservative, same as in life: the back is dark brown, the flanks are light brown with whitish spots and the limbs are light brown with indistinct dark brown crossbands. There is a white line along the canthus and from the nostril to the tip of the snout. There is a white band from underneath the anterior part of the eye, obliquely to the front. A large white triangular patch extends from underneath the posterior part of the eye, underneath the tympanum to the insertion of the arm. The ventral surface is cream with some scattered brown pigment. The upper rim of the palpebral membrane is pigmented. The iris is silvery grey with a dark brown reticulation, surrounded by a black ring (in preservative). In life, the iris is silvery in the middle, with an orange (mixed with brown) periphery.

The paratypes agree with the description above.

Et y mology. - The specific name is derived from the latin reticulum meaning net. It refers to the tubercles and ridges on the back, forming an irregular network.

\section{Boophis tephraeomystax group}

Diagn os is. - The members of this group are medium-sized species, which breed in temporary pools. The dorsum is yellow-brown (often silver-grey in preservative), mostly covered with dark speckles. There are indistinct transverse bars on the limbs. The flanks and the anterior part of the thighs are mostly also dark with light spots.
Fringes and dermal flaps are lacking on the limbs. Vomerine teeth are present. The horizontal diameter of the tympanum is one-third to half that of the eye. The skin on the dorsum is smooth, finely granular or verrucose. The vocal sac is single, median and subgular. The snout is rounded. The tibiotarsal articulation extends to the centre of the eye or beyond, but never extends as far as the tip of the snout. The discs are well developed. The fingers either have a trace of web, or they are to one-fourth webbed. The toes are about threefourths webbed, one to two phalanges of the fourth toe are free of web.

Contents: B. tephraeomystax (Duméril, 1853), $B$. idae (Steindachner, 1867), B. granulosus (Guibé, 1975), B. billenii sp. nov.

\section{Differential diagnosis}

1. Nostrils much nearer to tip of snout than to eye .

. . . . . . B. tephraeomystax (Duméril)

2. Nostrils equidistant from tip of snout and eye.

a. Skin of dorsum verrucose . . B. granulosus (Guibé)

b. Skin of dorsum finely granular ( $\hat{o}$ ), tibiotarsal articulation reaching the centre of the eye. .

. . . . . . . B. idae (Steindachner)

c. Skin of dorsum smooth ( $\hat{o})$, tibiotarsal articulation reaching the nostril. . . . B. billenii sp. nov.

Re m a rks . - Initially, it was observed that three distinct young Boophis developed from tadpoles, collected in temporary rainpools, in the forest around Perinet. High numbers of just emerged young of one of these species $(B$. billenii), together with single specimens of the other two ( $B$. granulosus and $B$. idae) were collected on the vegetation above one pool during daytime on April 4, 1972. Three different tadpoles were collected at various occasions, and could be linked to the young Boophis species by rearing. B. granulosus is readily distinguished from the other two by the skin of the back, which is coarsely granular, a feature already visible in the young. The other two are difficult to distinguish as adults, but the tadpoles and young are so clearly different, that I have described one of them as a new species, $B$. hillenii. $B$. tephraeomystax is a coastal species, breeding also in temporary pools. Its tadpole closely resembles the tadpoles of the afore-mentioned species. 
Boophis tephraeomystax (Duméril, 1853)

Text-figs. 26-27, 29; pl. II fig. 7.

Polypedates tephraeomystax Duméril, 1853: 153; Boettger, 1881: 505.

Polypedates crossleyi Peters, 1874: 618.

Polypedates dispar Boettger, 1879: 86; Boettger, 1881: 507, pl. V fig. 18.

Rhacophorus tephraeomstax; Boulenger, 1882: 78; Boettger, 1913: 276 (equals dispar); Ahl, 1931: 200, fig. 105 (equals dispar); Guibé, 1978: 65, figs. 140-147 (equals crossleyi, boulengeri, difficilis, bildebrandti, doulioti).

Rhacophorus bildebrandti Ahl, 1925: 18.

Rhacophorus doulioti Angel, 1934a: 169.

Boophis tephraeomystax; Bachmann \& Blommers-Schlösser, 1975: 17 (DNA); Blommers-Schlösser, 1978: 37 (chromosomes).

Boophis aff. tephraeomystax; Blommers-Schlösser, 1978: 37 (chromosomes).

Materia 1. - MNHP 1660 and 4584, syntypes of Polypedates tephraeomystax. Type locality: Nossi Bé and Madagascar. Coll. Boivin.

SMF 6766, $\&$ lectotype (designed by Mertens, 1967) of Polypedates dispar. Type locality: Nossi Bé. Coll. Stumpff. ZMB 10472, \& holotype of Rhacophorus bildebrandti.

Type locality: N.W. Madagascar. Coll. Hildebrandt.

MNHP 1891-356 and 357, syntypes of Rhacophorus doulioti. Type locality: Morondava. Coll. Douliot.

ZMA 6766 (5), 1-15.IV.71; 6767 (1), 19.IV.71; 6758 (11), 26.IV.71; 6759 (2), 5.IV.71; 6765 (7), 22.IV.71; 6775 (1), 15.I.71; collected near Tuléar, S.W. coast. ZMA 6785 (3), 23.IV.72; 6786 (10), 29.X1.72; 7010 (tadpoles and young reared from them), 2.V.72; 7011 (tadpoles), 2.V.72; all collected near Ampijoroa, Ankarafantsika forest (highroad R.N. 4 at km 465). - ZMA 6787 (1 \%), 10.II.72 collected near Tamatave, E. coast. - ZMA 6783 (2 $\hat{\delta} \hat{o}$ ), 13.II.72 collected near Foulpointe, $60 \mathrm{~km} \mathrm{~N}$. of Tamatave. - ZMA 6784 (1), 1.VIII.72 collected near Ivoloina, $13 \mathrm{~km} \mathrm{~N}$. of Tamatave.

$\mathrm{Natural}$ history. - B. tephraeomystax is a common species in all coastal areas of Madagascar visited by us. It is probably the only species of Boophis occurring in the S.W., almost the driest part of the island, where it is found in the irrigated area around Tuléar. There, as well as in the deciduous western coastal forest (Ankarafantsika), it leads a rather hidden life, sheltering in leaf-axils of plants, like bananas, during the dry season. But when the weather turns rainy, the frogs are found on the vegetation, also in daytime. Populations of this species (perhaps subspecies: differences in the karyotypes are found between specimens of the S.W. and E. coast, see BlommersSchlösser, 1978) from the humid eastern coastal area, are far from hidden. They are found there in rather open country, but still in the shrubbery, often close to human habitation. Some specimens were caught while seated in the sun during dry spells in the rainy season. The species has apparently the greatest tolerance for drought and heat of all Boophis species. This agrees with the low DNA amount (7 pg diploid) of this species, which could be an adaptation to fast development in an area of limited rainfall. B. tephraeomystax has the smallest genome size of the Boophis species examined (Bachmann \& Blommers-Schlösser, 1975).

The call of the males is heard in rainy nights, it resembles the yelping of a small dog. Calling males of this species were always situated a few metres from each other. They were observed moving down trees in the forest edge towards the ground, near pools. The amplexus is axillary.

The tadpoles were found in sunlit temporary rainpools with abundant vegetation.

Description (see table VI for measurements). - The ratio of hand length to snout-vent length is $0.26-0.31$ (mean 0.28 ). The ratio of tibia length to snout-vent length is 0.49-0.57 (mean 0.52 ). The ratio of foot length to snout-vent length is $0.37-0.47$ (mean 0.42). The ratio of the horizontal diameter of the tympanum to that of the eye is $0.45-0.60$ (mean 0.50). Snout-vent length is $35-50 \mathrm{~mm}$.

B. tephraeomystax resembles closely the species of the Mantidactylus depressiceps group, both in colouration and external morphology. However, the species of the $M$. depressiceps group have both an inner and outer metatarsal tubercle, while $B$. tepbraeomystax has only an inner metatarsal tubercle, just like all species of the genus Boophis (see Blommers-Schlösser, 1979).

Sexual dimorphism. - The male has white nuptial pads, located laterodorsally on the first and second fingers. The vocal slits are small, situated in the floor of the mouth, near the angles of the jaws. The vocal sac is single, median subgular and moderately distensible. The female is larger than the male, the skin on the back is smooth, while that of the male is finely granular. 
TABLE VI

Dimensions in $\mathrm{mm}$ of Boophis tephraeomystax, B. billenii, B. idae and B. granulosus. A = snout to vent; B = length of lower arm; $C=$ hand length; $D=$ length of hind limb; $E=$ tibia length; $F=$ length of foot and tarsus; $G=$ foot length; $H=$ horizontal diameter of tympanum; $I=$ horizontal diameter of eye.

\begin{tabular}{|c|c|c|c|c|c|c|c|c|c|}
\hline & $\mathbf{A}$ & B & C & D & $\mathrm{E}$ & $\mathbf{F}$ & G & $\mathbf{H}$ & $\mathbf{I}$ \\
\hline \multicolumn{10}{|l|}{ B. tepbraeomystax } \\
\hline 2 \% 9 syntypes MNHP & 48.49 & 23 & 14 & 77 & $25-26$ & 32 & 22 & & \\
\hline$\%$ lectotype dispar SMF & 49 & 23 & 14.5 & 81 & 28 & 36 & 23 & & \\
\hline o holotype bildebrandti & 40 & 18 & 11 & 64 & 21 & 25 & 17 & 2.5 & 5.5 \\
\hline $\begin{array}{l}\text { syntype doulioti MNHP } \\
7 \text { o } 9 \text { ZMA }(6758\end{array}$ & 38 & 17 & 11 & 55 & 20 & 24 & 16.5 & & \\
\hline $6786-87)$ & $41-50$ & $18-24$ & $11-16$ & $65-84$ & $21-27$ & 26.35 & $16-24$ & $2.5-3.5$ & $4.5-6.0$ \\
\hline 3 is \&MA $(6783,6786)$ & $35-42$ & $17 \cdot 18$ & $10-11$ & $56-64$ & $19-22$ & $23-26$ & $16-18$ & $2.5-3.0$ & $5.0-5.2$ \\
\hline \multicolumn{10}{|l|}{ B. billenii } \\
\hline ô holotype ZMA & 30 & 15 & 10 & 50 & 15 & 21 & 14 & 1.4 & 3.8 \\
\hline o paratype ZMA & 30 & 15 & 10 & so & 16 & 20 & 14 & 1.5 & 4 \\
\hline \multicolumn{10}{|l|}{ B. idae } \\
\hline juvenile holotype WM & 18 & 8 & 5 & 26 & 9 & 12 & 7 & & \\
\hline holotype femoralis BMNH & 29 & & & 44 & 13.5 & 18.5 & 12.5 & & \\
\hline holotype catalai MNHP & 30 & 13.5 & & 42.5 & 15 & 20 & 12.5 & & \\
\hline 3 \&ิ \&ิ ZMA & $33-36$ & $15.5-16.0$ & $10.5-11.0$ & $51-52$ & $16-17$ & $23-24$ & $15.0-15.5$ & $1.5-1.7$ & 4 \\
\hline \multicolumn{10}{|l|}{ B. granulosus } \\
\hline 7 \& \& ZMA & $35-40$ & $17-19$ & $10.0-11.5$ & $55-61$ & $18-20$ & $22.5-26.5$ & $16-18$ & $1.8-2.2$ & $4-5$ \\
\hline 1 \& ZMA & 36 & 17.5 & 10.5 & 56 & 18 & 25 & 16.5 & 1.9 & 4 \\
\hline
\end{tabular}

Colour in life. - The ground colour is beige or light brown. The back is covered with irregular brownish spots and markings. There are irregular brown crossbands on the limbs. The flanks are covered with light yellow spots. A light yellow longitudinal lateral band is mostly present. The belly is cream coloured.

Voice. - The species was heard on rainy evenings, in April in Ampijoroa, in January in Tuléar, in February and July in Foulpointe. The sonagram (fig. 29) made of a male (ZMA 6775) in January 1971 at 10 p.m. shows that the call consists of a series of melodious notes, with a duration of 0.3-0.4 sec. each, interrupted by very short clicks of $0.06 \mathrm{sec}$. The major frequencies are 1500 and $3000 \mathrm{~Hz}$. A similar sonagram was made of another male (ZMA 6785).

T a d poles. - Four tadpoles in stages 26-29 have body lengths of $8-10 \mathrm{~mm}$ and total lengths of $24-29 \mathrm{~mm}$. The average ratio of tail length to body length is 1.9 (range 1.8-2.0). Eleven tadpoles in stages 38-42 have body lengths of 12$16 \mathrm{~mm}$ and total lengths of $39-49 \mathrm{~mm}$. The average ratio of tail length to body length is 2.1 (range 1.8-2.3). Twenty metamorphosing young measure $15-20 \mathrm{~mm}$ from snout to vent (mean $18 \mathrm{~mm}$ ).

The mouth and lateral view of a tadpole in stage 37 (ZMA 7011) are shown in figs. 26-27. The body is ovoid. The nostrils are situated dorsally with anterolateral openings at equal distances from

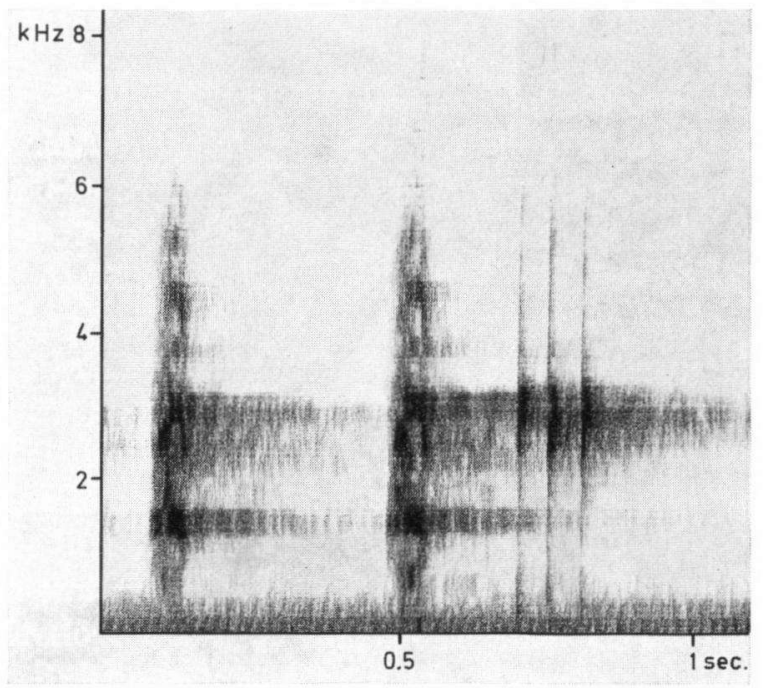

Fig. 29. Sonagram, filter wide, Boophis tephraeomystax. 
the tip of the snout and the anterior corners of the eyes. The eyes are large and directed laterally. The spiracular opening is sinistral, situated at about $5 / 8-2 / 3$ from the tip of the snout and the end of the body. The cloacal tube is located on the right side of the caudal fin. The caudal musculature is slender. The dorsal and ventral caudal fin are thickened alongside the caudal musculature in the anterior part of the tail (see dotted line in fig. 26). At midlength of the tail, the height of the caudal musculature represents about $2 / 5$ of the total tail height. The mouth is small and directed anteroventrally. The papillary border has a wide median gap anteriorly and a very small one medioposteriorly. There are two rows of papillae. The oral disc is indented laterally. The tooth formula is $1 / 4+4 / / 1+1 / 2$, or $1 / 3+3 / / 1+1 / 2$. The horny beak is well developed. The upper part of the lower beak is black.

Metamorphosis was observed in the beginning of May in Ampijoroa. I could not find tadpoles in Tuléar between February and April; they probably had already metamorphosed, the wet season being shorter in the southern part of Madagascar.

The colour in life of the tadpole is yellowish with beige spots and becomes mostly greenish in the late stages. The belly is milky white, speckled with minute dark spots in its anterior part.

Young. - The dorsum of the young is dark green (a juvenile colour, I never saw a green adult), and sometimes beige (as the adult). $A$ light yellow longitudinal lateral band is present as in the adult. The limbs are beige with dark brown crossbands.

Boophis hillenii sp. nov.

Text-figs. 28, 30; pl. III fig. 4.

Boophis aff. idae; Blommers-Schlösser, 1978: 37 (chromosomes).

Materia 1. - ZMA 7123A, ô holotype, ZMA 7123B, o paratype, 24.XII.72 collected near Perinet (highroad R.N. 2 at $\mathrm{km} \mathrm{142),} \mathrm{alt.} 900 \mathrm{~m}$.

ZMA 7122 (tadpoles and young reared from them), 20.I. $73 ; 7124$ (young), 4.IV.72; collected at the type locality. ZMA 7125 (1 juvenile), 3.VII.71 collected near Ranomafana (highroad R.N. 25), alt. $800 \mathrm{~m}$.
The present species is closiest allied to the sibling species, B. idae (Steindachner, 1867). It was discovered in the field that the larva and juvenile are clearly different in both. $B$. billenii can be distinguished from $B$. idae by the relatively longer hindlimbs.

Natural history. - The males were calling in the shrubbery around a temporary rainpool, in forest, during a rainy night. The tadpoles were found in that pool and the young on the leaves of marshy plants, above that pool. The juvenile (7125) was collected from the leaf-axil of a banana. The species is sympatric with $B$. granulosus (Guibé, 1975b) and B. idae (Steindachner, 1867).

Description (see table VI for measurements). - The ratio of the lower limb length to snout-vent length is 0.50 . The ratio of the hand length to snout-vent length is 0.33 . The ratio of the hindlimb length to snout-vent length is 1.67. The ratio of the tibia length to snout-vent length is 0.50 . The ratio of the foot length to snout-vent length is 0.47 . The ratio of the horizontal diameter of the tympanum to that of the eye is $0.37-0.38$. Snout-vent length of males $30 \mathrm{~mm}$.

Holotype: head length $9 \mathrm{~mm}$, head width 10 $\mathrm{mm}$, internarial and interorbital distance is $3 \mathrm{~mm}$; snout-vent length $30 \mathrm{~mm}$.

The body in the postaxillary region is little narrower than the greatest width of the head. The head is somewhat wider than long. The snout is acuminately rounded in dorsal profile, and sloping in lateral profile. The snout projects beyond the leading edge of the lower jaw. The snout is much longer than the horizontal diameter of the eye and equal to the distance between the anterior corners of the eye. The nostrils are at equal distances from the tip of snout and the anterior corners of the eye. The canthus is distinct, straight and slightly angular. The loreal region is barely concave. The interorbital region is flat. The ratio between the internarial distance and interorbital distance is 1 . The interorbital distance is $11 / 2$ times the width of an upper eyelid. The nostrils are barely protruding, the opening is lateral. The 
commissure of the mouth is straight. The pupil is horizontally elliptical.

There is a dermal fold from the posterior edge of the eye, over the tympanum, curving downwards to a point above the insertion of the arm. The fold covers the dorsal margin of the tympanum. The tympanum is distinct, its horizontal diameter is about $2 / 5$ of the horizontal diameter of the eye. The distance from the eye to the tympanum is about half the horizontal diameter of the tympanum.

The largest diameter of the disc of the third finger is equal to the horizontal diameter of the tympanum; the discs of the fourth and second fingers are about equal, but those of the first fingers are much smaller. The relative lengths of the fingers from shortest to longest are 1-2-4-3. The subarticular tubercles are small, round and protruding. The distal tubercle on the fourth finger is bifid. One distinct supernumerary tubercle is present on the base of each finger. There is an inner flat, oval metacarpal tubercle, and two flat oval palmar tubercles, a large and a small one. An oval unpigmented glandular nuptial pad is present laterodorsally on the first finger. There is a trace of web between the fingers. Between the fourth and third finger the web extends from the middle of the antepenultimate phalanx of the fourth to the base of the antepenultimate phalanx of the third. The web is glandular.

When the limbs are laid along the side, the knee and elbow overlap. The adpressed heels overlap noticeably. The tibiotarsal articulation extends to the nostril. The inner metatarsal tubercle is small, elliptical and protruding. There is no outer metatarsal tubercle. The discs on the toes are subequal to those on the fingers. The subarticular tubercles are small, round and protruding. The fifth toe is equal to the third in length. The formula of the webbing of the foot: $1(1 / 2), 2 \mathrm{i}(1), 2 \mathrm{e}(0), 3(1)$, $3 \mathrm{e}(1 / 2), 4 \mathrm{i}(1), 4 \mathrm{e}(1), 5(1)$. The ventral surface of the web is glandular. The lateral metatarsalia are separated.

The anal opening is directed posteriorly at the upper level of the thighs. The anal sheath is short.

The tongue is distinctly bifid posteriorly. The vomerine teeth are situated medially behind the choanae in two oblique groups. The vocal slits are small, situated in the floor of the mouth, near the angles of the jaws. The vocal sac is median, subgular and barely distensible.

The skin on the dorsum and on the ventral surfaces of the limbs (except the thighs) is smooth. The skin on the chin and throat is finely granular. The skin on the belly and on the posteroventral surface of the thighs is coarsely granular.

The colour in preservative is silvery grey with small round dark brown spots. The flanks are dark brown with large whitish spots. The limbs are light brown with irregular dark brown transverse bars and dark brown spots. The anterior part of the thighs is whitish with large brown spots. The posterior part of the thighs is brownish. The venter is evenly cream. The iris is blackish and the upper rim of the palpebral membrane is pigmented.

Unfortunately we made no diapositives of this species; the colour pattern in alcohol is the same as in $B$. idae, except that the back is silvery grey in the present species and brown or beige in $B$. idae.

T a d poles. - Two tadpoles in stage 25 have body lengths of $3.5-4.0 \mathrm{~mm}$ and total lengths of $9.5-10.0 \mathrm{~mm}$. Eight tadpoles in stages $26-30$ have body lengths of $4.0-6.5 \mathrm{~mm}$ and total lengths of 10.0-18.5 mm. Eleven tadpoles in stages 31-41 have body lengths of 6-9 $\mathrm{mm}$ and total lengths of $17-23 \mathrm{~mm}$. The average ratio of tail length to body length in the twenty-one tadpoles listed above is 1.7 (range 1.5-1.9). Thirty metamorphosing young have body lengths of 9-10 $\mathrm{mm}$.

The mouth and lateral view of a tadpole in stage 35 (ZMA 7122) are shown in figs. 28 and 30. The body is ovoid. The nostrils are dorsal, the opening is directed to the front and situated at equal distances from the tip of the snout and the anterior corners of the eye. The eyes are directed laterally. The spiracular opening is sinistral, situated at about $2 / 3$ from the tip of the snout and the end of the body. The cloacal tube is located on the right side of the caudal fin. The caudal musculature is slender. The caudal fin is well developed and goes on to the body. The dorsal and ventral caudal fins are thickened alongside the musculature in the first half of the tail (see dotted line in fig. 30). At midlength of the tail, 
the height of the caudal musculature represents about $1 / 5$ of the total tail height. The mouth is small and directed anteroventrally. The papillary border has a wide median gap anteriorly. There are 1-2 rows of papillae. The oral disc is round. The tooth formula is $1 / 4+4 / / 1+1 / 2$ or $1 / 5+5 / /$ $1+1 / 2$. The horny beak is well developed. The upper part of the lower beak is black.

The colour in life of the tadpole is yellowish, with a broad blackish middorsal line and blackish lateral lines. There is a white spot on the tip of the snout. The belly is silvery.

The entire development took 3-5 weeks in our rearings.

Y o u $\mathrm{g}$. - The ground colour in life is silvery. The back is covered with light green spots. There are brown crossbands on the limbs. A large brown spot is present between the eyes and a brown line is present along the canthus and above the tympanum. The webbing formula is the same as in the adult. The tibiotarsal articulation extends beyond the eye.

Etymology. - The present species is dedicated to my colleague, the herpetologist Dr. D. Hillenius.

\section{Boophis idae (Steindachner, 1867)}

Text-figs. 31-32, pl. III figs. 2, 5 .

Hyperolius idae Steindachner, 1867: 52, pl. V fig. 10.

Rhacophorus idae; Guibé, 1978: 68 (equals femoralis and catalai).

Rhacophorus femoralis Boulenger, 1882: 466.

Rhacophorus albiventer; Ahl, 1929: 478 (substitute name for femoralis).

Rhacophorus catalai Angel, 1934b: 247.

Materia 1. - WM 14845, the holotype of Hyperolius idae. Type locality: Madagascar. Coll. Pfeiffer.

BMNH 1947.2.27.60, the holotype of Rhacophorus femoralis. Type locality: East Betsileo. Coll. Cowan.

MNHP 1933-237, the holotype of Rhacophorus catalai. Type locality: Fianarantsoa. Coll. Catala.

ZMA 7014 (1), 13.X.72; 7015 (1), 15.XI.72; 7196 (tadpole), 13.X.72; 7198 (tadpoles), 13.X.72; 7199 (tadpoles and young reared from them), 13.X.72; collected in the Mandraka valley (highroad R.N. 2 at $\mathrm{km} 69$ ), alt. $1100 \mathrm{~m}$. ZMA 7197 (1), 13.XI.72 collected near Perinet (highroad R.N. 2 at km 142), alt. $1100 \mathrm{~m}$; ZMA 7200 (one young), 4.IV.72 collected at the same locality, but alt. $900 \mathrm{~m}$.
Natura l history. - Only in October and November we heard the males calling in the evening, near stagnant, sunlit pools. One specimen was found resting in the leaf-axil of a banana plant near the same pool, during the day. The tadpoles were found in the same pool near which the adults were found in Mandraka. In Perinet we found the species together with $B$. granulosus (Guibé, 1975 ) and $B$. billenii sp. nov.

T a x o n o my. - I agree with Guibé (1978) that $R$. femoralis (holotype examined by Dr. M. S. Hoogmoed, Leyden) and $R$. catalai are synonyms of B. idae. Since Boophis idae and B. hillenii are very much alike, I give only a description of the features of $B$. idae in which it differs from $B$. billenii. All remaining features are examined and proved to be the same as in $B$. billenii.

Description (see table VI for measurements). - The ratio of the lower arm to snoutvent length is $0.44-0.47$ (mean 0.45 ). The ratio of the hand length to snout-vent length is 0.28 0.32 (mean 0.30 ). The ratio of the length of the hindlimb to snout-vent length is 1.42-1.55 (mean $1.50)$. The ratio of the tibia length to snout-vent length is $0.44-0.50$ (mean 0.47). The ratio of the foot length to snout-vent length is $0.40-0.45$ (mean 0.43 ). The ratio of the horizontal diameter of the tympanum to that of the eye is $0.33-0.42$ (mean 0.38). Snout-vent length $29-36 \mathrm{~mm}$.

The snout is rounded in dorsal profile and bluntly rounded in lateral profile. The snout is slightly longer than the horizontal diameter of the eye. The canthus is indistinct, rounded and slightly concave. The interorbital distance is $11 / 4$ times the width of an upper eyelid. The commissure of the mouth is curved upwards.

The tympanum is rather indistinct, its horizontal diameter is about $1 / 3-2 / 5$ of the horizontal diameter of the eye.

When the limbs are laid along the side, the knee and elbow meet. The adpressed heels meet or slightly overlap. The tibiotarsal articulation extends to the centre of the eye. The formula of the webbing of the foot: $1(0-1 / 2), 2 \mathrm{i}(1), 2 \mathrm{e}(0)$, $3 i(1), 3 e(0), 4 i(11 / 2-2), 4 e(11 / 2-2), 5(0-1 / 2)$. 
The skin on the back is finely granular (in the male).

The ground colour in life of the dorsal surface is yellowish brown. The back is covered with minute light green spots surrounded with dark brown. The flanks, groin and anterior part of the thigh are turquoise with large brown spots. The posterior part of the thighs is brownish. There are irregular brown crossbands on the limbs. The discs are orange. The throat is yellow and the belly white. The iris is orange-brown.

In preservative, the general colouration is beige or brown with irregular small brown spots. The turquoise area is whitish, with dark brown spots. The belly is cream. The iris is silvery grey with a dark brown ring. The upper rim of the palpebral membrane is pigmented, and sometimes the lower rim too.

Tadpoles. - Seven tadpoles in stage 25 have body lengths of $3.6 \mathrm{~mm}$ and total lengths of 8.0-14.5 mm. The average ratio of tail length to body length in this stage is 1.5 (range 1.4-1.6). Nine tadpoles in stages 26-29 have body lengths of $6.5-9.0 \mathrm{~mm}$ and total lengths of $16.5-25.0 \mathrm{~mm}$. The average ratio of tail length to body length in these stages is 1.7 (range 1.6-1.8). Thirteen tadpoles in stages 31-41 have body lengths of 9-13 $\mathrm{mm}$ and total lengths of $25-38 \mathrm{~mm}$. The average ratio of tail length to body length is 1.9 (range 1.75-2.10). Eight metamorphosing young have body lengths of 14.5-16.0 mm (mean $15 \mathrm{~mm}$ ).

The mouth and lateral view of a tadpole in stage 28 (ZMA 7196) are shown in figs. 31-32. The body is ovoid. The nostrils are dorsal, the openings are directed to the front and situated at equal distances from the tip of the snout and the anterior corners of the eyes. The eyes are directed laterally. The spiracular opening is sinistral, situated at about $1 / 2-5 / 8$ from the tip of the snout and the end of the body. The cloacal tube is located on the right side of the caudal fin. The caudal musculature is slender. The caudal fin is well developed. At midlength of the tail, the height of the caudal musculature represents about $1 / 5$ of the total height. The mouth is small and directed anteroventrally. The papillary border has a wide median gap anteriorly. There is one row of large papillae, and there are some supernumerary papillae lateroposteriorly. The oral disc is indented laterally. The tooth formula is $1 / 3+$ $3 / / 1+1 / 2-1 / 5+5 / / 1+1 / 2$. The horny beak is well developed; the upper rim of the lower beak is black.

The colour in life of the tadpole is greyish. A white spot on the tip of the snout and a white transversal bar on the middle of the back is most distinct in the earlier stages of development. The belly is silvery.

The entire development took two months in our rearings.

Young. - The ground colour in life of the back is greenish or brownish. The back is covered with minute green spots, which are rimmed with black. On the upper arm, thigh, heel and tarsus turquoise longitudinal bands are present. Irregular dark brown crossbands are present on the limbs. The hands and feet are yellow. The belly is uniformly creamish. The webbing is the same as in the adult. The tibiotarsal articulation extends to the centre of the eye.

\section{Boophis granulosus (Guibé, 1975) \\ Text-figs. 33-34; pl. III fig. 3, pl. IV fig. 7.}

Rhacophorus granulosus Guibé, 1975b: 1083, fig. 3; Guibé, 1978: 66 , figs. 148-149.

Material. - MNHP 1953-150, the holotype of $R$. granulosus. Type locality: forest of Moramanga.

ZMA 6853 (8), 13.XI.72; 7201 (eggs deposited by ZMA 6853); 7202 (tadpoles and young reared from them), 22.X. 72; collected near Perinet (highroad R.N. 2 at $\mathrm{km} \mathrm{142),} \mathrm{alt.}$ $1100 \mathrm{~m} ; 7203$ (one young), 4.IV.72; 7204 (tadpoles and young reared from them), 20.I.73; collected at the same locality, but alt. $900 \mathrm{~m}$.

Natural history. - The species was found on a rainy evening in November on leaves of shrubs and trees around a pool, near forest. The males were calling loudly. One day later, a female deposited blackish, very sticky eggs. In the same pool we had found jelly, containing very young larvae ( 3 weeks before), which developed in our rearings to the present species. Close to the same pool one specimen of $B$. idae (Steindachner, 1867) was found on the leaves, and on the 


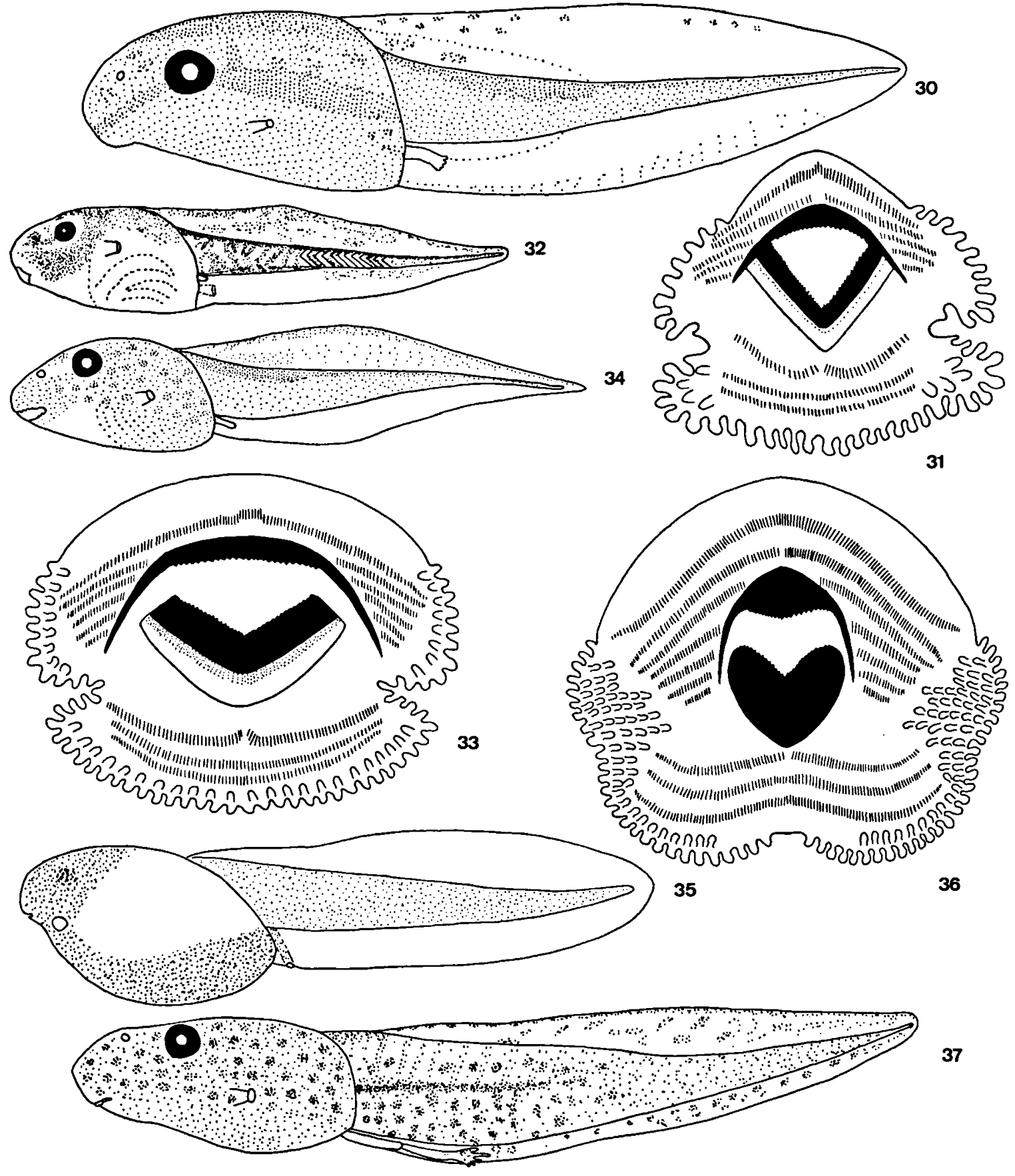

Figs. 30-37. 30, Boophis hillenii: tadpole, ZMA 7122.X.6; 31-32, B. idae: 31, mouth of tadpole, ZMA 7196.X.25; 32, tadpole, ZMA 7196.X.3; 33-34, B. granulosus: 33, mouth of tadpole, ZMA 7202.X.25; 34, tadpole, ZMA 7202.X.3; 35-37, B. microtympanum: 35, hatchling, ZMA 7086.X.12.5; 36, mouth of tadpole, ZMA 7085.X.12.5; 37, tadpole, ZMA 7006.X.1.5. 
ground Aglyptodactylus madagascariensis (Duméril, 1853), of which we also found young larvae in the pool. The tadpoles collected in January were found in a pool as well, near forest.

Description (see table VI for measurements). - The ratio of hand length to snout-vent length is $0.28-0.30$ (mean 0.29). The ratio of tibia length to snout-vent length is $0.50-0.53$ (mean 0.51 ). The ratio of foot length to snout-vent length is $0.44-0.47$ (mean 0.45 ). The ratio of the horizontal diameter of the tympanum to that of the eye is $0.43-0.49$ (mean 0.46). Snout-vent length $35-40 \mathrm{~mm}$.

The species is closely related to $B$. idae (Steindachner, 1867) and $B$. billenii sp. nov.; therefore only the differential characters are described below.

The skin of the dorsum is verrucose. The nostrils are strongly protruding. The foot is entirely webbed, except the penultimate phalanx of the fourth toe, which is free of web. The anal opening is directed posteroventrally at midlevel of the thighs.

The ground colour in life is yellowish brown (silvery grey in alcohol). The back is covered with irregular blackish spots and markings, which are bordered with light green. There are dark brown crossbands over the limbs. The discs and the first and second fingers are orange. The pupil is orange-brown. There are light spots on the flanks (pl. IV fig. 7).

Sexual dimorphism. - The male has white nuptial pads laterodorsally on the first and second fingers. The vocal slits are small, situated in the floor of the mouth, near the angles of the jaws. The vocal sac is median subgular and moderately distensible. The arms are robust in the male and slender in the female. The skin on the throat is granular in the male and smooth in the female.

Eggs . - Diameter $2 \mathrm{~mm}$ and about 200 in number.

Tadpoles. - Twenty-six tadpoles in stage 25 have body lengths of $3.0-7.5 \mathrm{~mm}$ and total lengths of $8.0-20.5 \mathrm{~mm}$. The average ratio of tail length to body length in this stage is 1.7 (range 1.5-1.9). Twenty-one tadpoles in stages 26-30 have body lengths of 7.5-9.0 $\mathrm{mm}$ and total lengths of $21.5-25.0 \mathrm{~mm}$. The average ratio of tail length to body length is 1.85 (range 1.7-2.0). Eighteen tadpoles in stages 31-40 have body lengths of 9$12 \mathrm{~mm}$ and total lengths of $26-36 \mathrm{~mm}$. The average ratio of tail length to body length in these stages is 1.95 (range 1.8-2.0). Sixteen metamorphosing young measure $11-14 \mathrm{~mm}$ (mean $13 \mathrm{~mm}$ ) from snout to vent.

The mouth in stage 35 and the lateral view in stage 31 of a tadpole (ZMA 7202) are shown in figs. 33-34. The body is ovoid. The nostrils are dorsal with anterolateral openings, situated at equal distances from the tip of the snout and the anterior corners of the eyes. The eyes are directed laterally. The spiracular opening is sinistral, situated at about $2 / 3$ from the tip of the snout and the end of the body. The cloacal tube is located on the right side of the caudal fin. The caudal musculature is slender. The caudal fin is well developed. At midlength of the tail, the height of the caudal musculature represents about $1 / 4$ of the total tail height. The mouth is small and directed anteroventrally. The papillary border has a wide median gap anteriorly. There are two rows of papillae. The oral disc is indented laterally. The tooth formula is $1 / 4+4 / / 1+1 / 2$ or $1 / 5+5 / /$ $1+1 / 2$. The horny beak is well developed. The upper rim of the lower beak is black.

The colour in life of the tadpole is yellowish, covered with brown spots. The belly is silvery. There is a white spot on the tip of the snout and there are white lines from the nostrils to the anterior corners of the eye.

The entire development took two and a half to three months in captivity.

Y o u n g. - The colour in life is beige or silvery grey covered with irregular black spots and markings, which are bordered with green. The discs are yellow. The pupil is orange. The skin of the dorsum is warted as in the adult.

The nostrils are strongly protruding and the webbing is the same as in the adult.

\section{Boophis opisthodon group}

Diagnosis. - This group comprises only one large-sized species $(90 \mathrm{~mm})$, which breeds 
probably in temporary pools. The dorsum is brown. There are transverse bars on the limbs. Fringes and dermal flaps are lacking on the limbs. There is a white margin on the upper jaw. The snout is long and acuminate. Vomerine teeth are present. The tympanum is very large, its horizontal diameter is three-fourths of that of the eye. The vocal sac is single, median and subgular. The discs are well developed. The fingers have only a trace of web, the toes are three-fourths webbed, reaching the discs of the first and fifth toe. The tibiotarsal articulation extends to the nostril. Guibé (1978) described that the tibiotarsal articulation extends beyond the tip of the snout. This does not agree with my observation and the original description by Boulenger (1888).

Contents: B. opisthodon (Boulenger, 1888).

\section{Boophis opisthodon (Boulenger, 1888) Pl. II fig. 8.}

Rhacophorus opisthodon Boulenger, 1888: 105; Guibé, 1978: 63, figs. 134-135.

Boophis opisthodon; Bachmann \& Blommers-Schlösser, 1975: 17 (DNA); Blommers-Schlösser, 1978: 36 (chromosomes)

Material. - ZMA 6932 (1 ô), 2.VIII.72; 6851 (4 $\hat{\delta} \hat{o}$ ), 13.II.72; collected near Foulpointe, $60 \mathrm{~km} \mathrm{~N}$. of Tamatave, E. coast of Madagascar.

$\mathrm{Natural}$ history. - The males were calling in the shrubbery $30-50 \mathrm{~cm}$ above shallow pools in February (these pools had disappeared by July), in forest, during a rainy night. The sound was very loud and resembled the blow of a trumpet. Calling males were situated at rather large distances (about $10 \mathrm{~m}$ ) from each other. Once captured they clasped each other in axillary amplexus, even other species were clasped.

Colour in life. - The colouration is brown. The temporal and loreal regions are dark brown. A white line borders the upper jaw. There are dark brown crossbands on the limbs. The inguinal spots and the ventral surface of the hindlimb are orange. The iris is yellow-orange. The belly is cream.

$\mathrm{M}$ a le. - The back is covered with small tubercles (smooth in the female according its description). There is a small blackish nuptial pad in dorsolateral position on the first finger.

\section{Boophis paulianigroup}

Diagnosis. - This group is created for the only species of Boophis without vomerine teeth. It is a small-sized species $(20 \mathrm{~mm})$, breeding probably in temporary pools. The colour in life is greenish, and the bones are green. Indistinct transverse bars are present on the limbs. There is a row of white granules along the lateral edge of the tarsus and lower arm. The tympanum is very small. The snout is short and rounded. The vocal sac is single, median and subgular. The fingers are one-third webbed and the toes are three-fourths webbed. The tibiotarsal articulation does not extend beyond the tip of the snout.

Contents: B. pauliani (Guibé, 1953).

Boophis pauliani (Guibé, 1953) comb. nov. Text-fig. 43.

Hyperolius pauliani Guibé, 1953: 101; Guibé, 1978: 89.

Materia l. - MNHP 1953-169-170, two syntypes ( $\hat{\delta}$ and $P$ ) of Hyperolius pauliani. Type localities: forests of Moramanga and Perinet. Coll. Guibé.

ZMA 6915 (2 ô $\hat{o}$ ), 24.XII.72 collected near Perinet, alt. $900 \mathrm{~m}$.

$\mathrm{Natural}$ history. - The males were collected calling in shrubs near a pool in forest, in the evening. Guibé (1953) found the male also in a shrub, near a pool in forest in January 1951.

Colour in life. - The ground colour is greenish, the bones are green.

T a x o n o my. - Our material agrees with the type material. The species has no vomerine teeth, but the style of the omosternum is entire and shorter than the sternal style (see fig. 43), indicating that it belongs to Boophis and not to Hyperolius. The male type specimen has a welldeveloped nuptial pad, just as in the males collected by us.

$$
\text { Montane species group }
$$

Five medium-sized Boophis species are known only from the High Mountains Area (cf. Koechlin, 
1972). We have found B. microtympanum (Boettger, 1881) and B. williamsi (Guibé, 1974) in the Ankaratra mountains, above $2000 \mathrm{~m}$, in wooded country, characterized by bushes of ericoid appearance. $B$. microtympanum is also known from the Andringitra mountains.

B. brygooi (Guibé, 1974) and B. laurenti Guibé, 1947 are only known from the Andringitra mts.; B. microtis (Guibé, 1974) is apparently restricted to the Chaines Anosyennes. These three species are not further considered here.

B. microtympanum and B. williamsi are streambreeding species. They can be distinguished readily by their completely different colouration (also in alcohol, see under the species description).

\section{Boophis microtympanum (Boettger, 1881)}

comb. nov.

Text-figs. 35-38; pl. III fig. 6.

Hylambates microtympanum Boettger, 1881: 47.

Rhacophorus boettgeri; Boulenger, 1882: 467 (substitute name); Guibé, 1978: 69, figs. 156-158 (equals arboreus).

Boophis boettgeri; Blommers-Schlösser, 1978: 36 (chromosomes).

Rbacophorus arboreus Ahl, 1928: 312.

Materia 1. - ZMB 30498, holotype of Rhacophorus arboreus. Type locality: central Madagascar. Coll. Hildebrandt.

ZMA 6850 (1 of and 1 q), 13.IV.72; 6931 (1), 21.III. $73 ; 7006$ (tadpoles and young) from rearing during nine months, coll. 13.IV.72-3.VI.72; 7084 (eggs), 13.IV.72; 7085 (tadpole), 21.III.73; 7086 (eggs and young larvae), 21.III. 73; 7087 (eggs and young larvae), 13.IV.72; 7088 (tadpoles), 13.IV.72; 7089 (tadpole and juvenile), from rearing during several months, coll. 21.III.73; all collected at Manjakotompo forest station, Ankaratra mts. (near Ambatolampy), alt. $2200 \mathrm{~m}$.

Natural history. - The species was collected in clear mountain brooks, with stony bottom, in wooded country with ericoid bushes. The male and female collected were in axillary amplexus in the water. The males call in the evening. This species is a poor jumper and climbs badly. The tadpoles and the eggs were found in the same brooks as the adults, the eggs were attached around a twig in a clutch of about 100 in a fast flowing part of the current. The clutch was covered with small particles.
Colour in life.- The ground colour of the male is dark green; of the female yellowgreen. The irregular spots on the back, on the flanks over the limbs and under the tympanic fold are blackish, surrounded by a narrow orange line. Between the blackish spots on the flanks the skin is orange. The discs are orange too. The iris is greenish.

S e x u a l dimorphis m. - The back of the male is covered with small tubercles, the back of the female is smooth. An unpigmented glandular nuptial pad is present dorsally on the first finger in the male. The male is much smaller than the female.

Voice. - The species was heard in April during the evening. The sonagram (fig. 38) made of a male (ZMA 6850) on the 13th of April 1972 at 10 p.m. shows that the call consists of a number of short notes. One call group consists of 4-9 notes. The duration of one call group varies from 2-4.5 sec. The dominant frequency is about $3000 \mathrm{~Hz}$.

E g g s . - The eggs measure $3 \mathrm{~mm}$ in diameter, $5 \mathrm{~mm}$ with the capsule; their number amounts to \pm 100 . The colour is black with white. The eggs hatch within 7-10 days. The hatchling (fig. 35) has no external gills; a mouth opening, two small suckers and an anal tube are present. The eyes are visible through the skin and the external nares are about to open.

$\mathrm{T}$ a d po les. - Thirty-two tadpoles in stage 25 have body lengths of $5-14 \mathrm{~mm}$ and total lengths of $13.5-41.0 \mathrm{~mm}$. The average ratio of tail length to body length in this stage is 1.7 (range 1.5-1.9). Eight tadpoles in stages $26-28$ have body lengths of $12.20 \mathrm{~mm}$ and total lengths of $34-57 \mathrm{~mm}$. Eight tadpoles in stages 30-40 have body lengths of $19-24 \mathrm{~mm}$ and total lengths of $53-71 \mathrm{~mm}$. The average ratio of tail length to body length in the stages $26-40$ is 1.9 (range 1.8-2.0). One metamorphosing young measures $24 \mathrm{~mm}$ from snout to vent.

The mouth (ZMA 7085) and lateral view of a tadpole (ZMA 7006) in stage 37 are shown in figs. 36-37. The body is ovoid. The nostrils are dorsal, their dorsolateral openings are situated at 


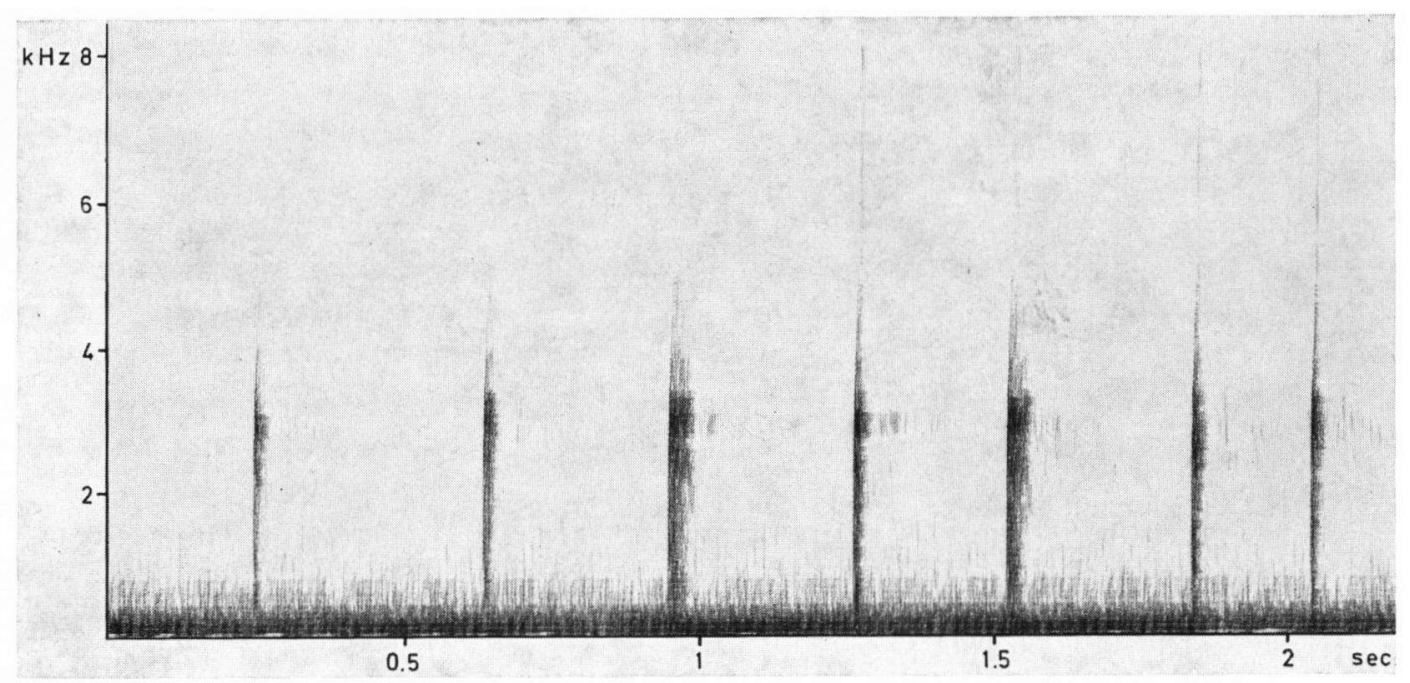

Fig. 38. Sonagram, filter wide, Boophis microtympanum.

equal distances from the tip of the snout and the anterior corners of the eyes. The eyes are situated dorsolaterally. The spiracular opening is sinistral, situated at about $5 / 8$ to $2 / 3$ from the tip of the snout and the end of the body. The cloacal tube is long and situated on the right side of the caudal fin. The caudal musculature is robust, especially in the anterior part of the tail. The caudal fin is reduced anteriorly. At midlength of the tail, the height of the caudal musculature accounts for about $1 / 2$ of the total tail height. The mouth is small and directed ventrally. The oral disc is slightly indented medioposteriorly. The papillary border has a wide median gap anteriorly and a very narrow gap posteriorly. There are 1-7 rows of papillae laterally and 1-2 posteriorly. The horny beak is well developed. The tooth formula is $1 / 5+5 / / 1+1 / 2$ generally; but also $1 / 4+4 / /$ $1+1 / 2$ or $1 / 6+6 / / 1+1 / 2$ occurs.

The colour of the tadpole in life is greyish with dark grey spots.

The development proceeds very slowly; the estimated duration is about one year, as we could observe in our rearings and in the field. This is also indicated by the large amount of growth in each stage of development.

Young. - The reared young resembles the adult so much, that it could easily be assigned to this species.
Boophis williamsi (Guibé, 1974)

Text-figs. 39-40; pl. III fig. 7.

Rhacophorus williamsi Guibé, 1974: 1178, fig. 6; Guibé, 1978: 68, figs. 152-155.

Boophis williamsi; Blommers-Schlösser, 1978: 36 (chromosomes).

Materia 1. - MNHP 1973-1091, the holotype of Rbacophorus williamsi. Type locality: Ambohimirandana, Ankaratra mts. Coll. Ch. P. Blanc.

ZMA 6933 (one young reared from tadpoles ZMA 7012); 7012 (tadpoles), 21.III.73; 7195 (one tadpole), 21.III.73; 7013 (tadpoles), 13.IV.72-3.VI.72; collected at Manjakotompo forest station, Ankaratra mts. (near Ambatolampy), alt. $2200 \mathrm{~m}$.

Natural history. - The tadpoles were collected in clear mountain brooks with stony bottom, in wooded country with bushes of ericoid appearance. The tadpoles were found together with those of $B$. microtympanum (Boettger, 1881). We failed to capture adult frogs.

Tadpoles. - Fifteen tadpoles in stage 25 have body lengths of $7-15 \mathrm{~mm}$ and total lengths of $17.5-40.0 \mathrm{~mm}$. The average ratio of tail length to body length in this stage is 1.5 (range 1.4-1.7). Eighteen tadpoles in stages $26-28$ have body lengths of $14-30 \mathrm{~mm}$ and total lengths of $38-85$ $\mathrm{mm}$. The average ratio of tail length to body length in these stages is 1.7 (range 1.6-1.8). One tadpole in stage 42 has a body length of $32 \mathrm{~mm}$ and a total length of $82 \mathrm{~mm}$. One metamorphosing young measures $30 \mathrm{~mm}$ from snout to vent. 


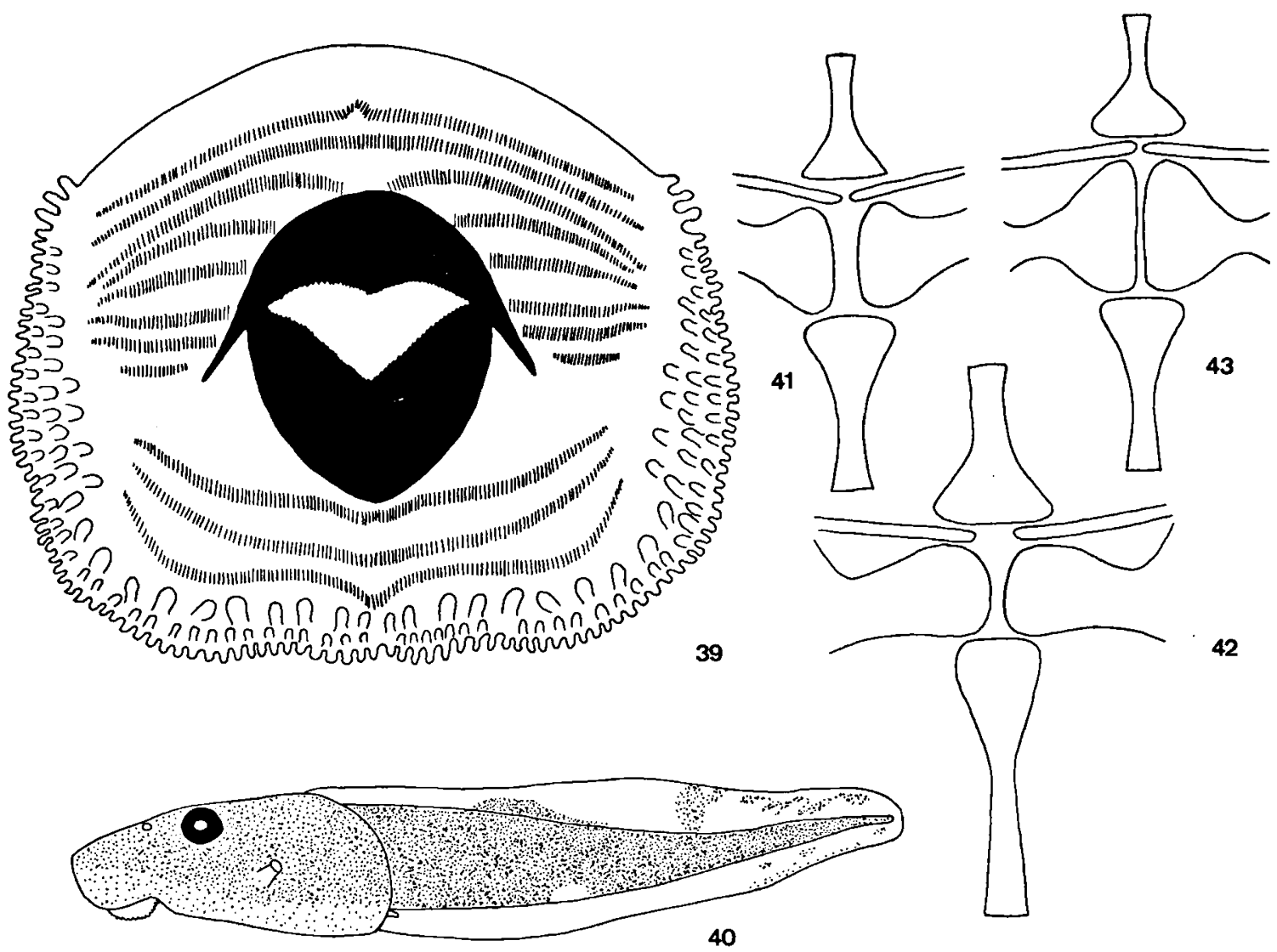

Figs. 39-43. 39-40, Boophis williamsi: 39, mouth of tadpole, ZMA 7012.X.12.5; 40, tadpole, ZMA 7012.X.1.5; 41-43, ventral views of bony elements of the shoulder girdle. From top to bottom: bony style of omosternum, procoracoids, coracoids, bony style of sternum. 41, B. mandraka, ZMA 7119.X.12.5; 42, B. madagascariensis, ZMA 6849.X.6; 43, B. pauliani, ZMA 6915.X.12.5.

The mouth and lateral view of a tadpole in stage 27 (ZMA 7012) are shown in figs. 39-40. The body is depressed. The nostrils are dorsal, their openings dorsolateral, situated at equal distances from the tip of the snout and the anterior corner of the eye. The eyes are situated dorsolaterally. The spiracular opening is sinistral, situated at about $1 / 2-5 / 8$ from the tip of the snout and the end of the body. The cloacal tube is long and situated on the right side of the caudal fin. The caudal musculature is robust, especially in the anterior part of the tail. The caudal dorsal fin extends on to the body. At midlength of the tail, the height of the caudal musculature accounts for about $1 / 2$ of the total height. The mouth is broad and directed ventrally. The margin of the oral disc is round; if folded inside it has a notch medioposteriorly. The papillary border has a wide me- dian gap anteriorly. There are 3-4 rows of papillae. The horny beak is heavy. The tooth formula is $2 / 5+5 / / 3$ or $2 / 6+6 / / 3$.

The colour of the tadpole in life is black with some bright yellow patches, in the early stages. These colours fade gradually with age. The development of the tadpole proceeds very slowly, and considerable growth occurs in each stage of development. The estimated duration is at least one year, perhaps even longer, as we could observe in the field and in our rearings.

Young. - Our metamorphosed young is very large $(30 \mathrm{~mm})$, while the known adults reach a size of $38 \mathrm{~mm}$. The colour in life of the young was olive-green with brown spots. It could be easily identified as $B$. williamsi. 


\section{DISCUSSION}

In an earlier paper on the biosystematics of the Malagasy Mantellinae (Blommers-Schlösser, 1979), it has been argued already that Boophis Tschudi, 1838 , is not so closely related to the genera Mantella Boulenger, 1882, Mantidactylus Boulenger, 1895 (= Gephyromantis Methuen, 1919), and Trachymantis Methuen, 1919, as has been presumed by most previous workers but Laurent, 1946. Mainly on the basis of the peculiar way of mating, the genera Mantella, Mantidactylus and Trachymantis were considered to form the subfamily Mantellinae of the Ranidae, while Boophis was considered a genus of the Rhacophoridae (Blommers-Schlösser, 1979). The present study confirms this opinion.

A normal sort of amplexus is common, if not general, in Boophis. We watched axillary amplexus in B. rappiodes, luteus, majori, goudoti, tephraeomystax, opisthodon and microtympanum. We watched lumbal amplexus in B. madagascariensis; Arnoult \& Razarihelisoa, 1966, recorded lumbal amplexus in $B$. goudoti. Calling males of various species showed a pronounced clasping reflex.

The accessory sexual characters, generally connected with this way of mating, are present in the species of the genus Boophis. Every male collected in the breeding season has nuptial pads. The males are also distinctly smaller than the females. Only submerged eggs were collected. In contrast, the species of Mantellinae lack a real amplexus, the males possess femoral glands but nuptial pads are absent, the sexes are of about equal size and eggs were found outside the water. Nevertheless, morphological differences between some Mantidactylus species groups and some Boophis species are scanty.

The best criterion I could find is the shoulder girdle, which I examined in B. mandraka, erythrodactylus, luteus, majori, goudoti, madagascariensis, reticulatus, tephraeomystax, granulosus, idae, opisthodon, pauliani and microtympanum. The bony style of the sternum is always longer than the bony style of the omosternum, the latter being never really forked, while in Mantidactylus the bony style of the omosternum is broadly or moderately forked; its length is equal to or greater than that of the sternal style.
Cytogenetic studies showed that the karyotypes within the genus Boophis (12 species) are very similar $(2 \mathrm{n}=26)$, and that acrocentric chromosomes never occur (Blommers-Schlösser, 1978). The quantitative nuclear DNA amount shows little variation; 7-9.9 diploid in eight species (Bachmann \& Blommers-Schlösser, 1975). The characters mentioned above indicate that Boophis is a natural unit at generic level.

The distribution of the genus Boophis appears to be largely confined to the rain forests (East Area, Centre Area and Sambirano Area) and the High Mountains Area of Madagascar. Only two species may also be found in farmland (B. goudoti) or in the savanna and deciduous woodland (B. tephraeomystax). The more arid biotopes are occupied primarily by species of the genus Heterixalus Laurent, 1944, which likewise belongs to the Rhacophoridae (Hyperolius Rapp, 1842, probably does not occur in Madagascar, Blommers-Schlösser in preparation).

Most species in the genus Boophis are genuine tree frogs which are active at night. Only $B$. goudoti, $B$. untersteini and the montane species $B$. microtympanum are found normally on the ground. Some diurnal activity was observed in B. goudoti and $B$. madagascariensis only. Various brown species (B. madagascariensis, untersteini and tephraeomystax) have a juvenile hue, which is predominantly green and probably serves for camouflage.

The differentiation within this genus is manifested most clearly in the variety of aquatic habitats, occupied by the tadpoles. While some groups of species are confined in this respect to stagnant waters, others are found in streams of varying velocity. Because stagnant water is rarely permanent in the hilly rain forest in eastern Madagasacar, the fauna connected with this sort of breeding sites seems dependent mainly on the availability of temporary pools and puddles. The development in these species is rather rapid, the young hatch before the onset of the drier winter season. Species of this biotope are notably those in the $B$. tephraeomystax group and probably also $B$. pauliani and $B$. opistbodon. The webbing of the fingers is reduced in these frogs.

The larvae of both $B$. goudoti and B. madagas- 
cariensis are occasionally found also in these pools, although they are most often found in small, shallow streams and in the relatively lentic parts of large streams together with the tadpoles of $B$. rappiodes.

Larval development in these species appears to be slower, or the egg-laying period is more extended than that of real pool dwellers. Hatching shows two peaks, one at the onset of the winter, the other at the start of the next hot season. During the dry and cold winter (May-September), these tadpoles grow slowly and no metamorphosis takes place.

While the tadpoles of $B$. luteus, B. sp. and of the montane species $B$. microtympanum and $B$. williamsi live in currents and mountain brooks, the larvae of $B$. erythrodactylus, B. mandraka and $B$. majori are found in real torrents. Here larval development takes nearly a year, for the young hatch in the beginning of the hot season, while new eggs are laid a couple of months later. Development in the montane species may even take two years (B. williamsi).

A comparison of the habitats occupied by the larvae of species of the genus Boophis and of the genus Mantidactylus shows that the tadpoles of both concur largely in relatively lentic streams and in temporary pools. In fast running currents and torrents in Madagascar, I only found tadpoles belonging to Boophis species. Neither arboreal tadpoles nor direct development, both known in the genus Mantidactylus, occur in the genus Boophis.

\section{REFERENCES}

AHL, E., 1925. Herpetologische Notizen. Zool. Anz., 65 $(1 / 2): 18-20$.

- 1928. Neue Frösche der Gattung Rhacophorus aus Madagascar. Zool. Anz., 75 (11/12): 311-318.

- 1929. Beschreibung neuer Frösche aus Madagascar. Mitt. zool. Mus. Berl., 14 (3/4): 469-484.

—, 1931. Amphibia. Anura III, Polypedatidae. Tierreich, 55: i-xvi, 1-477.

ANGel, F., 1934a. Description d'un Vipéridé nouveau, du Congo Belge, et de deux Batraciens de Madagascar. Bull. Soc. zool. Fr., 59: 169-172.

- $1934 \mathrm{~b}$. Reptiles et Batraciens de Madagascar et description d'une espèce nouvelle du genre Rhacophorus. Bull. Mus. natn. Hist. nat. Paris, (2) 6 (3): 247-249.

Arnoult, J. \& M. RazarihelisoA, 1966. Contribution à l'étude des Batraciens de Madagascar. Ecologie et formes larvaires de Rhacophorus goudoti (Tschudi). Bull. Mus. natn. Hist. nat. Paris, (2) 38 (2): 111-117.

BaChMANN, K. \& R. Blommers-SChlösSER, 1975. Nuclear DNA amounts of the frogs of Madagascar. Zool. Anz., $194(1 / 2)$ : 13-21.

Blommers-Schiösser, R. M. A., 1978. Cytotaxonomy of the Ranidae, Rhacophoridae, Hyperoliidae (Anura) from Madagascar with a note on the karyotype of two amphibians of the Seychelles. Genetica, 48 (1): 23.40.

- 1979. Biosystematics of the Malagasy frogs. I. Mantellinae (Ranidae). Beaufortia, 29 (352): 1-77.

Boettger, O., 1879. Die Reptilien und Amphibien von Madagascar, 2. Nachtrag. Abh. senckenb. naturforsch. Ges., 11: 457-497, pl. I.

- 1881. Die Reptilien und Amphibien von Madagascar, 3. Nachtrag. Abh. senckenb. naturforsch. Ges., 12: 435 . 558, pls. I.V.

- 1882. Diagnoses Reptilium et Batrachiorum novorum insulae Nossi-Bé Madagascariensis. Zool. Anz., 5 (120): $478-480$.

- 1892. Katalog der Batrachier-Sammlung im Museum der Senckenbergischen Naturforschenden Gesellschaft in Frankfurt am Main: i-x, 1.73 (Gbr. Knauer, Frankfurt a. M.).

—, 1913. Reptilien und Amphibien von Madagascar, den Inseln und dem Festland Ostafrikas. In: Reise in OstAfrika von Prof. A. Voeltzkow, 3 (4): 269-376, pls. XXIII-XXX (E. Schweizerbart, Stuttgart).

Boulenger, G. A., 1882. Catalogue of the Batrachia Salientia s. Ecaudata in the collection of the British Museum (2nd ed.): i-xvi, 1-503, pls. I-XXX (Trustees British Museum, London).

- 1888. Descriptions of new reptiles and batrachians from Madagascar. Ann. Mag nat. Hist., (6) 1 (2): 101-107, pls. V-VI.

,- 1895 . On a genus of frogs peculiar to Madagascar. Ann. Mag. nat. Hist., (6) 15 (89): 450.

- 1896. Descriptions of new batrachians in the British Museum. Ann. Mag. nat. Hist., (6) 17 (101): 401-406, pl. XVII.

Dueliman, W. E., 1970. The hylid frogs of Middle Amer. ica. Monogr. Univ. Kan. Mus. nat. Hist., 1 (1): i-xi, 1-427; (2): [i-iv], 429-753, pls. I-LXXII.

DumÉril, A., 1853. Mémoire sur les Batraciens anoures, de la famille des Hylaeformes ou Rainettes, comprenant la description d'un genre nouveau et de onze espèces nouvelles. Annls. Sci. nat., (3, Zool.) 19: 135-179, pl. VII.

GoSNER, K. L., 1960. A simplified table for staging anuran embryos and larvae with notes on identification. Herpetologica, 16: 183-190.

GuIBÉ, J., 1947. Description d'un Batracien nouveau de Madagascar (Boophis laurenti n. sp.), et synonymie de plusieurs espèces du genre Boophis. Bull. Mus. natn. Hist. nat. Paris, (2) 19 (6): 438-439.

$\longrightarrow, 1953$. Deux Hyperolius nouveaux pour la faune malgache (Batraciens). Naturaliste malgache, 5: 101-103. , 1974. Batraciens nouveaux de Madagascar. Bull. Mus. natn. Hist. nat. Paris, (3) 1973 (171) (Zool. 116): 1169-1192.

$\longrightarrow, 1975 a$. Le statut générique de quelques Batraciens malgaches. Bull. Mus. natn. Hist. nat. Paris, (3) 1974 (266) (Zool. 188): 1761-1766.

, 1975b. Batraciens nouveaux de Madagascar. Bull. Mus. 
natn. Hist. nat. Paris, (3) 1975 (323) (Zool. 230): 1081-1089.

1978. Les Batraciens de Madagascar. Bonn. zool Monogr., 11: 1-140, pls. I-LXXXII.

Koechlin, J., 1972. Flora and vegetation of Madagascar. In: R. BATTISTINI \& G. RICHARD-VINDARD eds., Biogeography and ecology in Madagascar. Monographiae biol., 21: 145-190 (W. Junk, The Hague).

KuHL, H. \& J. C. vaN HASSELT, 1822. Uittreksel uit de brieven van de Heeren Kuhl en van Hasselt, aan de Heeren C. J. Temminck, Th. van Swinderen en W. de Haan. Algemeene Konst- en Letterbode, 1822 (7): 99-104.

LAurent, R., 1943. Contribution à l'ostéologie et à la systématique des Rhacophorides non africains. Bull. Mus. r. Hist. nat. Belg., 19 (28): 1-16, pls. I-II.

- 1944. Contribution à l'ostéologie et à la systématique des Rhacophoridés africains. Deuxième note. Revue Zool. Bot. afr., 38: 110-138.

- 1946. Mises au point dans la taxonomie des Ranidés. Revue Zool. Bot. afr., 39 (4): 336-338.

LIEM, S. S., 1970. The morphology, systematics, and evolution of the Old World treefrogs (Rhacophoridae and Hyperoliidae). Fieldiana Zool., 57: i-vii, 1-145.

Mertens, R., 1967. Die herpetologische Sektion des NaturMuseums und Forschungs-Institutes Senckenberg in Frankfurt a. M. nebst einem Verzeichnis ihrer Typen. Senckenberg. biol., 48 (Sonderheft A): 1-106, figs. 1-12.
Methuen, P. A., 1919. Descriptions of a new snake from the Transvaal, together with a new diagnosis and key of the genus Xenocalamus, and of some Batrachia from Madagascar. Proc. zool. Soc. Lond., 1919 (22): 349-355.

MoCQUARD, F., 1902. Sur une collection de Reptiles et de Batraciens recueillis par $M$. Alluaud dans le sud de Madagascar. Bull. Soc. philomath. Paris, (9) 4: 5-23, pls. I-II.

Peters, W., 1874. Utber neue Amphibien (Gymnopis, Syphonops, Polypedates, Rhacophorus, Hyla, Cyclodus, Euprepes, Clemmys). Mber. K. preuss. Akad. Wiss. Berlin, 1874: 616-624, pls. I-II.

RAPP, W. voN, 1842. Neue Batrachier. Arch. Naturgesch., 8 (1): 289-291, pl. VI.

RazarihelisoA, M., 1969. Observations sur les Batraciens aquatiques du centre des hauts plateaux de Madagascar. Verh. int. Verein. theor. angew. Limnol., 17: 949-955.

STEINDACHNER, F., [1867]. Amphibien. In: Reise der Österreichischen Fregatte Novara um die Erde in den Jahren $1857,1858,1859$ [unter den befehlen des Commodore] B. VON WÜLleRSTORF-URBAIR. Zoologischer Theil, 1 (4) : 1-70, i-v, pls. I-V (K.-K. Hof- und Staatsdruckerei, Wien).

TschUdi, J. J., [1838]. Classification der Batrachier, mit Berücksichtigung der fossilen Thiere dieser Abtheilung der Reptilien. Mém. Soc. Sci. nat. Neuchâtel, 2: 1-100, pls. I-VI. 


\section{LEGENDS TO THE PLATES}

\section{Plate I}

1, Boophis erytbrodactylus, tadpole, ZMA 7207; 2, B. erytbrodactylus, hatched young, ZMA 7207; 3, B. luteus, hatched young, ZMA 7005; 4, B. sp., hatched young, ZMA 7154; 5, B. majori, male, ZMA 7102; 6, B. miniatus, male, ZMA $7162 ; 7$, B. goudoti, male and female in amplexus, ZMA 6808.

\section{Plate II}

1, Boophis goudoti, hatched young, ZMA 7210; 2, B. madagascariensis, male, ZMA 6837; 3, B. madagascariensis, hatched young, ZMA 7069; 4, B. untersteini, hatched young, ZMA 7189; 5, B. untersteini, hatched young, ZMA 7190; 6, B. untersteini, male, three months old, ZMA 7190; 7, B. tephraeomystax, male, ZMA 6775; 8, B. opisthodon, male, ZMA 6851.

\section{Plate III}

1, Boophis reticulatus, male, ZMA 7101; 2, B. idae, male, ZMA 7014; 3, B. granulosus, hatched young, ZMA 7204; 4, B. billenii, tadpole, ZMA 7122; 5, B. idae, hatched young, ZMA 7199; 6, B. microtympanum, male, ZMA 6850; 7, B. williamsi, tadpole, ZMA 7013.

\section{Plate IV}

1, Boophis rappiodes, male and female, ZMA 7164; 2, B. mandraka, male, ZMA 7119; 3, B. erytbrodactylus, male, ZMA $6930 ; 4$, B. luteus, female, ZMA 6838; S, B. viridis, male, ZMA 7100; 6, B. difficilis, male, ZMA 7099; 7, B. granulosus, male, ZMA 6853. 

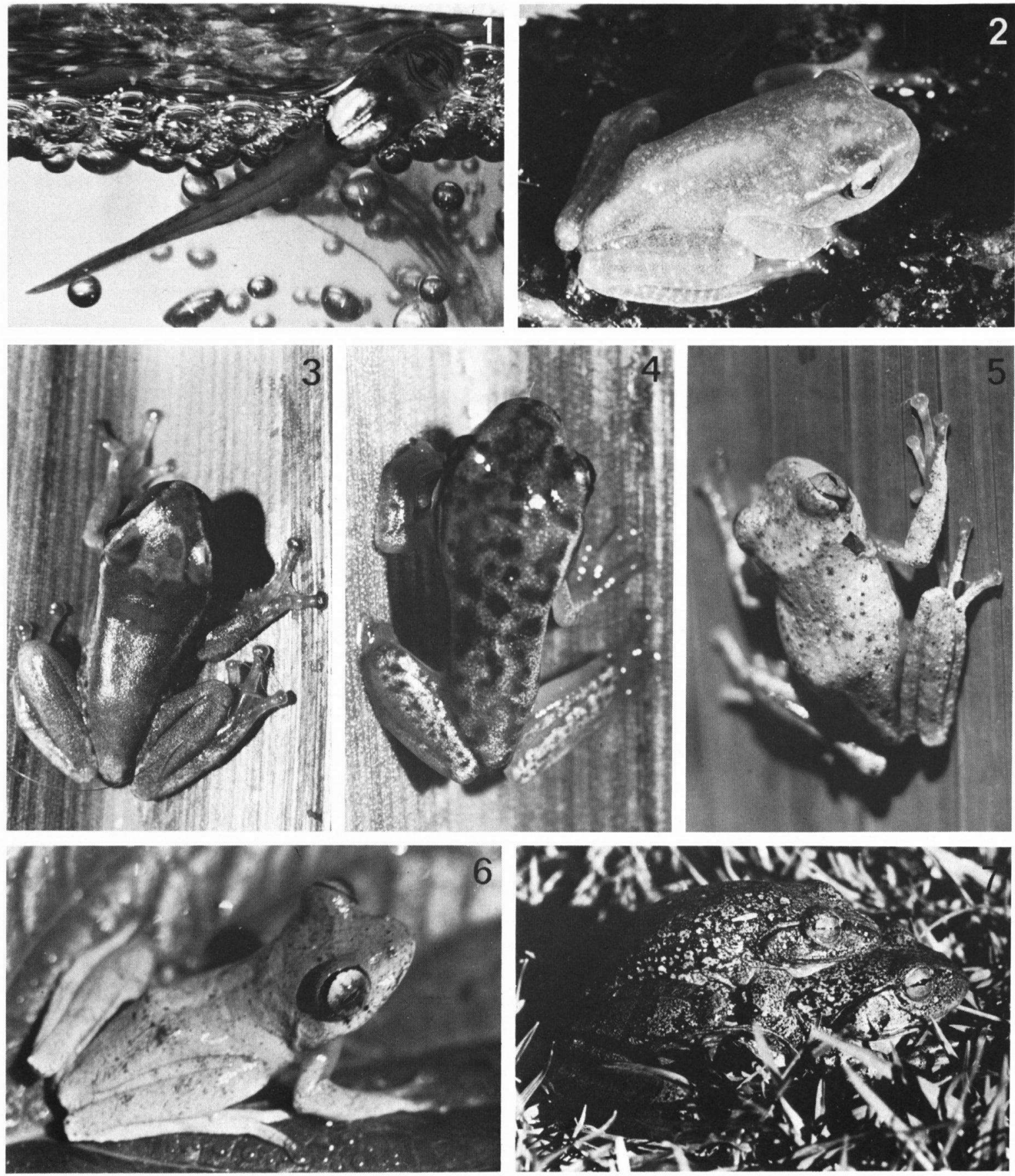

Plate I 

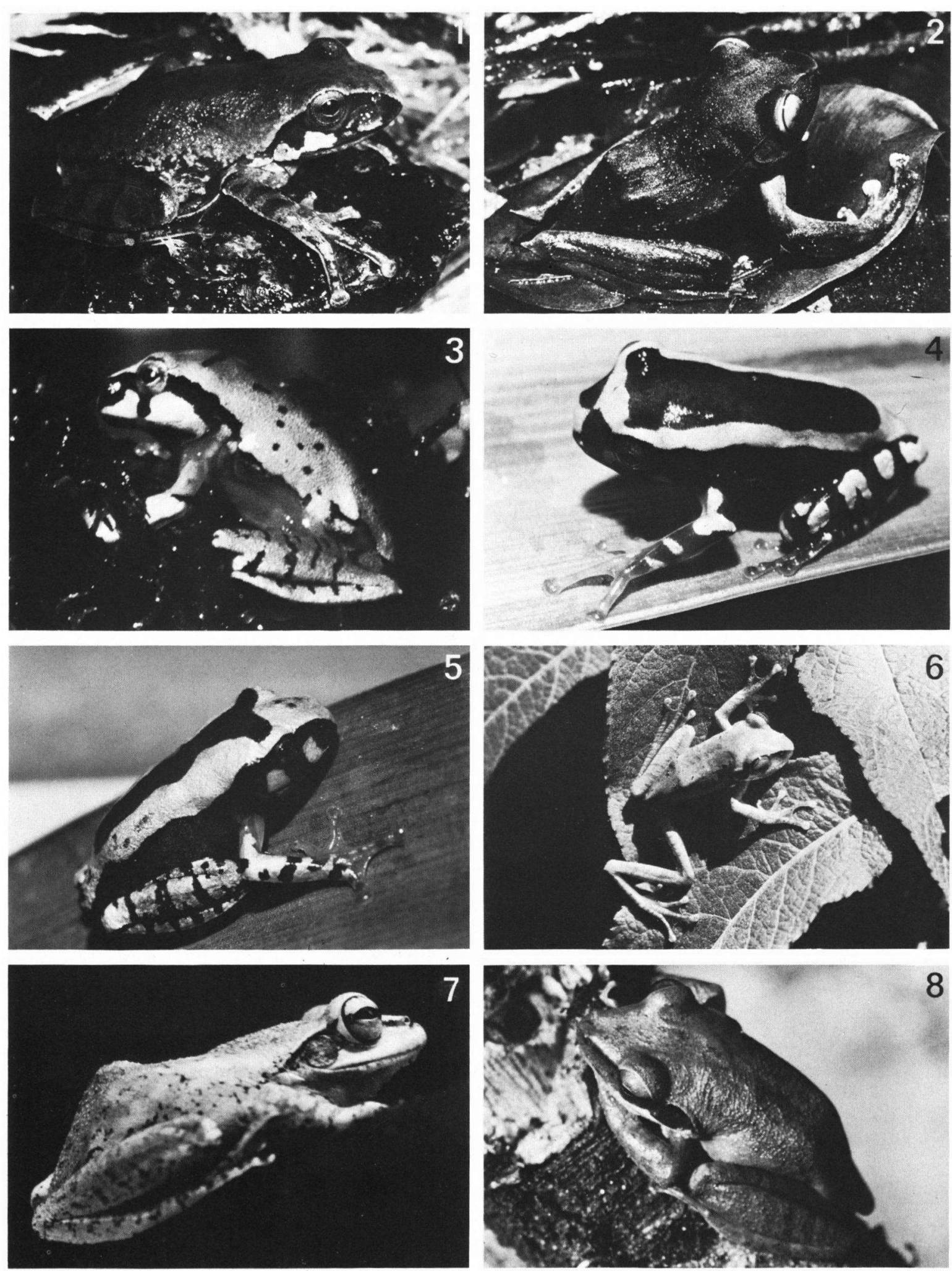

Plate II 

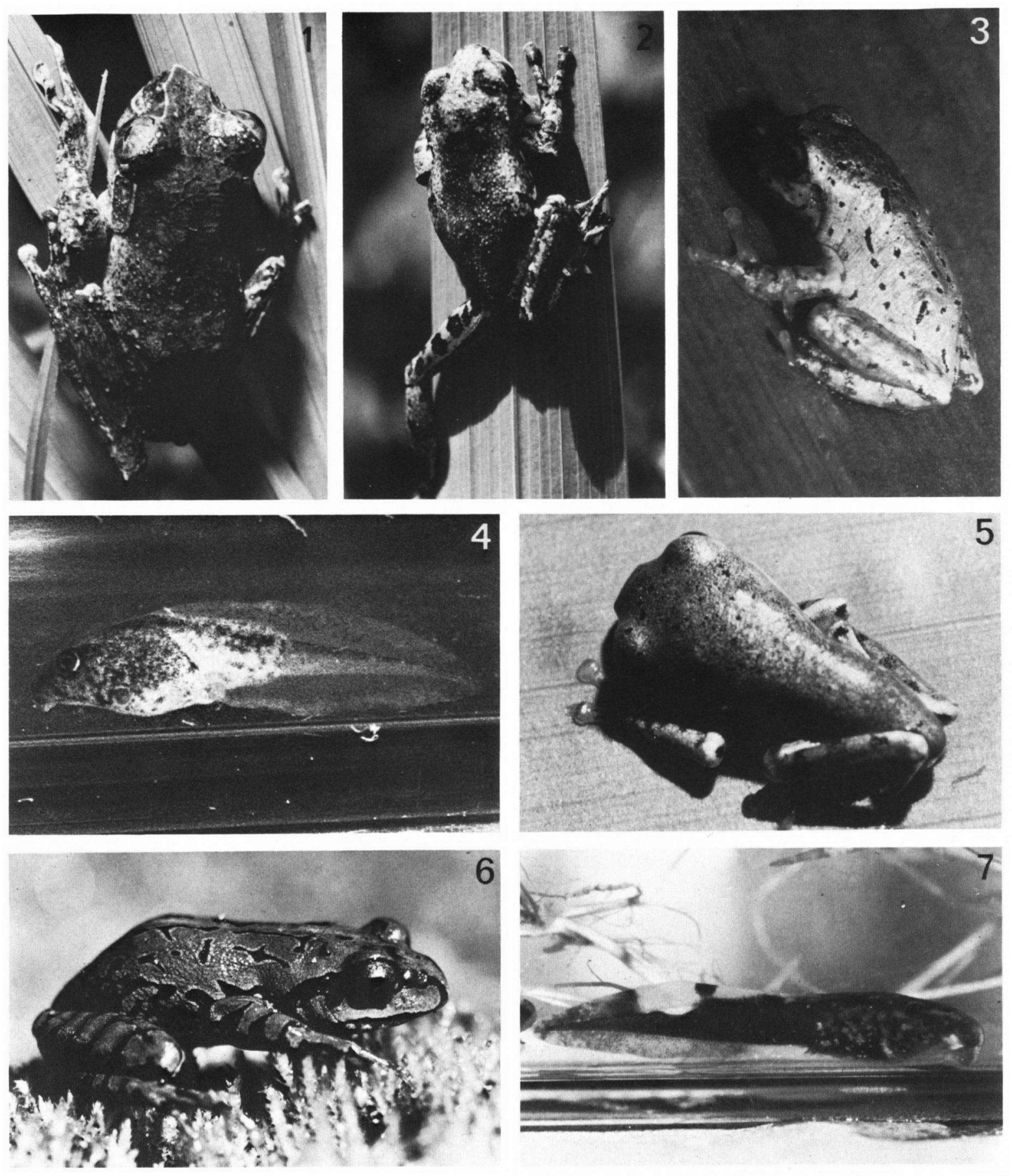

Plate III 

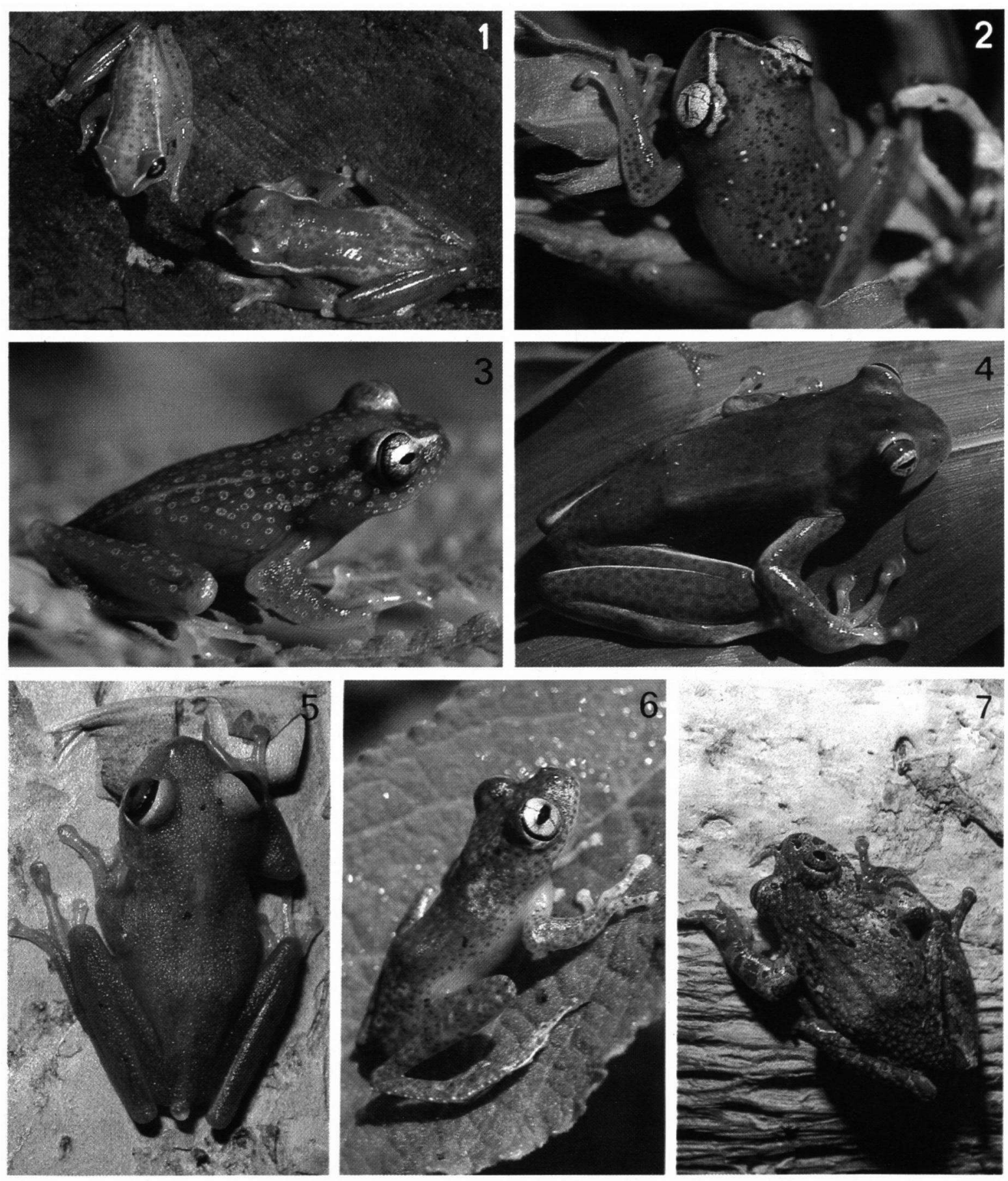

Plate IV 